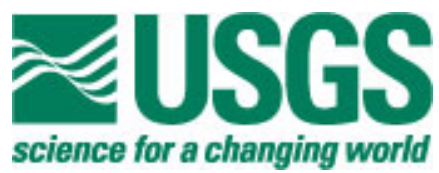

\title{
Audio-Magnetotelluric Survey to Characterize the Sunnyside Porphyry Copper System in the Patagonia Mountains, Arizona
}

By Jay A. Sampson and Brian D. Rodriguez

Open-File Report 2010-1311

U.S. Department of the Interior

U.S. Geological Survey 


\section{U.S. Department of the Interior \\ KEN SALAZAR, Secretary}

\section{U.S. Geological Survey \\ Marcia K. McNutt, Director}

U.S. Geological Survey, Reston, Virginia: 2010

For product and ordering information:

World Wide Web: http://www.usgs.gov/pubprod

Telephone: 1-888-ASK-USGS

For more information on the USGS-the Federal source for science about the Earth, its natural and living resources, natural hazards, and the environment:

World Wide Web: http://www.usgs.gov

Telephone: 1-888-ASK-USGS

Suggested citation:

Sampson, J.A., and Rodriguez, B.D., 2010, Audio-magnetotelluric survey to characterize the Sunnyside porphyry copper system in the Patagonia Mountains, Arizona: U.S. Geological Survey Open-File Report 2010-1311, 57 p.

Any use of trade, product, or firm names is for descriptive purposes only and does not imply endorsement by the U.S. Government. This report has not been reviewed for stratigraphic nomenclature.

Although this report is in the public domain, permission must be secured from the individual copyright owners to reproduce any copyrighted material contained within this report. 


\section{Contents}

Abstract

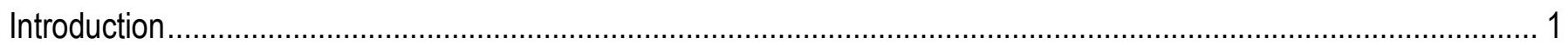

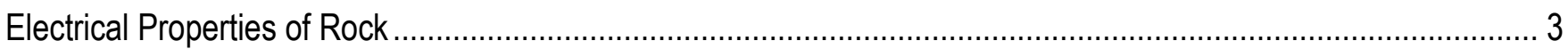

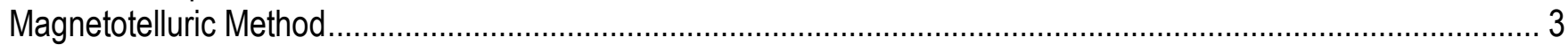

Audio-Magnetotelluric Survey Across the Sunnyside Porphyry Copper System.................................................... 4

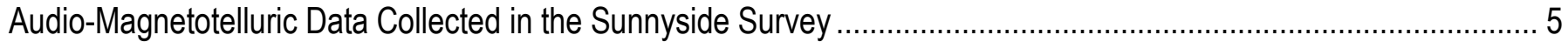

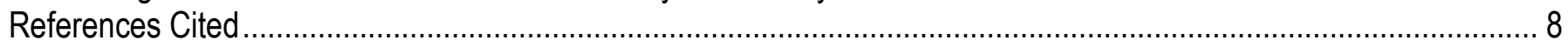

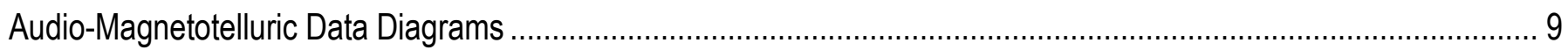

\section{Appendix}

Audio-Magnetotelluric Data Diagrams

Figure

1. Audio-magnetotelluric profile across the Sunnyside porphyry copper system in the Patagonia

Mountains, Arizona

\section{Table}

1. Audio-magnetotelluric station coordinates.

Vertical coordinate information is referenced to the 1866 Clarke Spheroid.

Horizontal coordinate information is referenced to the North American Datum of 1927 (NAD 27).

Altitude, as used in this report, refers to distance above the vertical datum.

\section{Abbreviations Used in This Report}

$\begin{array}{ll}\Omega-m & \text { ohm-meter } \\ \mathrm{km} & \text { kilometer } \\ \mathrm{m} & \text { meter } \\ \text { AMT } & \text { audio-magnetotelluric } \\ \mathrm{FFT} & \text { fast Fourier transform } \\ \mathrm{Hz} & \text { hertz } \\ \mathrm{MT} & \text { magnetotelluric } \\ \mathrm{S} / \mathrm{m} & \text { Siemens/meter } \\ \text { TE } & \text { transverse electric } \\ \text { TM } & \text { transverse magnetic } \\ \text { UTM } & \text { Universal Transverse Mercator }\end{array}$




\title{
Audio-Magnetotelluric Survey to Characterize the Sunnyside Porphyry Copper System in the Patagonia Mountains, Arizona
}

\author{
By Jay A. Sampson and Brian D. Rodriguez
}

\begin{abstract}
The Sunnyside porphyry copper system is part of the concealed San Rafael Valley porphyry system located in the Patagonia Mountains of Arizona. To help characterize the size, resistivity, and skin depth of the polarizable mineral deposit concealed beneath thick overburden, a regional east-west audio-magnetotelluric sounding profile was acquired. Further studies will attempt to determine if induced polarization parameters extracted from the magnetotelluric data can also be used to determine the size and resistivity of the mineralized area. The purpose of this report is to release the audio-magnetotelluric sounding data collected along that east-west profile. No interpretation of the data is included.

\section{Introduction}

The Great Basin province of the western United States holds great potential for concealed mineral deposits. This study uses the magnetotelluric (MT) method to determine if a polarizable mineral deposit (indicative of metallic content) can be detected buried beneath thick overburden. Conventional geophysical exploration methods employing induced polarization surveys produce signals of limited penetration depth and require large, cumbersome transmitters. The MT method measures and records the Earth's natural time-varying electromagnetic signals as they pass through the subsurface. A relatively new technique, known as natural field induced polarization (Gasperikova and Morrison, 2001), extracts induced polarization parameters from MT data. To do so, however, the skin depth of the target must be known in order to distinguish the electromagnetic response of the mineral deposit from the response of the surrounding host medium. One must know the general size, depth, and electrical resistivity of the target to calculate the skin depth.

The Sunnyside porphyry copper system is part of the concealed San Rafael Valley porphyry system located in the Patagonia Mountains of Arizona. To help characterize the size and resistivity of the mineralized area beneath cover, a regional east-west audio-magnetotelluric (AMT) sounding profile was acquired the first week of May, 2008 (fig. 1). Resistivity modeling of the audio-magnetotelluric (high frequency MT) data can be used to help resolve the size and resistivity of the target. The purpose of this report is to release the AMT sounding data collected along that east-west profile. No interpretation of the data is included.
\end{abstract}




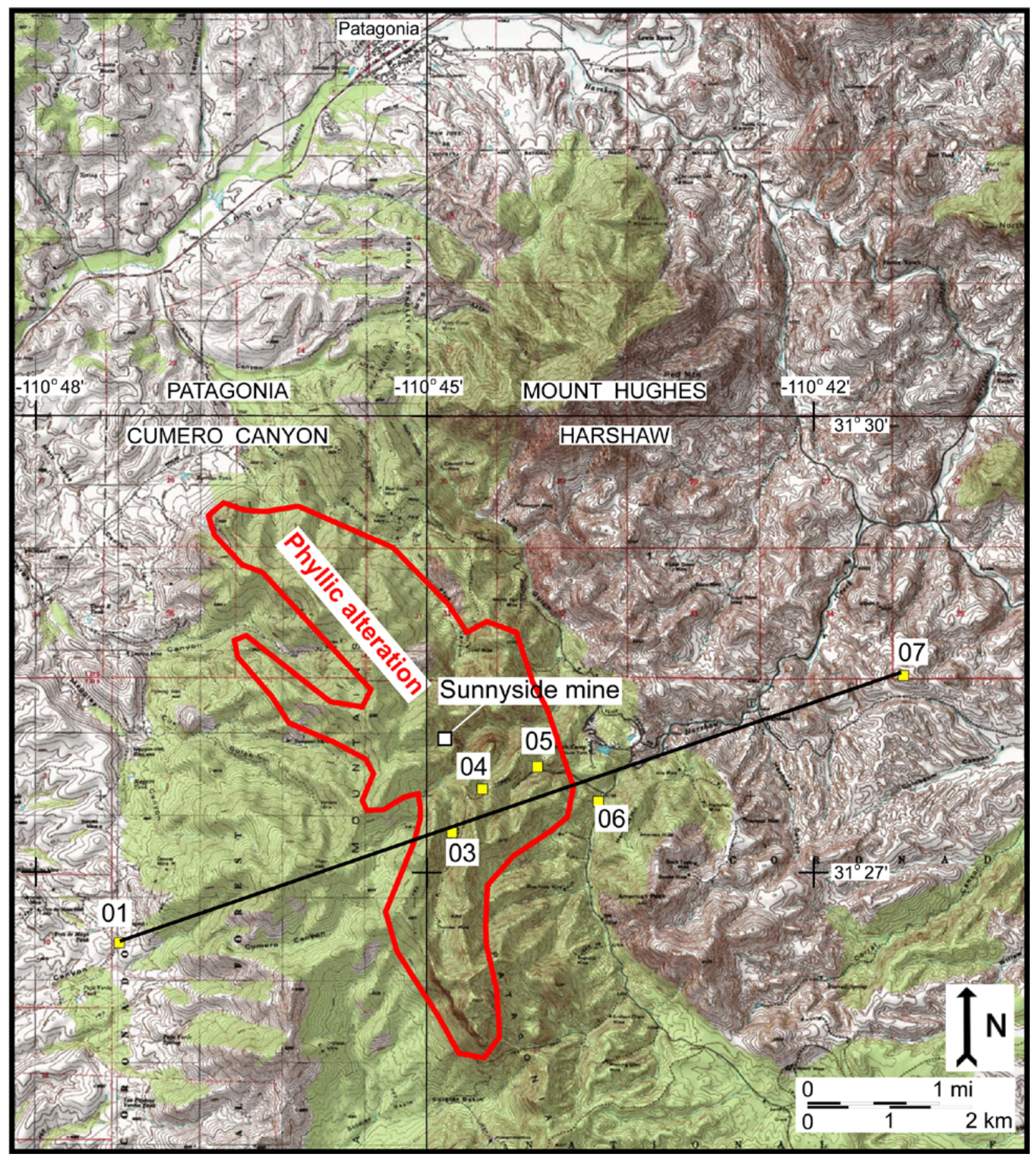

Figure 1. Audio-magnetotelluric profile across the Sunnyside porphyry system in the Patagonia Mountains, Arizona. Audio-magnetotelluric stations acquired in May 2008 are numbered yellow squares (station 2 not acquired). Base map from Cumero Canyon, Harshaw, Patagonia, and Mount Hughes, Arizona, 1:24,000 topographic quadrangles. 


\section{Electrical Properties of Rock}

Electromagnetic geophysical methods detect variations in the electrical properties of rock units - in particular, electrical resistivity, in units of ohm-meters [ $\Omega-\mathrm{m}]$, or its inverse, electrical conductivity in units of Siemens/meter $(\mathrm{S} / \mathrm{m})$. Electrical resistivity can be correlated with geologic units on the surface and at depth by using lithologic logs to provide a three-dimensional picture of subsurface geology. In the upper crust, the resistivities of geologic units largely depend upon their fluid content, pore-volume porosity, interconnected fracture porosity, and the presence of conductive minerals (such as clay, graphitic carbon, and metallic minerals). Fluids in the pore spaces and fracture openings, especially saline fluids, can increase electrical conductance in an otherwise electrically resistive rock matrix (Keller and Frischknecht, 1966; Hearst and Nelson, 1985; Keller, 1987; Palacky, 1987; Hallenburg, 1998; Hearst and others, 2000). Although no one-to-one relation exists between lithology and resistivity, some general correlations can be made by using typical values, even though different values can be found at other localities (Palacky, 1987) that may fall outside of the ranges presented below. It is common for altered volcanic rocks to contain replacement minerals that have resistivities only one tenth as high as those of the surrounding rocks (Nelson and Anderson, 1992). Fine-grained sediments, such as clay-rich alluvium, marine shales, and other mudstones, are normally conductive and have resistivities of a few ohm-meters to tens of ohm-meters (Keller, 1987; Palacky, 1987). Metamorphic rocks (not containing graphite) and unaltered, unfractured igneous rocks are normally moderately to highly resistive (a few hundred to thousands of ohm-meters). Porous carbonate rocks having low fluid content and few impurities can have similarly high resistivities (Keller, 1987; Palacky, 1987). Fault zones may be moderately conductive (tens of ohm-meters) when composed of rocks fractured enough to have hosted fluid transport and consequent mineralogical alteration (Eberhart-Phillips and others, 1995). At greater depths, higher subsurface temperatures decrease fluid viscosity that causes greater mobility of ions in the fluids and reduces rock resistivity (Hallenburg, 1998). Tables of electrical resistivity for a variety of rocks, minerals, and geological environments may be found in Keller (1989) and Palacky (1987).

\section{Magnetotelluric Method}

The MT method is a passive ground-based electromagnetic geophysical technique that investigates the distribution of electrical resistivity (or its inverse, electrical conductivity) below the surface at depths of tens of meters to tens of kilometers (Vozoff, 1991). It does so by measuring time variations in the Earth's natural electric and magnetic fields. Worldwide lightning activity at frequencies of about $10,000 \mathrm{hertz}(\mathrm{Hz})$ to $1 \mathrm{~Hz}$ and geomagnetic micropulsations at frequencies of $1 \mathrm{~Hz}$ to $0.001 \mathrm{~Hz}$ provide the main source of signals used by the MT method. The natural electromagnetic waves propagate vertically in the Earth because the very large contrast in the resistivity of the air and the Earth causes a vertical refraction of the electromagnetic wave at the Earth's surface (Vozoff, 1972).

The horizontal electric and magnetic fields are recorded in two orthogonal directions and the vertical magnetic field is also recorded. The resulting time-series signals are used to derive tensor apparent resistivities and phases after first converting them to complex cross spectra by using fast Fourier transform (FFT) techniques and least-squares, cross-spectral analysis (Bendat and Piersol, 1971) to solve for a tensor transfer function. If one assumes that the Earth consists of a two-input, two-output linear system in which the orthogonal magnetic fields are input and the orthogonal electric fields are output, then a transfer function can be calculated that relates the 
observed electric fields to the magnetic fields. Before it is converted to apparent resistivity and phase, the tensor is normally rotated parallel to geologic strike. Subsurface geologic strike can be estimated by determining the horizontal direction (Hxy or Hyx) that the vertical magnetic field "tips" (the tipper strike direction).

For a two-dimensional Earth, the MT fields can be decoupled into transverse electric and transverse magnetic modes (commonly referred to as the TE and TM modes). Two-dimensional resistivity modeling is generally computed to fit both modes. When the geology satisfies the two-dimensional assumption, the MT data for the transverse electric mode is assumed to represent the electric field oriented along geologic strike, and the data for the transverse magnetic mode is assumed to represent the electric field oriented across strike. The MT method is well suited for studying complicated geological environments because the electric and magnetic field transfer functions are sensitive to vertical and horizontal variations in resistivity. High-resolution shallow-subsurface characterization is possible for closely spaced MT stations, but the resolution of the subsurface decreases for deeper measurements and for widely spaced stations. The method is capable of establishing whether the electromagnetic fields are responding to subsurface rock bodies of effectively one, two, or three dimensions. An introduction to the MT method and references for a more advanced understanding are contained in Dobrin and Savit (1988) and Vozoff (1991).

\section{Audio-Magnetotelluric Survey Across the Sunnyside Porphyry Copper System}

Six AMT soundings were collected in May 2008 along a 10-km-long profile in southern Arizona (fig. 1). The profile starts along the western foothills of the Patagonia Mountains about 6 kilometers $(\mathrm{km})$ northeast of Nogales International Airport, then continues northeasterly, passing roughly halfway between the Sunnyside mine and Thunder mine, and ends almost $2 \mathrm{~km}$ northeast of the town of Harshaw. The profile location dissects the northwest-trending Sunnyside porphyry copper system, whose location is coincident with the phyllic alteration zone mapped by Graybeal (1996).

Station locations were chosen for proximity to roads and in order to avoid electrical noise from power lines. All data at the stations were collected with a portable Electromagnetic Instruments, Inc., MT-1 system (Electromagnetic Instruments, Inc., 1996). Horizontal electric fields were recorded using titanium electrodes placed in an L-shaped, three-electrode array with dipole lengths of 30 meters $(\mathrm{m})$. The orthogonal horizontal magnetic fields were measured in the direction of the electric-field array and were sensed using high magnetic permeability mu-metalcored induction coils. Frequencies were sampled from about $4 \mathrm{~Hz}$ to $23,000 \mathrm{~Hz}$ at each station.

Table 1 lists the six AMT station locations (data from station 2 was not acquired because of site access problems). Remote reference stations were not used because man-made noise sources were assumed to be minimal in this inactive mining area. Coordinates are referenced to the 1866 Clarke spheroid and North American 1927 Western United States datum. Longitude and latitude format is degrees, minutes, seconds. Universal Transverse Mercator (UTM) units and station elevations are in meters. The accuracy of the north and east component is $\pm 5 \mathrm{~m}$; for elevation it is $\pm 10 \mathrm{~m}$. 
Table 1. Audio-magnetotelluric station coordinates.

[m, meter; X direction, electrode-array direction in degrees clockwise from true north]

\begin{tabular}{crrlccc}
\hline Station & $\begin{array}{c}\mathbf{X} \\
\text { direction }\end{array}$ & Longitude & Latitude & $\begin{array}{c}\text { North } \\
(\mathbf{m})\end{array}$ & $\begin{array}{c}\text { East } \\
(\mathbf{m})\end{array}$ & $\begin{array}{c}\text { Elevation } \\
(\mathbf{m})\end{array}$ \\
\hline 01 & 19 & $-110^{\circ} 47^{\prime} 21^{\prime \prime}$ & $31^{\circ} 26^{\prime} 32^{\prime \prime}$ & $3,478,446$ & 520,029 & 1,377 \\
03 & 241 & $-110^{\circ} 44^{\prime} 48^{\prime \prime}$ & $31^{\circ} 27^{\prime} 15^{\prime \prime}$ & $3,479,792$ & 524,068 & 1,737 \\
04 & 0 & $-110^{\circ} 44^{\prime} 34^{\prime \prime}$ & $31^{\circ} 27^{\prime} 33^{\prime \prime}$ & $3,480,321$ & 524,436 & 1,718 \\
05 & 320 & $-110^{\circ} 44^{\prime} 08^{\prime \prime}$ & $31^{\circ} 27^{\prime} 41^{\prime \prime}$ & $3,480,590$ & 525,131 & 1,622 \\
06 & 45 & $-110^{\circ} 43^{\prime} 40^{\prime \prime}$ & $31^{\circ} 27^{\prime} 28^{\prime \prime}$ & $3,480,174$ & 525,872 & 1,561 \\
07 & 208 & $-110^{\circ} 41^{\prime} 19^{\prime \prime}$ & $31^{\circ} 28^{\prime} 17^{\prime \prime}$ & $3,481,710$ & 529,577 & 1,551 \\
\hline
\end{tabular}

\section{Audio-Magnetotelluric Data Collected in the Sunnyside Survey}

The recorded time-series data were converted to the frequency domain and processed to determine the impedance tensor, which is used to derive apparent resistivities and phases at each site. Rotation of the impedance tensor allows for decoupling into the transverse electric and transverse magnetic modes. The data provided here have not been rotated from the original acquisition orientation (X direction) listed in table 1. During the analysis and interpretation process, each station should be rotated to a fixed angle determined by the given nominal profile orientation. Cross-power files were sorted to select optimal signal-to-noise time-series data sets (see appendix).Cultural features such as fences, pipelines, communication lines, moving vehicles and trains, and other manmade sources of electromagnetic noise can contaminate the responses of the MT system. Care was taken to avoid these sources of noise when we acquired these data.

The figures in the appendix represent the field-processed AMT data for each station, after the time-series data were converted to the frequency domain and the tensor-transfer function was developed.

Data for each station are presented in eight diagrams:

1. Apparent resistivity ( $\mathrm{x}$ and $\mathrm{o}$ symbols are $\mathrm{xy}$ and $\mathrm{yx}$ components)

2. Impedance phase ( $\mathrm{x}$ and o symbols are $\mathrm{xy}$ and $\mathrm{yx}$ components)

3. Impedance skew

4. Multiple coherency ( $\mathrm{x}$ and o symbols are xy and yx components)

5. Impedance polar plots

6. Tipper magnitude

7. Tipper strike

8. HzHx (x symbol) and HzHy (o symbol) coherency

Error bars (],[) on the diagrams of apparent resistivity, impedance phase, skew, tipper magnitude, and tipper strike plots represent probable errors within one standard deviation of the sample variance (Gamble and others, 1979). 
Apparent resistivity is calculated from the ratio of the electric field strength magnitude over the magnetic field strength magnitude for a given frequency. The impedance phase is proportional to the slope of the apparent-resistivity curve on a log-log plot, relative to a baseline at -45 degrees (Vozoff, 1991). A measure of the dimensionality for MT data is provided by the impedance skew of the impedance tensor (Vozoff, 1972). If the effective, measured resistivity response to the geology beneath an MT station is truly one- or two-dimensional, then the skew will be zero. Both instrument and environmental sources of noise contribute to nonzero skew values but are typically small (about 0.1 ) for relatively low-noise-level recordings. Higher skews (more than 0.2) indicate either the resistivity response to three-dimensional geology or higher levels of noise.

In the study area, noise from a number of small power lines and small moving vehicles was negligible beyond $0.25 \mathrm{~km}$ from the noise source. Power-line signal amplitudes were measured at each site and were typically less than 20 percent of the maximum recordable signals. Noise from larger power lines, power generators, pipelines, and trains was negligible at distances more than $5 \mathrm{~km}$. Local lightning, wind, and rainstorms also can degrade data quality, but these noise sources were avoided by not recording during active thunderstorms. Burying the magnetic induction coils and keeping the electric dipole wires flat on the ground helped to minimize wind noise.

The figures in the appendix represent the field-processed AMT data at each station, and they include some data scatter and poor signal-to-noise ratios. The only effort aimed at removing noisy data points was to visually inspect and select the best signal-to-noise field data to combine into the final data plots.

Predicted values of the electric field can be computed from the measured values of the magnetic field (Vozoff, 1991). The coherence of the predicted electric field with the measured electric field is a measure of the signal-to-noise ratio provided in the multiple coherency plots. Values are normalized between 0 and 1, where values at 0.5 signify signal levels equal to noise levels. For this data set, coherencies were generally above 0.9 , except in the higher frequencies (greater than about $1 \mathrm{kHz}$ ) for stations $1,3,4$, and 7.

The impedance polar plots provide a measure of the MT data dimensionality (Reddy and others, 1977). For one-dimensional resistivity structures, the principal impedance (off-diagonal elements) polar diagram (dashed line) is a circle. For two-dimensional or three-dimensional resistivity structures, the principal impedance polar diagram (dashed line) elongates either parallel to or perpendicular to strike direction. Over resistors, the principal impedance polar diagram elongates perpendicular to strike direction, while over conductors the principal impedance polar diagram elongates parallel to strike direction. For two-dimensional resistivity structures, the additional impedance polar diagram (solid line) attains the shape of a symmetric clover leaf. For three-dimensional resistivity structures, the additional impedance polar diagram (solid line) elongates in one direction, and its amplitude is comparable to that of the principal impedance polar diagram (dashed line), although high noise levels can produce the same effect on the polar diagram. A three-dimensional analysis of polar plots at each frequency should also take into account the corresponding coherence and skew values along with their associated error levels. The polar plots computed for our data show the electromagnetic response for all stations was three-dimensional throughout all frequencies measured at acceptable noise levels.

The tipper can be calculated from the vertical component of the magnetic field. The tipper magnitude is a measure of the tipping of the magnetic field out of the horizontal plane (Vozoff, 1991). The magnitude is zero for the one-dimensional case, typically increases to values 
between 0.1 and 0.5 , and rarely is as great as 1 as it responds to vertical and subvertical structures. The tipper strike typically is used to help resolve the 90 -degree ambiguity in the impedance rotation angle. The tipper magnitudes of these stations were all above 0.1 indicating vertical and subvertical structure at depth.

The HzHx and HzHy coherency is a measure of the signal-to-noise ratio of the vertical magnetic field with respect to each of the orthogonal, horizontal magnetic field directions. Values are normalized between 0 and 1 , where values of 0.5 signify signal levels equal to noise levels. These three components of magnetic-field coherence provide a check on the quality of the measured values in the tipper magnitude and tipper strike plots. 


\section{References Cited}

Bendat, J.S., and Piersol, A.G., 1971, Random data-Analysis and measurement procedures: New York, Wiley Interscience, $407 \mathrm{p}$.

Dobrin, M.D., and Savit, C.H., 1988, Introduction to geophysical prospecting (4th ed.): New York, McGraw-Hill, $867 \mathrm{p}$.

Eberhart-Phillips, Donna, Stanley, W.D., Rodriguez, B.D., and Lutter, W.J., 1995, Surface seismic and electrical methods to detect fluids related to faulting: Journal of Geophysical Research, v. 100, no. B7, p. 12919-12936.

Electromagnetic Instruments, Inc., 1996, MT-1 magnetotelluric system operation manual, version 3.2: Richmond, Calif., Electromagnetic Instruments, Inc., 220 p.

Gamble, T.D., Goubau, W.M., and Clarke, J., 1979, Error analysis for remote reference magnetotellurics: Geophysics, v. 44, no. 5, p. 959-968.

Gasperikova, Erika, and Morrison, H. F., 2001, Mapping of induced polarization using natural fields: Geophysics, v. 66, no.1, p.137-147.

Graybeal, F.T., 1996, Sunnyside, a vertically preserved porphyry copper system, Patagonia Mountains, Arizona: Society of Economic Geologists Newsletter, no. 26, p. 1, 10-14.

Hallenburg, J.K., 1998, Non-hydrocarbon methods of geophysical formation evaluation: Boca Raton, Fla., Lewis Publishers, 265 p.

Hearst, J.R., and Nelson, P.H., 1985, Well logging for physical properties: New York, McGrawHill, $571 \mathrm{p}$.

Hearst, J.R., Nelson, P.H., and Paillet, F.L., 2000, Well logging for physical properties, 2d ed.: New York, John Wiley, 483 p.

Keller, G.V., 1987, Rock and mineral properties, in Nabighian, M.N., ed., Electromagnetic methods in applied geophysics theory: Tulsa, Okla., Society of Exploration Geophysicists, v. 1, p. 13-51.

Keller, G.V., 1989, Electrical properties, in Carmichael, R.S., ed., Practical handbook of physical properties of rocks and minerals: Boca Raton, Fla., CRC Press, p. 359-427.

Keller, G.V., and Frischknecht, F.C. 1966, Electrical methods in geophysical prospecting: Oxford, Pergamon Press Inc., 519 p.

Nelson, P.H., and Anderson, L.A., 1992, Physical properties of ash flow tuff from Yucca Mountain, Nevada: Journal of Geophysical Research, v. 97, no. B5, p. 823-841.

Palacky, G.J., 1987, Resistivity characteristics of geologic targets, in Nabighian, M.N., ed., Electromagnetic methods in applied geophysics: Tulsa, Okla., Society of Exploration Geophysicists, v. 1, p. 53-129.

Reddy, I.K., Rankin, David, and Phillips, R.J., 1977, Three-dimensional modelling in magnetotelluric and magnetic variational sounding: Geophysics Journal of the Royal Astronomical Society, v. 51, p. 313-325.

Vozoff, Keeva, 1972, The magnetotelluric method in the exploration of sedimentary basins: Geophysics, v. 37, p. 980-141.

Vozoff, Keeva, 1991, The magnetotelluric method, in Nabighian, M.N., Electromagnetic methods in applied geophysics: Tulsa, Okla., Society of Exploration Geophysicists, v. 2, pt. B, p. 641-711. 


\section{Appendix}

\section{Audio-Magnetotelluric Data Diagrams}

Data for each station are presented in eight diagrams:

1. Apparent resistivity for the unrotated $x y$ (x symbol) and yx (o symbol) modes

2. Impedance phase for the unrotated $x y(x$ symbol) and $y x$ (o symbol) modes

3. Impedance skew for the impedance tensor

4. Multiple coherency for the xy (x symbol) and minimum (o symbol) modes of the electric field

5. Impedance polar plots (at 12 selected frequencies)

6. Tipper magnitude for the vertical magnetic field

7. Tipper strike for the vertical magnetic field

8. HzHx (x symbol) and HzHy (o symbol) coherency

Refer to the "Audio-Magnetotelluric Data Collected in the Sunnyside Survey" section in this report for an explanation of these diagrams. 


\section{Station 1}

APPARENT RESISTTVITY

Patagonia Mtns, Arizona

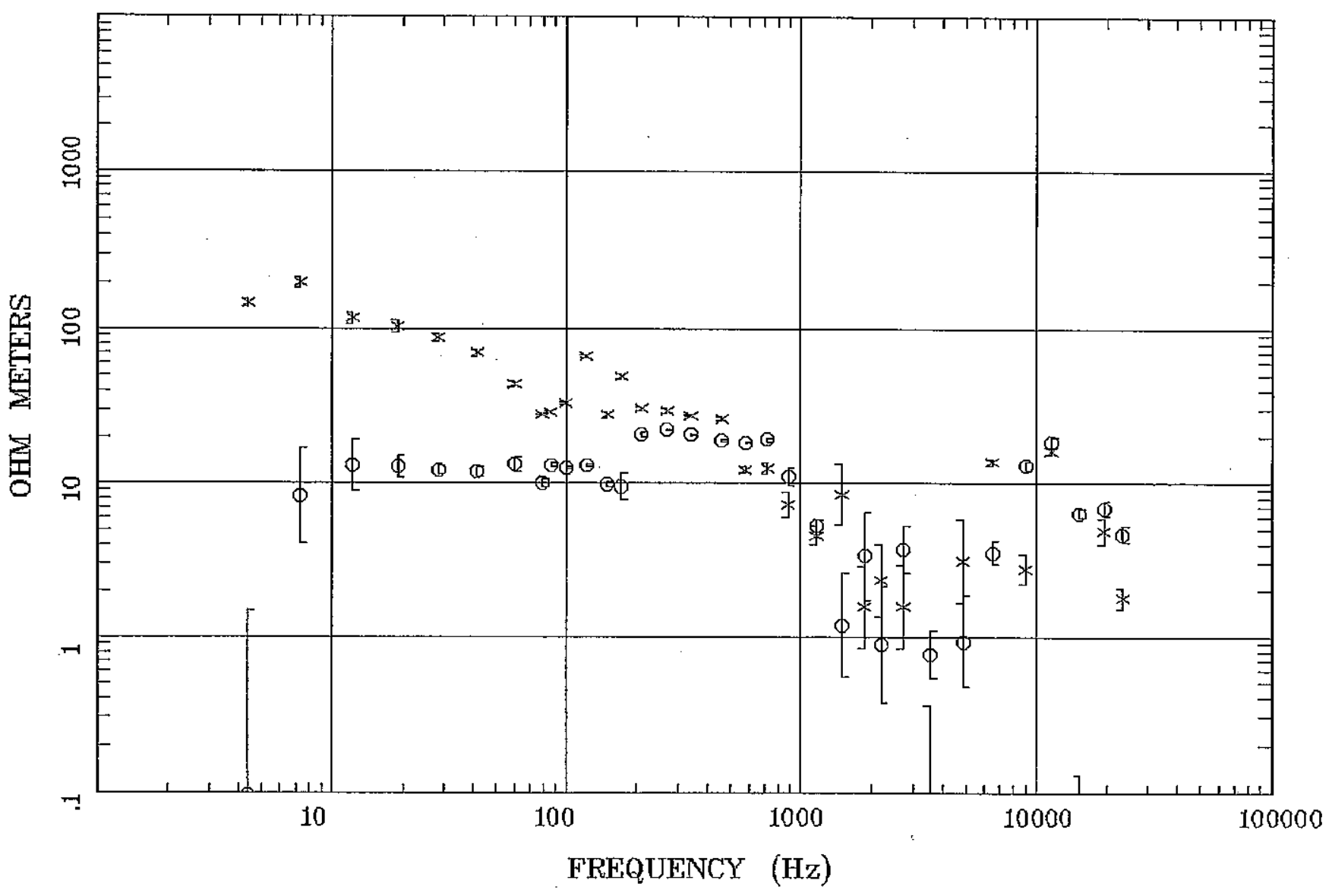

Client: Mineral Resources Program Remate: none

Acquired: 11:3 May 04, 2008

Survey Co:USGS
Rotation:

Filename: sp01az.avg

Channels: Ch1 Ch2 Ch3 Ch4 Ch5 Ch3 Ch4

Plotted: 11:07 Mar 16, 2010

< EMI - ElectroMagnetic Instruments > 


\section{Station 1}

IMPEDANCE PHASE

Patagonia Mtns, Arizona

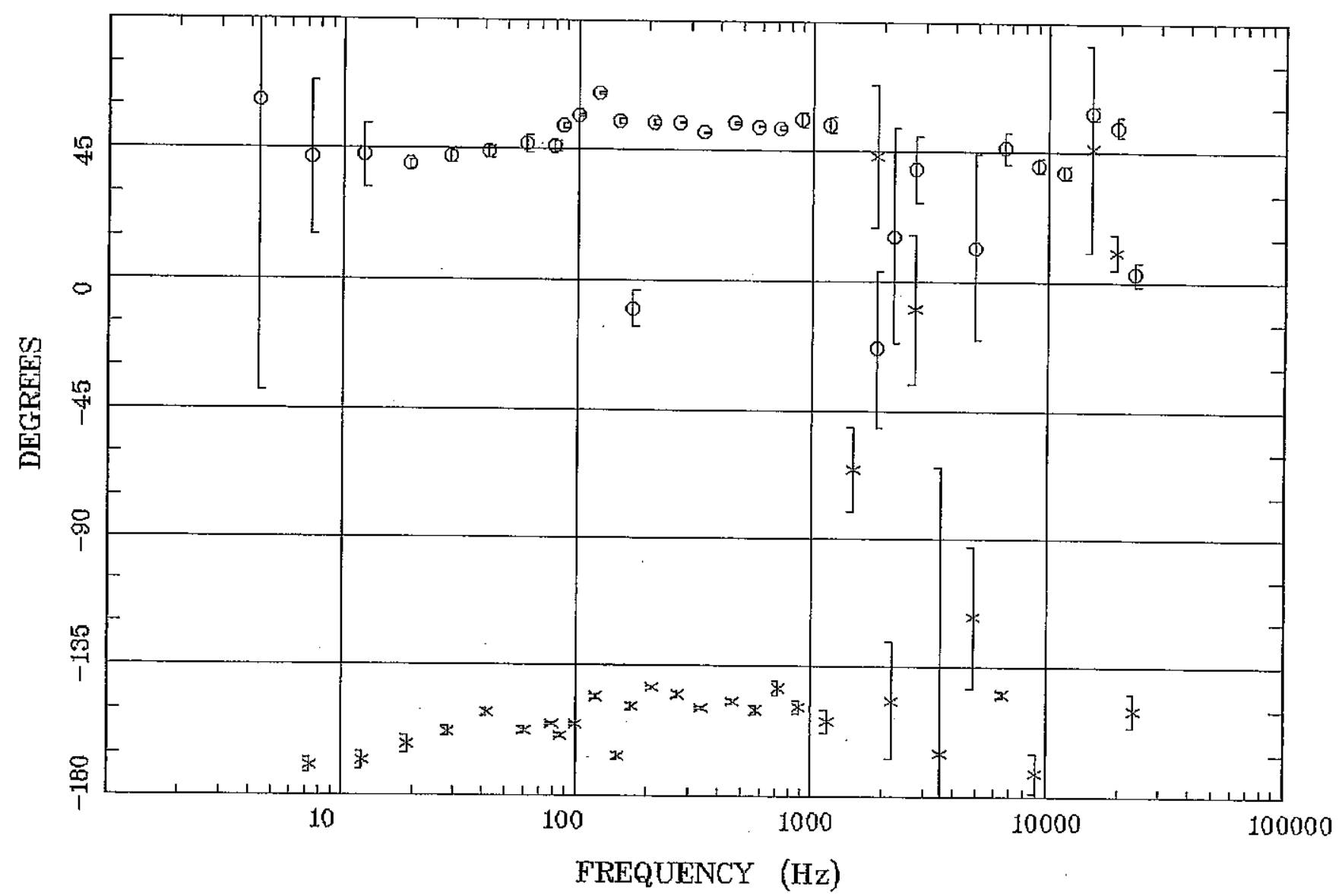

Rotation:

Client: Minerel Resources Program Remote: none

Acquired: 11:3 May 04, 2008

Filename: sp01az.avg

Channels: Ch1 Ch2 Ch3 ch4 ch5 Ch3 Ch4

Plotted: 11:07 Mar 16, 2010

Survey Co:USGS

< EMI - ElectroMagnetic Instruments > 


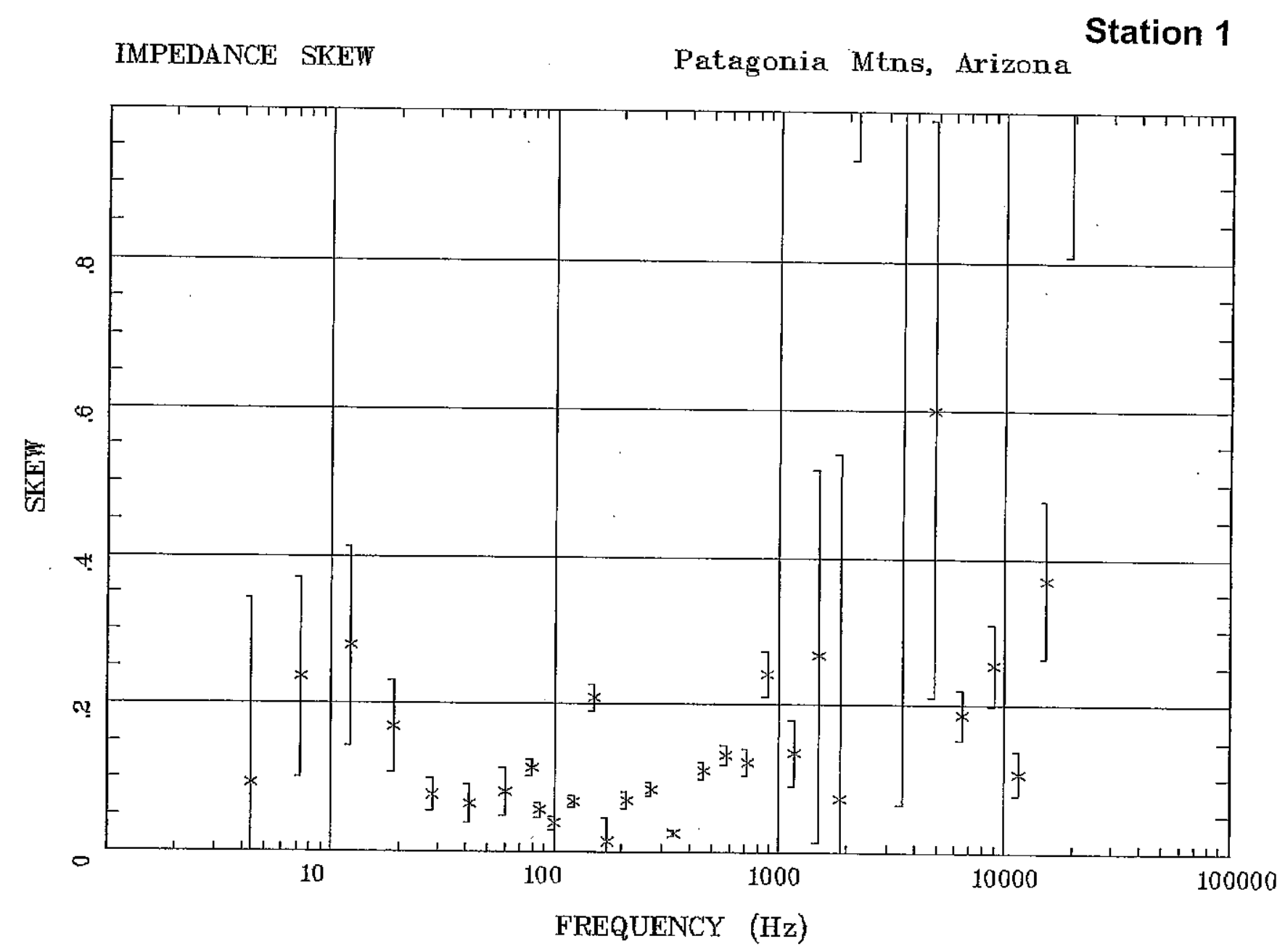

Client: Mineral Resources Program

Rotation:

Remote: none

Acquired: 11:3 May 04, 2008

Filename: sp01a2.avg

Channels: Ch1 Ch2 Ch3 Ch4 Ch5 Ch3 Ch4

Plotted: 11:0\% Mar 16, 2010

< EMI - ElectroMagnetic Instruments > 


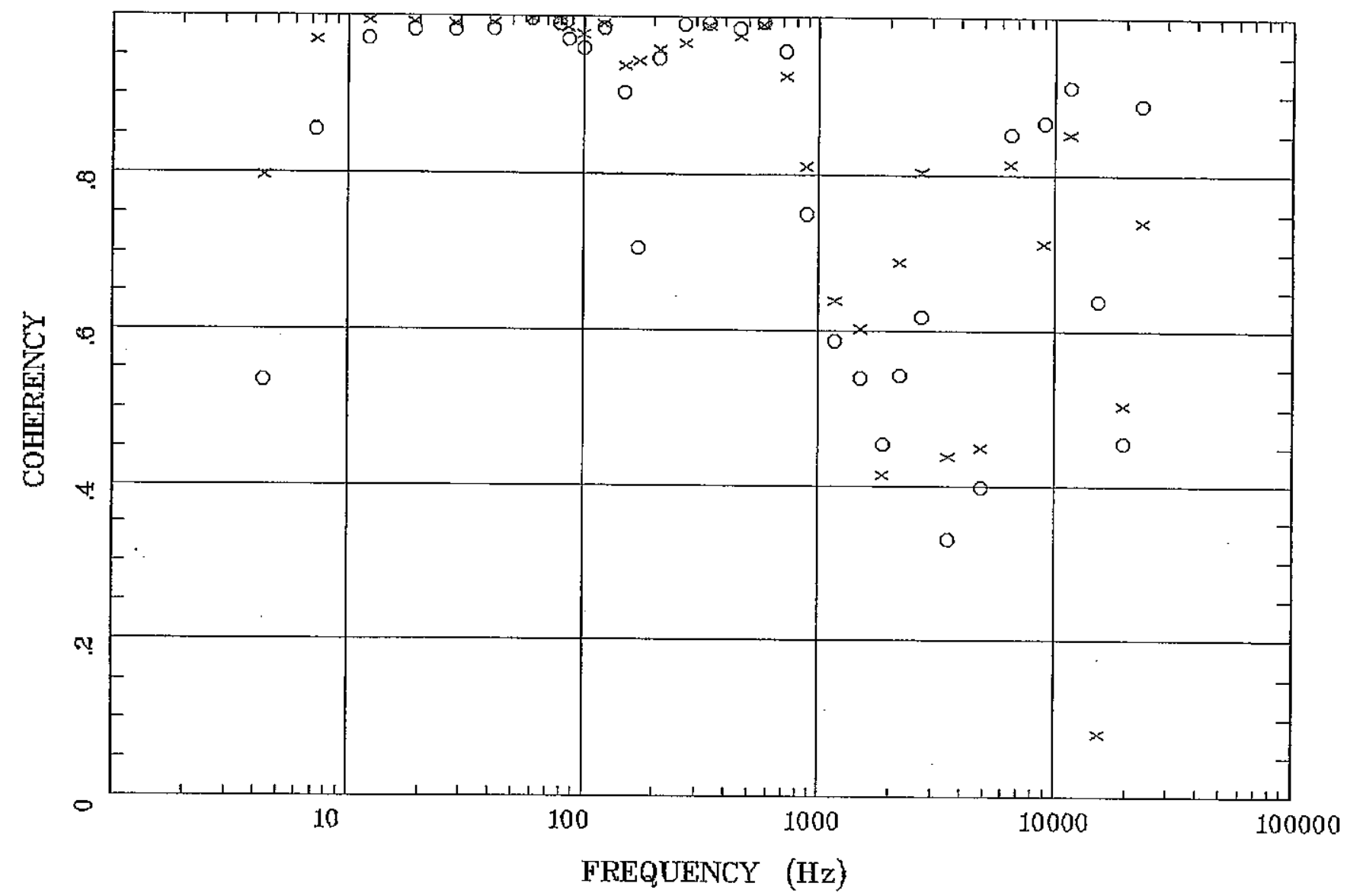

Client: Mineral Resources Program

Rotation:

Remote: none

Filename: sp01az.avg

Acquired: 11:3 May 04, 2008

Channels: Ch1 Ch2 Ch3 Ch4 Ch5 Ch3 Ch4

Plotted: 11:0'7 Mar 16, 2010

Survey Co:USGS

< EMI - ElectroMagnetic Instruments > 


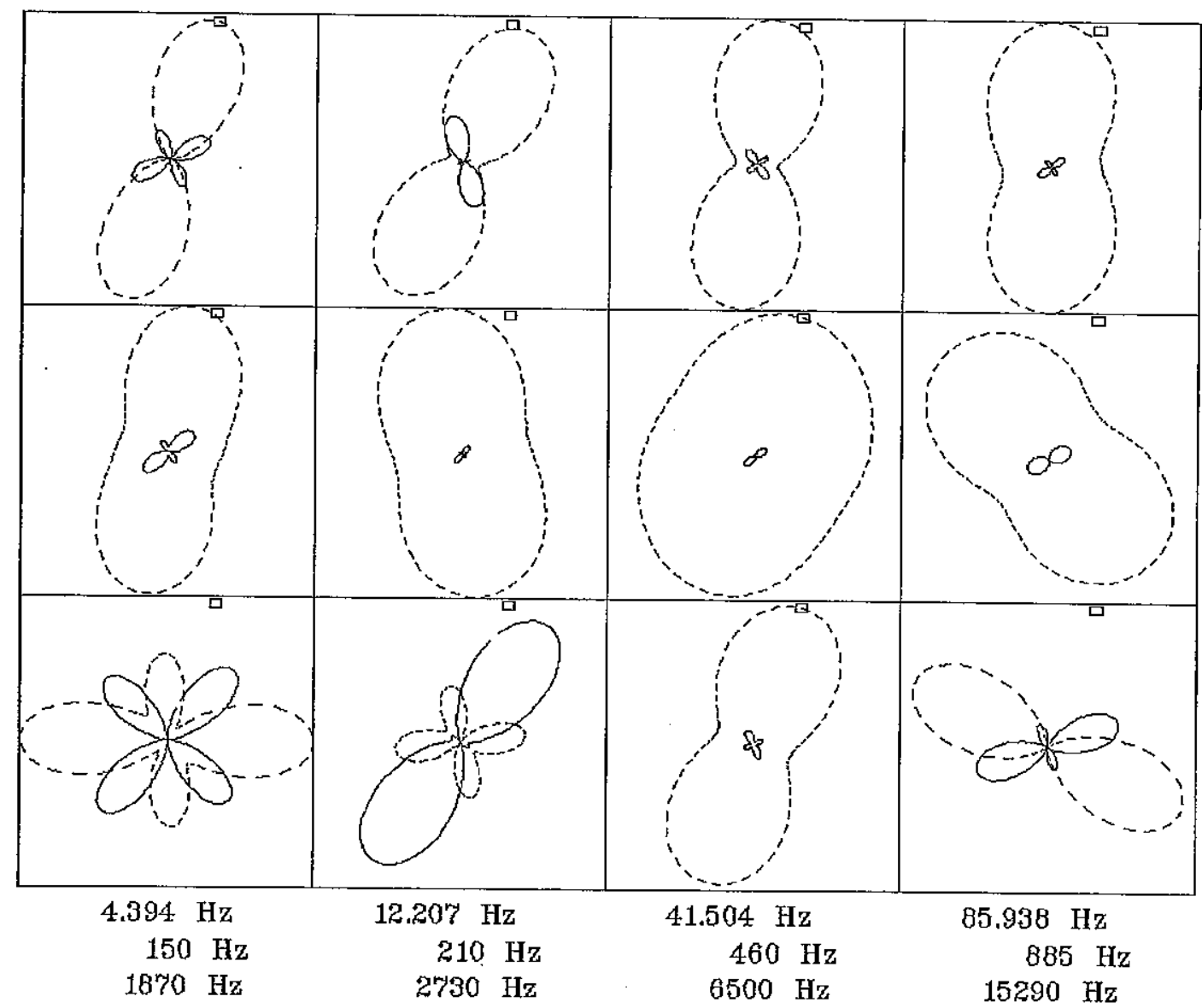

Client: Mineral Resources Program Remote: none

Acquired: 11:3 May 04, 2008

Rotation:

Filename: sp01az.avg

Channels: Ch1 Ch2 Ch3 Ch4 Ch5 Ch3 Ch4 Survey Co:USGS

Plotted: 11:07 Mar 16, 2010

$<$ EMI - ElectroMagnetic Instruments 


\section{Station 1}

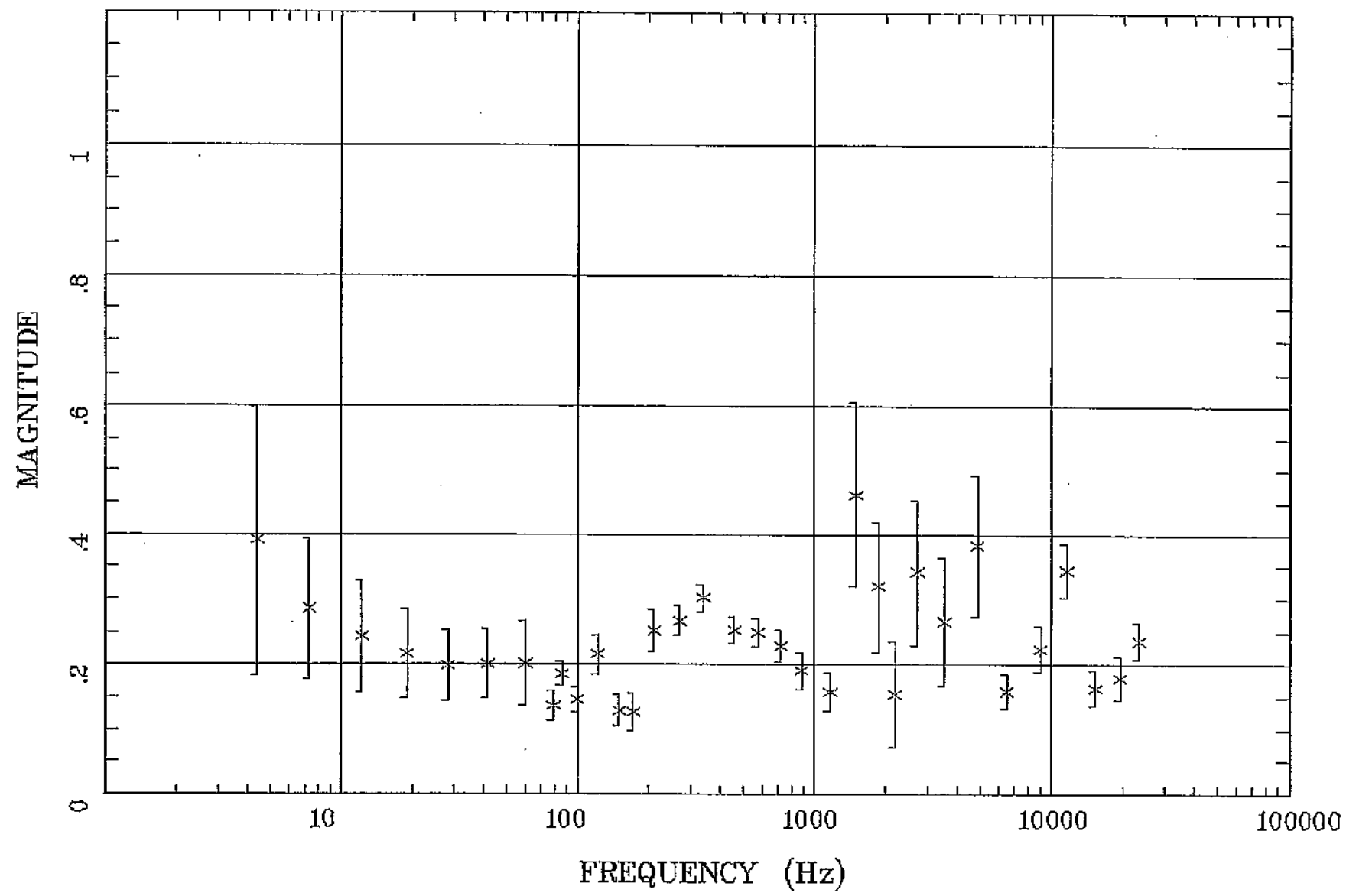

Client: Mineral Resaurces Program Remote: none

Acquired: 11:3 May 04, 2008 Survey Co:USGS
Rotation:

Filename: sp0laz.avg

Channels: Ch1 Ch2 Ch3 Ch4 Ch5 Ch3 Ch4

Plotted: 11:07 Mar 16, 2010

$<$ EMI - ElectroMagnetic Instruments > 


\section{TIPPER STRIKE}

Patagonia Mtns, Arizona

Station 1

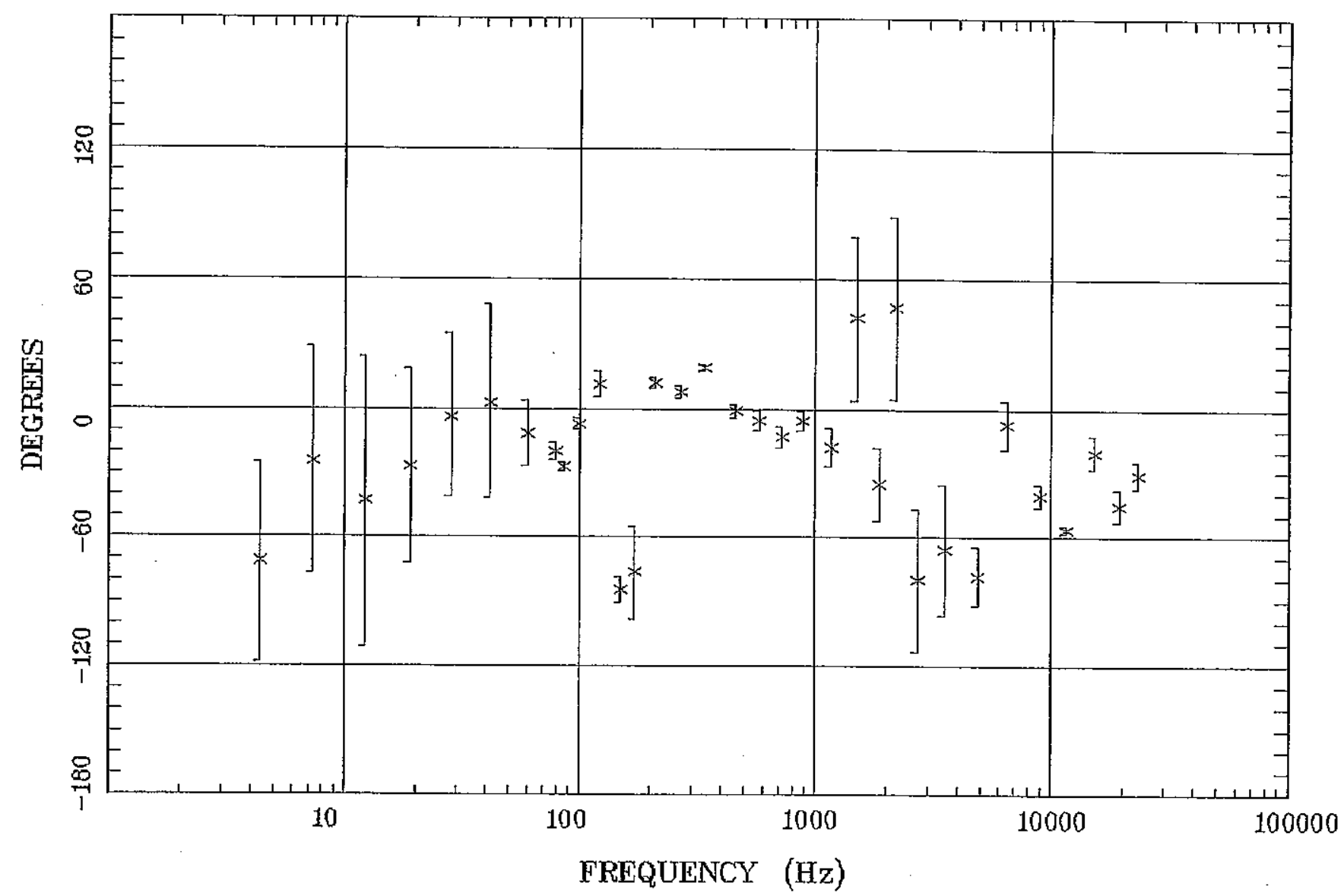

Client: Minerel Resources Program

Rotation:

Remote: none

Filename: sp01a2.avg

Channels: Ch1 Ch2 Ch3 Ch4 Ch5 Ch3 Ch4

Acquired: 11:3 May 04, 2008

Platted: 11:07 Mar 16, 2010

Survey Co:USGS

< EMI - ElectroMagnetic Instruments 
HzHx.x. Coh HzHy.o

Patagonia Mtns, Arizona

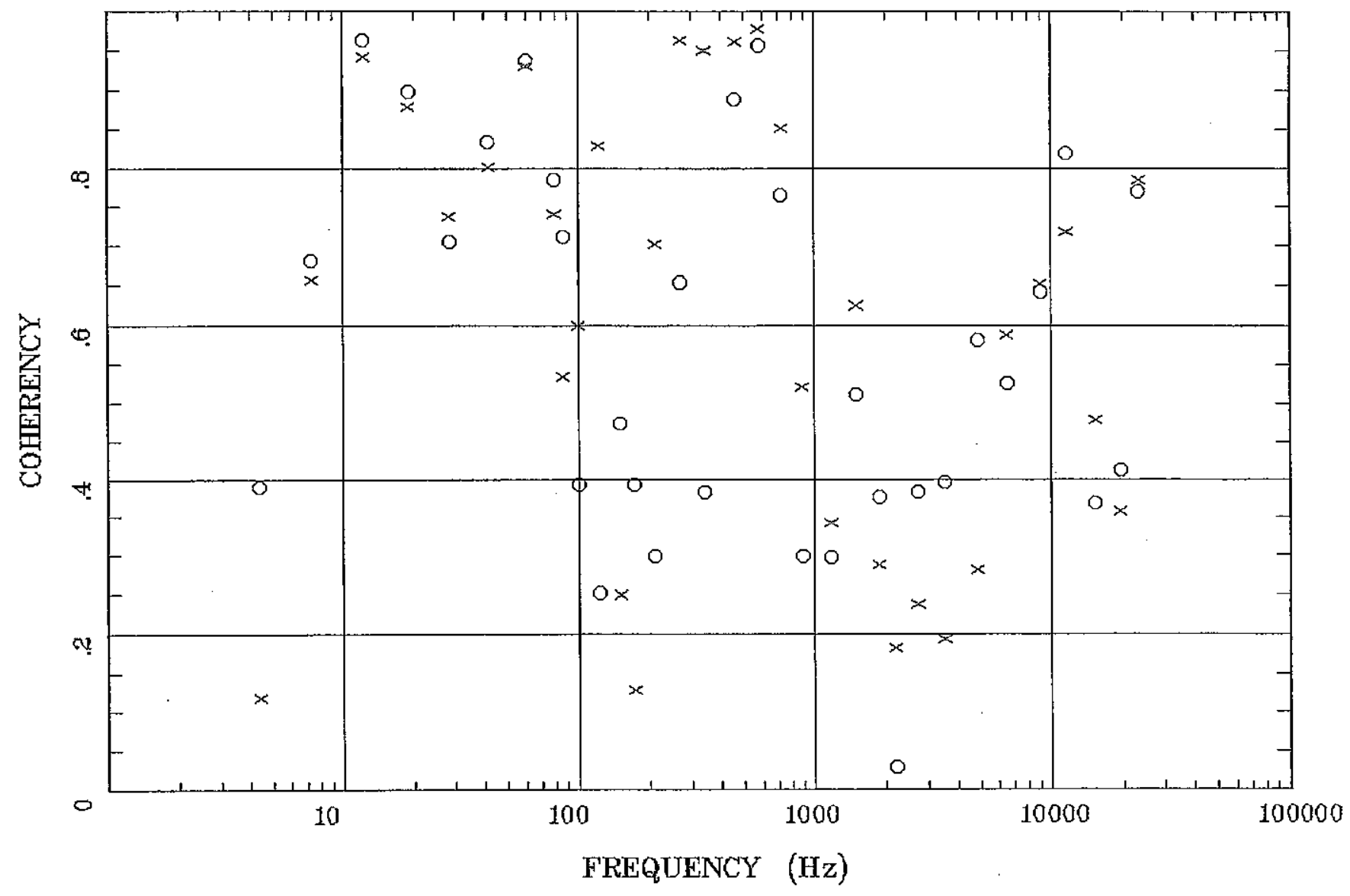

\section{Rotation:}

Client: Mineral Resources Program Remote: none

Acquired: 11:3 May 04, 2008 Survey Co:USGS
Filename: sp01az.avg

Channels: Ch1 Ch2 Ch3 Ch4 Ch5 Ch3 Ch4

Plotted: 11:0' Mar 16, 2010

< EMI - ElectroMagnetic Instruments > 


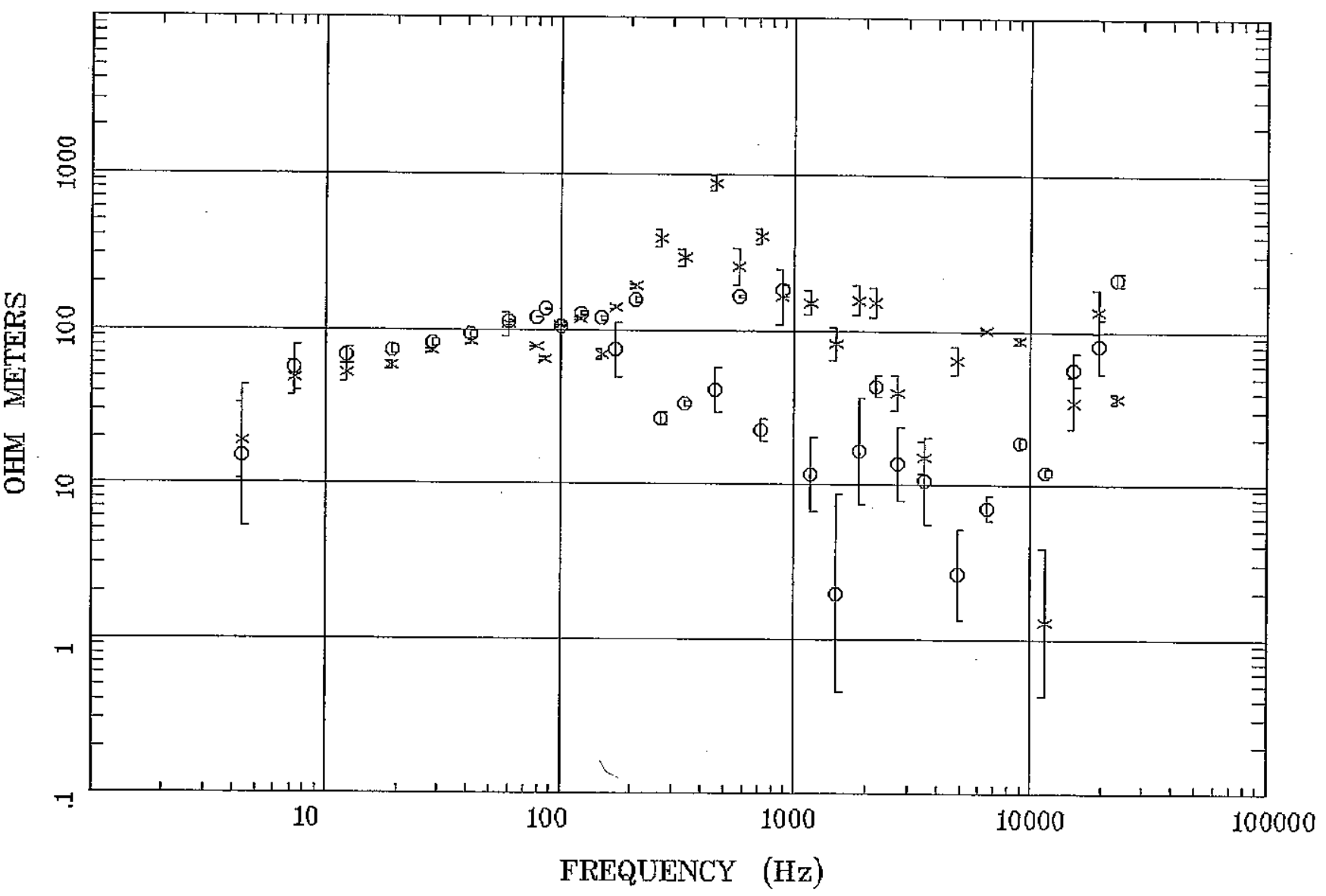

Client: Mineral Resources Program

Rotation:

Remote: none

Filename: sp03a1.avg

Acquired: 14:0 May 01, 2008

Channels: Ch1 Ch2 Ch3 ch4 Ch5 ch3 Ch4

Platted: 11:08 Mar 16, 2010

Survey Co:USGS

$<$ EMI - ElectroMagnetic Instruments > 


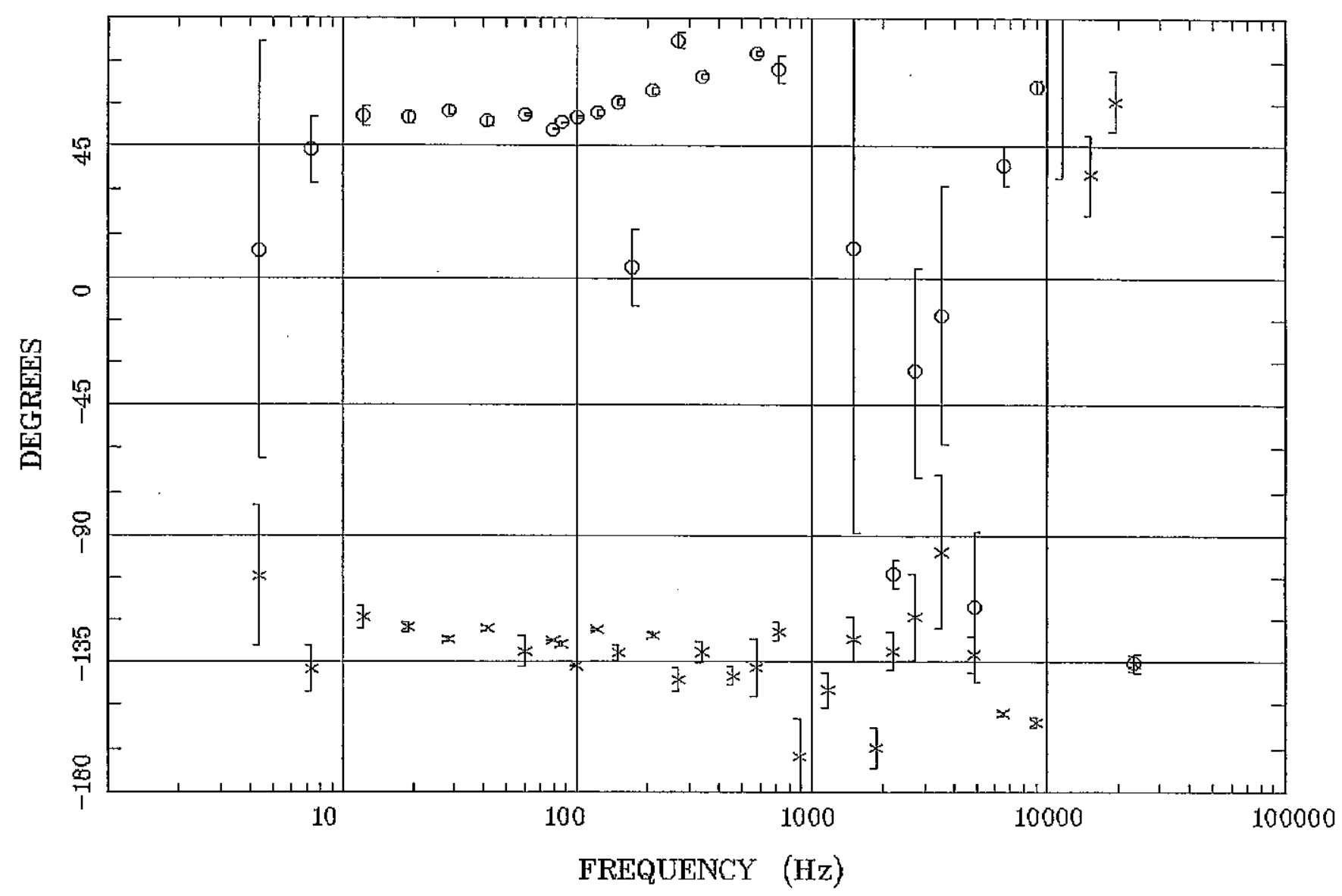

Client: Mineral Resources Program Remote: none

Acquired: 14:0 May 01, 2008

Survey Co:USGS

\section{Rotation:}

Filename: sp03a1.avg

Channels: Ch1 Ch2 Ch3 Ch4 Ch5 Ch3 Ch4

Plotted: 11:08 Mar 16, 2010

< EMI - ElectroMagnetic Instruments 


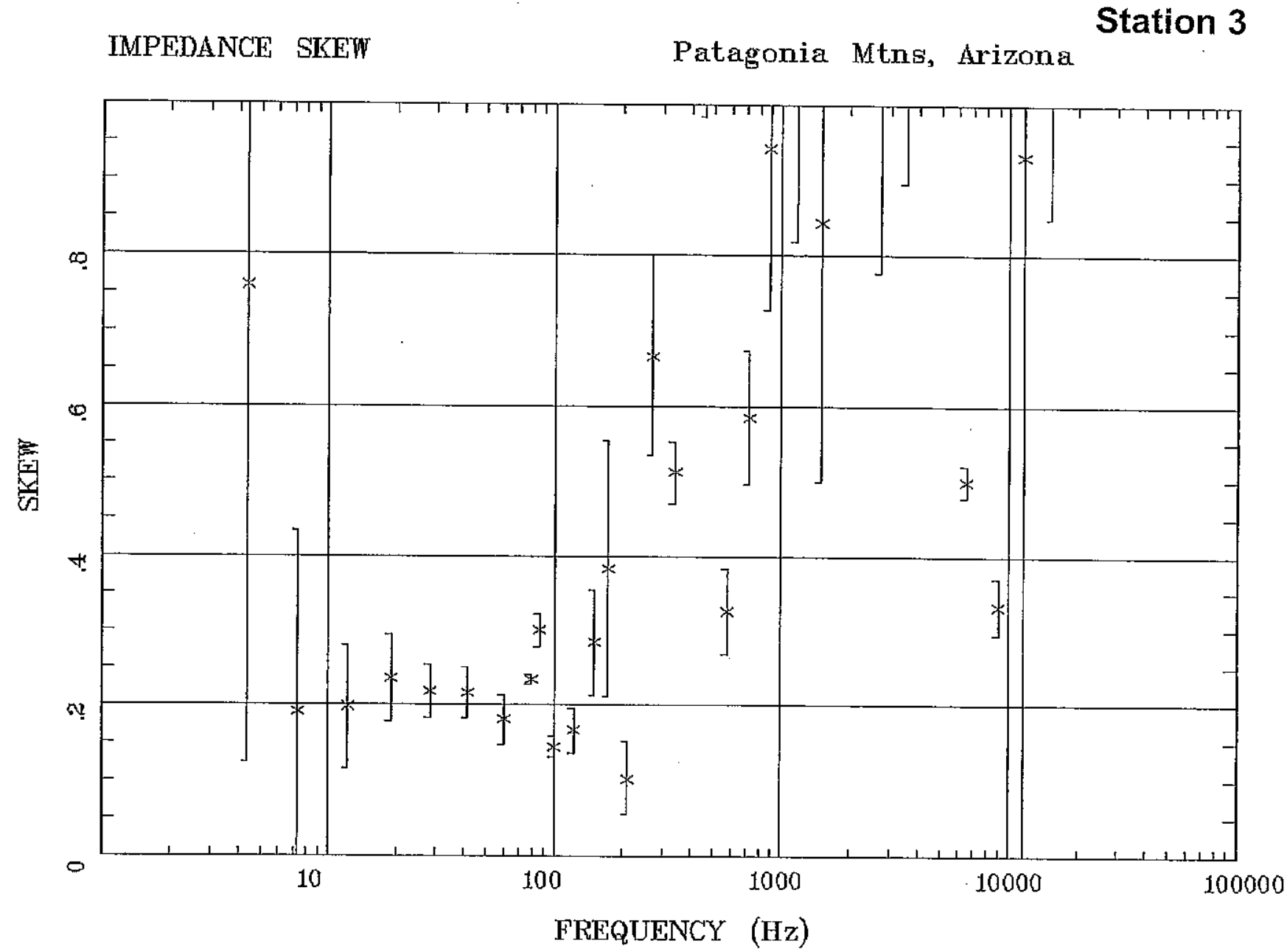

Client; Mineral Resources Program

Rotation:

Remote: none

Filename: sp03a1.avp

Acquired: 14:0 May 01, 2008

Channels: Ch1 Ch2 Ch3 Ch4 Ch5 Ch3 ch4

Plotted: 11:08 Mar 16, 2010

Survey Co:USGS

< EMI - ElectroMagnetic Instruments > 
Station 3

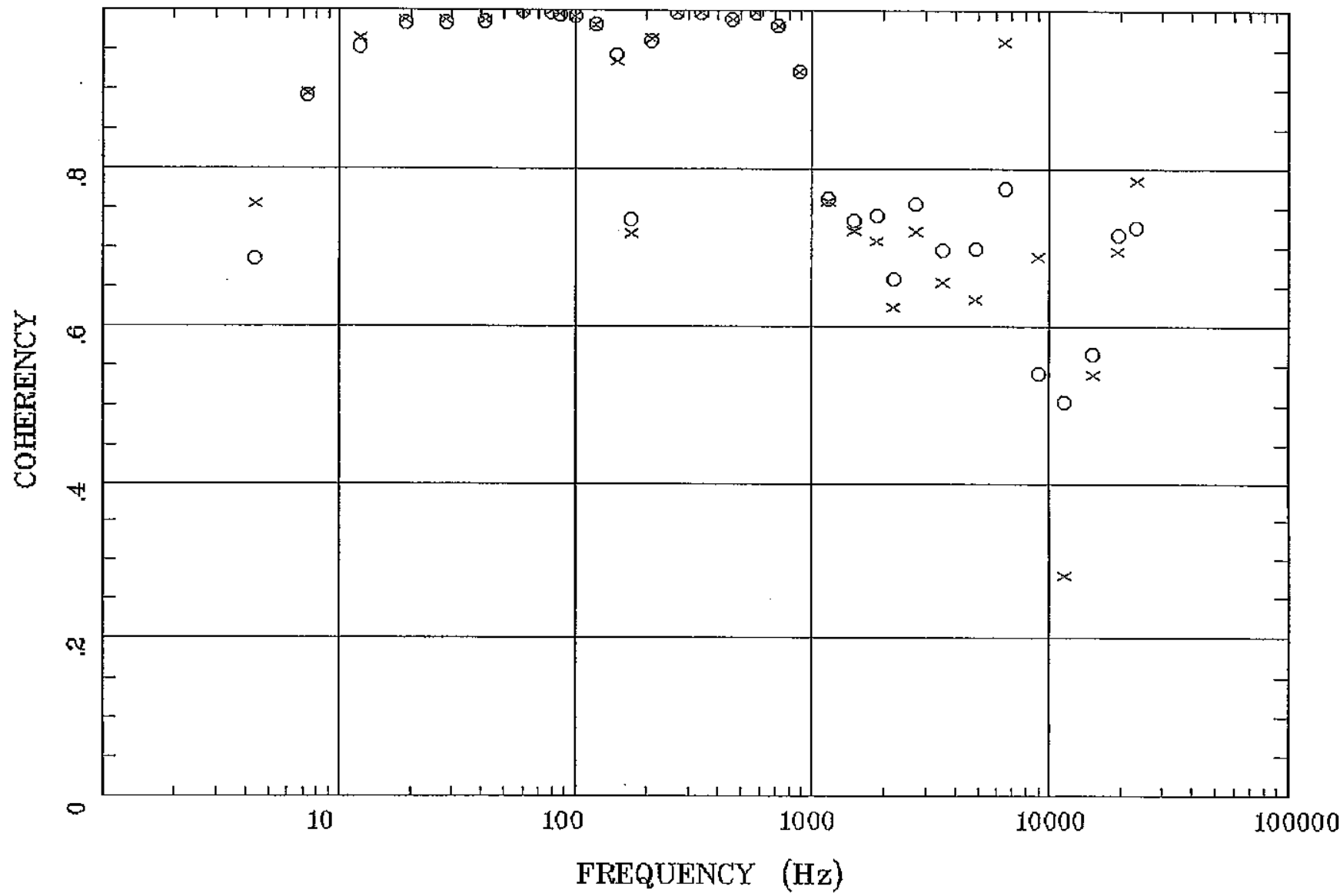

Client: Mineral Resources Program Remote: none

Acquired: 14:0 May 01, 2008 Survey Co:USGS
Rotation:

Filename: sp03a1.avg

Channels: Ch1 Ch2 Ch3 Ch4 Ch5 Ch3 Ch4

Plotted: 11:08 Mar 16, 2010

< EMI - ElectroMagnetic Instruments 


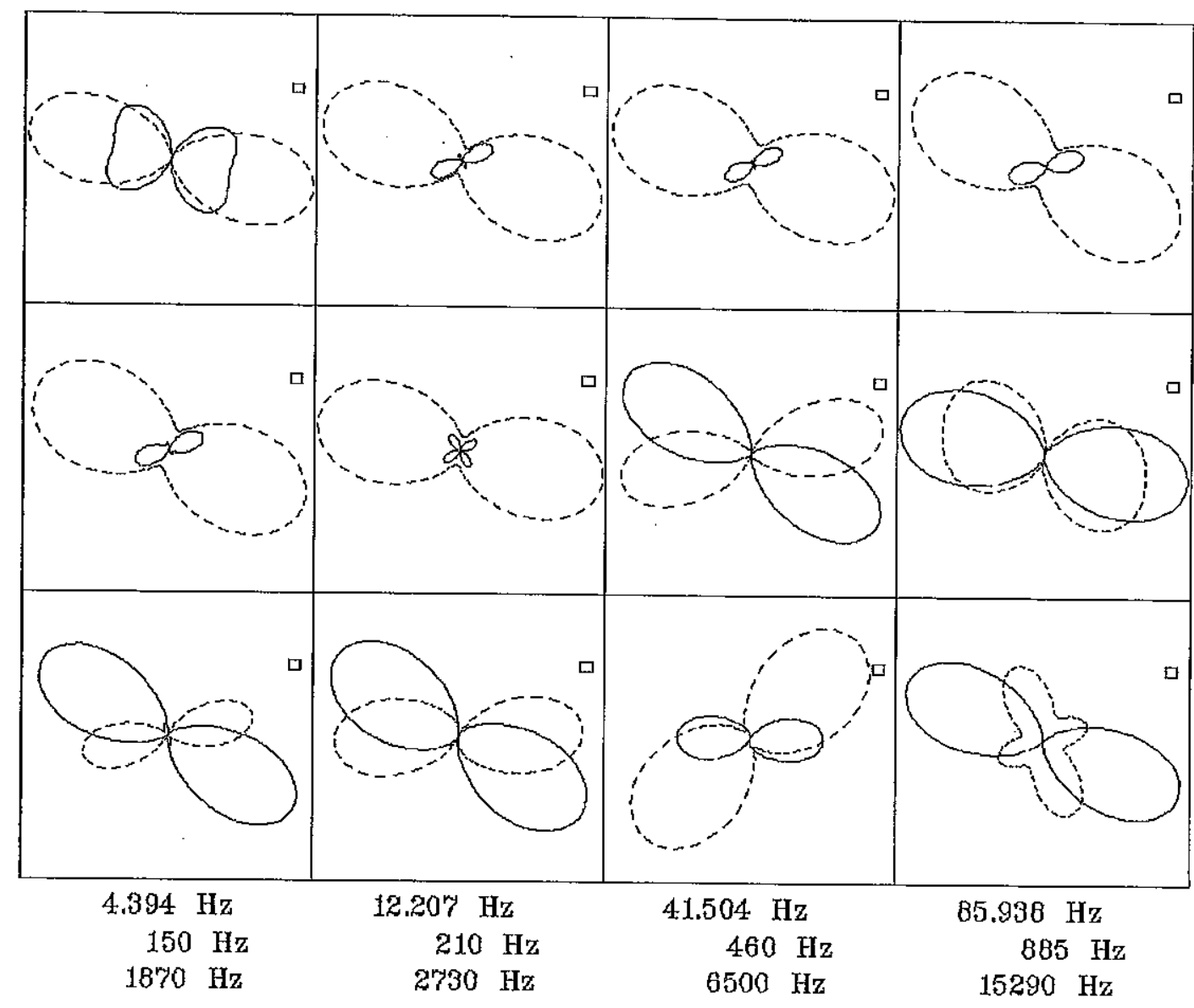

Client: Mineral Resources Program

Rotation:

Remote: none

Acquired: 14:0 May 01, 2008

Filename: sp03a1.avg

Survey Co:USGS

Channels: Ch1 Ch2 Ch3 Ch4 Ch5 Ch3 Ch4

Plotted: 11:31 Mar 16, 2010

< EMI - ElectroMagnetic Instruments > 


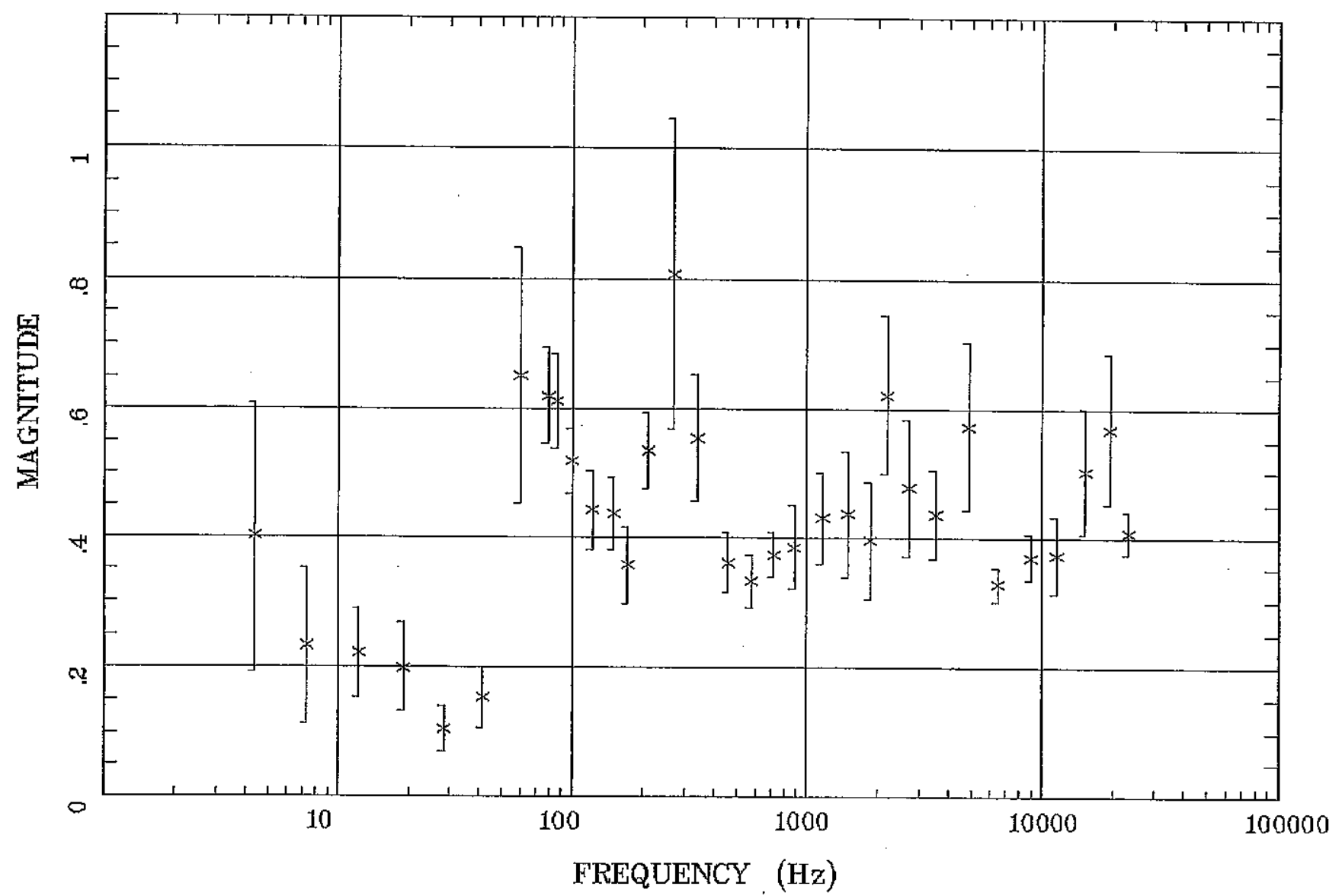

Client: Mineral Resources Program Remote: none

Acquired: 14:0 May 01, 2008 Survey Co:USGS
Rotation:

Filename: spo3a1.avg

Channels: Ch1 Ch2 ch3 Ch4 Ch5 Ch3 Ch4

Plotted: 11:08 Mar 16, 2010

< EMI - ElectroMagnetic Instruments > 


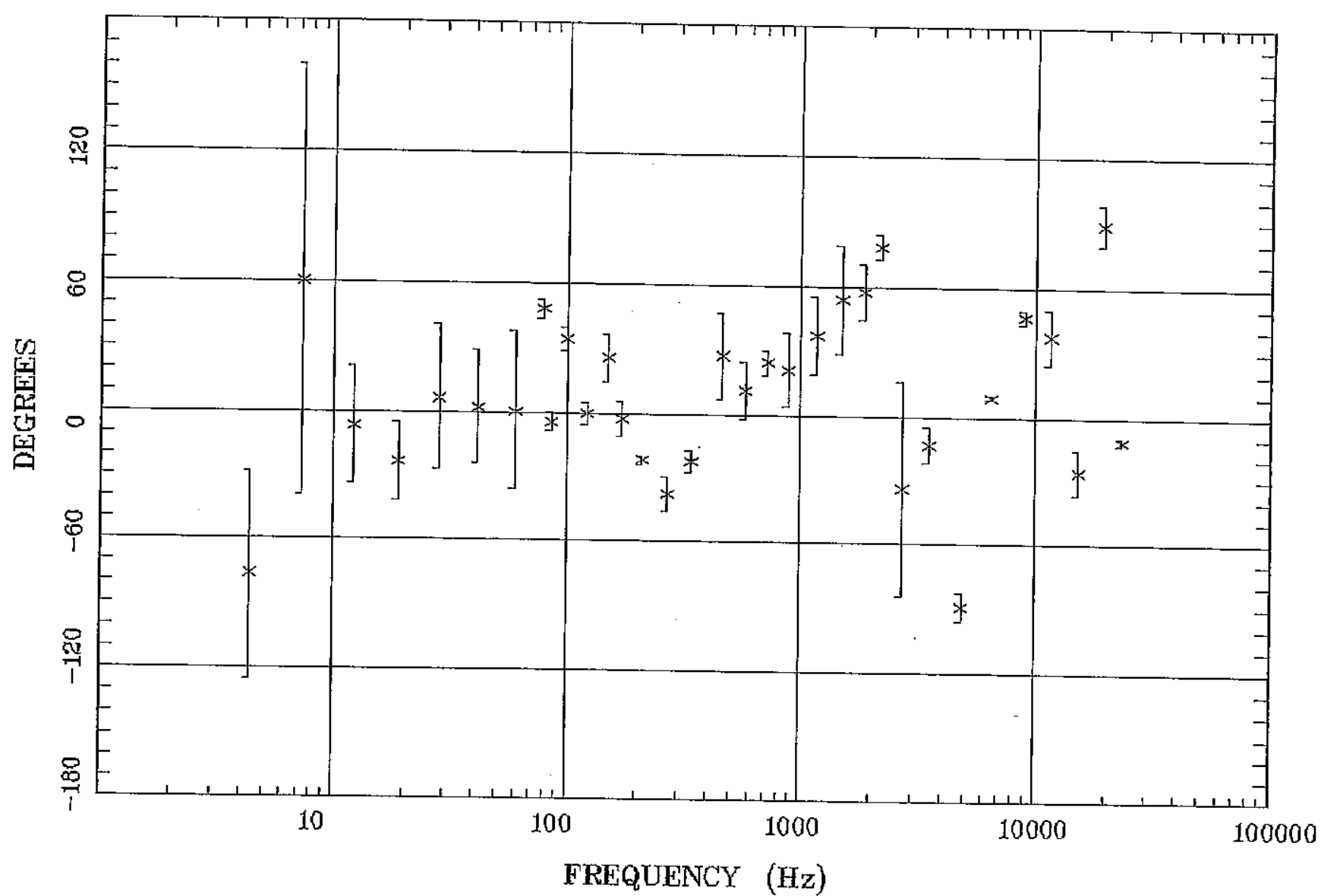

Client: Mineral Resources Program Remote: none

Acquired: 14:0 May 01, 2008 Survey Co:USGS
Rotation:

Filename: sp03a1.avg

Channels: Ch1 Ch2 Ch3 Ch4 Ch5 Ch3 Ch4

Platted: 11:08 Mar 16, 2010

< EMI - ElectroMagnetic Instruments > 


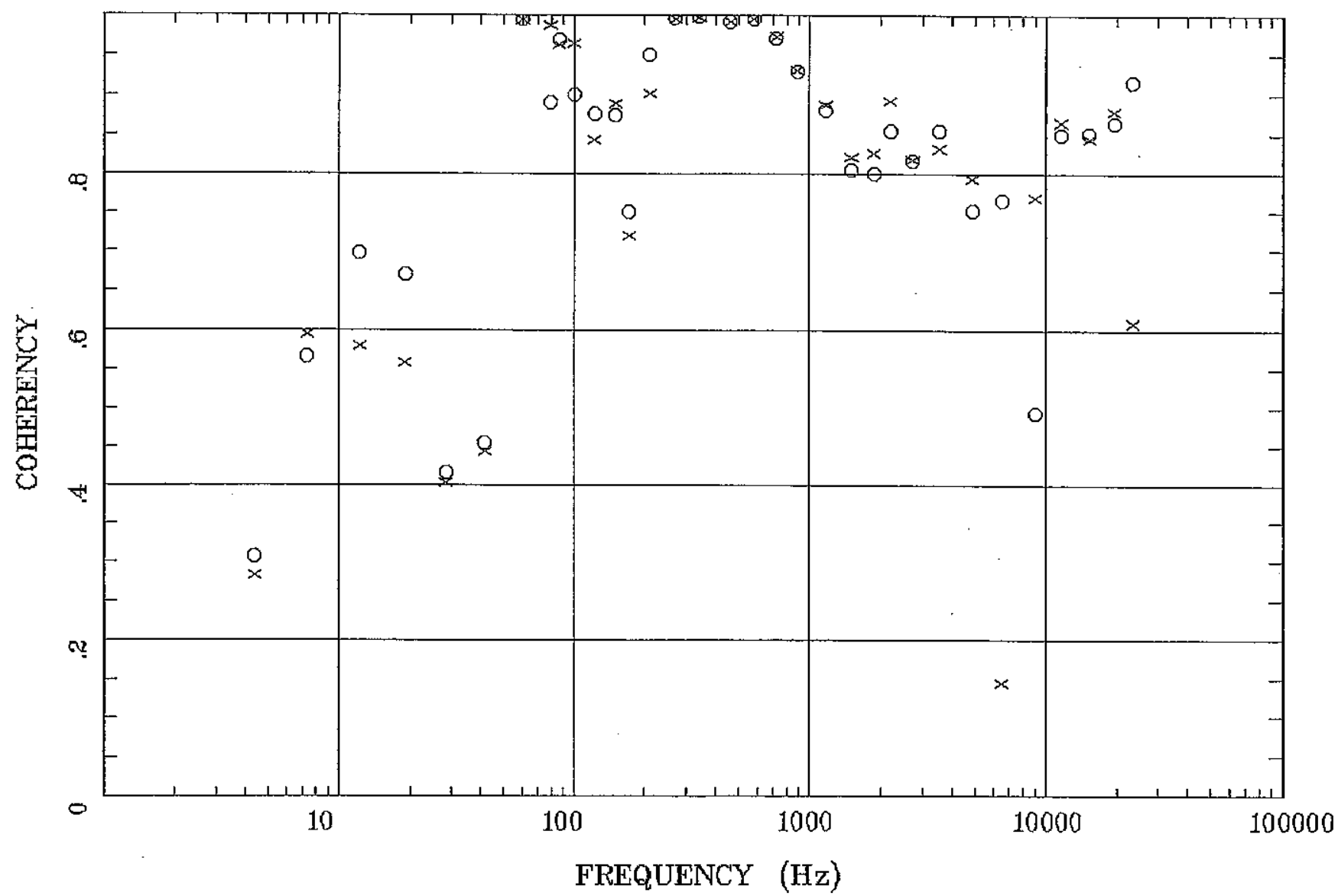

Client: Mineral Resources Program Remote: none

Acquired: 14:0 May 01, 2008 Survey Co:USGS

\section{Rotation:}

Filename: sp03a1.avg

Channels: Ch1 Ch2 Ch3 Ch4 Ch5 Ch3 Ch4 Plotted: 11:08 Mar 16, 2010

< EMI - ElectroMagnetic Instruments > 


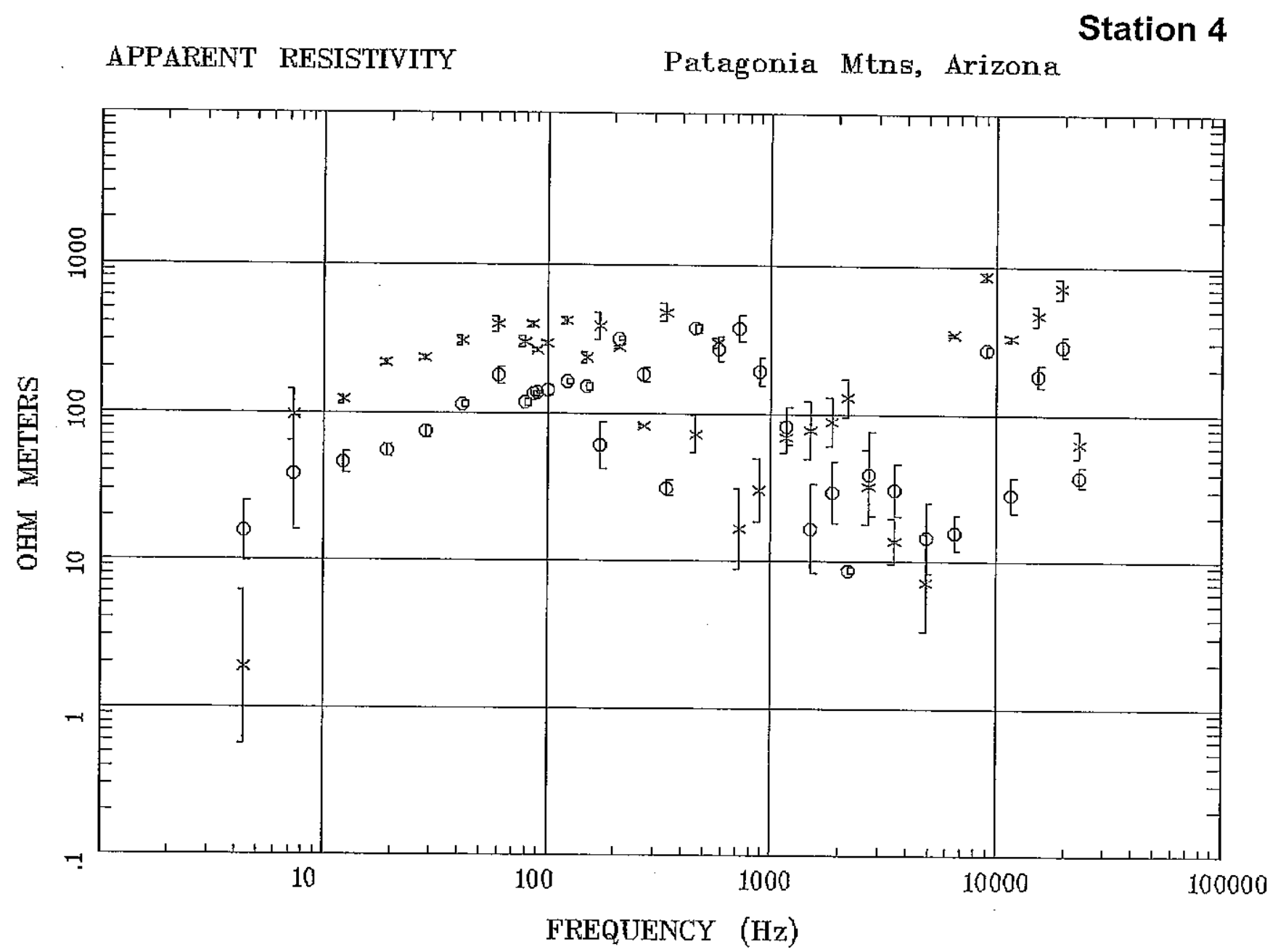

Client: Mineral Resources Program

Rotation:

Remote: none

Filename: sp04aall,avg

Acquired: 15:5 Apr 30, 2008

Survey Co:USGS

Channels: Ch1 Ch2 Ch3 Ch4 Ch5 ch3 ch4

Plotted: 11:08 Mar 16, 2010

< EMI - ElectroMagnetic Instruments > 
Station 4

IMPEDANCE PHASE

Patagonia Mtns, Arizona

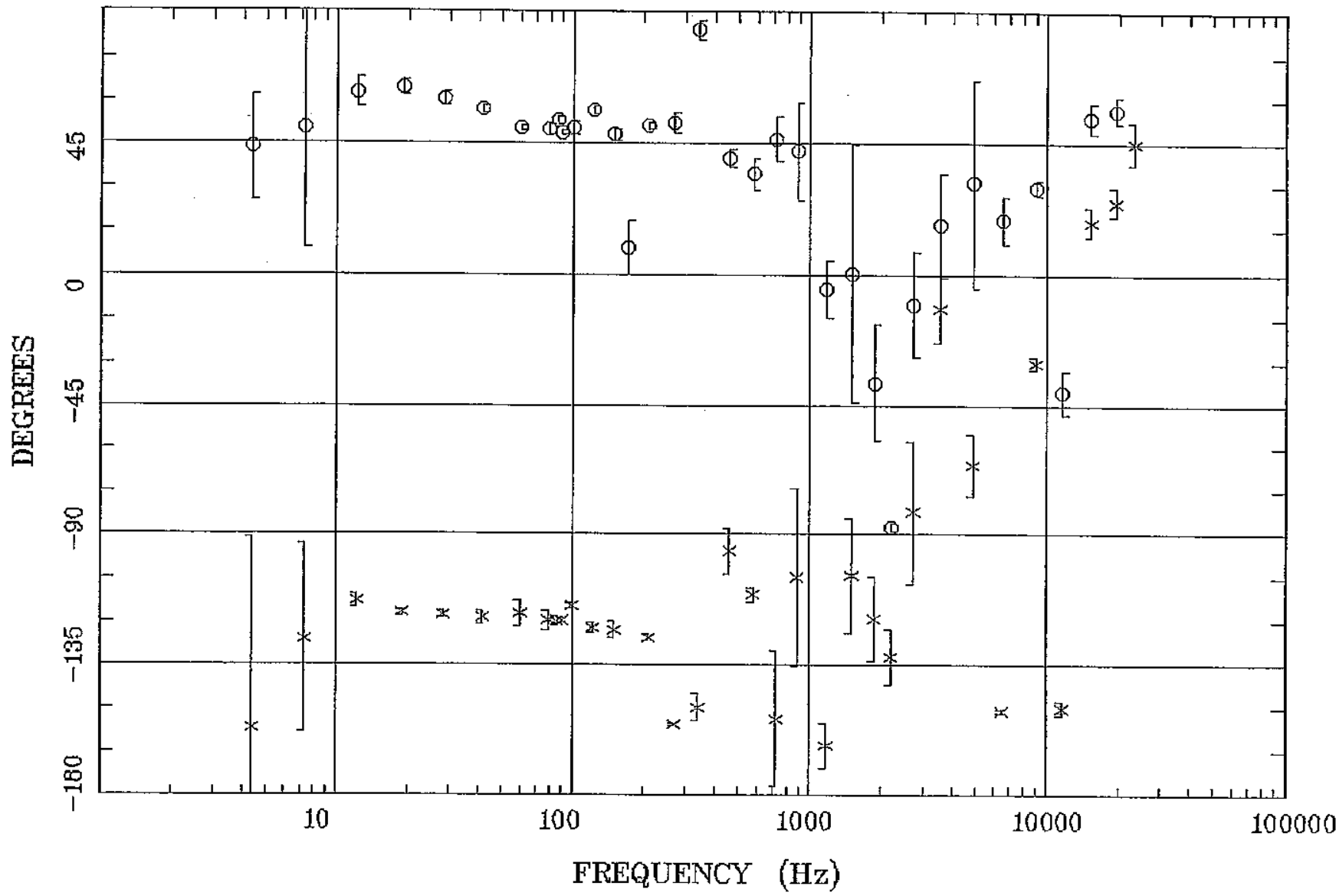

Client: Mineral Resources Program Remote: none

Acquired: 15:5 Apr 30, 2008 Survey Co:USGS
Rotation:

Filename: sp04aall.avg

Channels: Ch1 Ch2 Ch3 Ch4 Ch5 Ch3 Ch4

Plotted: 11:08 Mar 16, 2010

< EMI - EIectroMagnetic Instruments > 
Station 4

Patagonia Mtns, Árizona

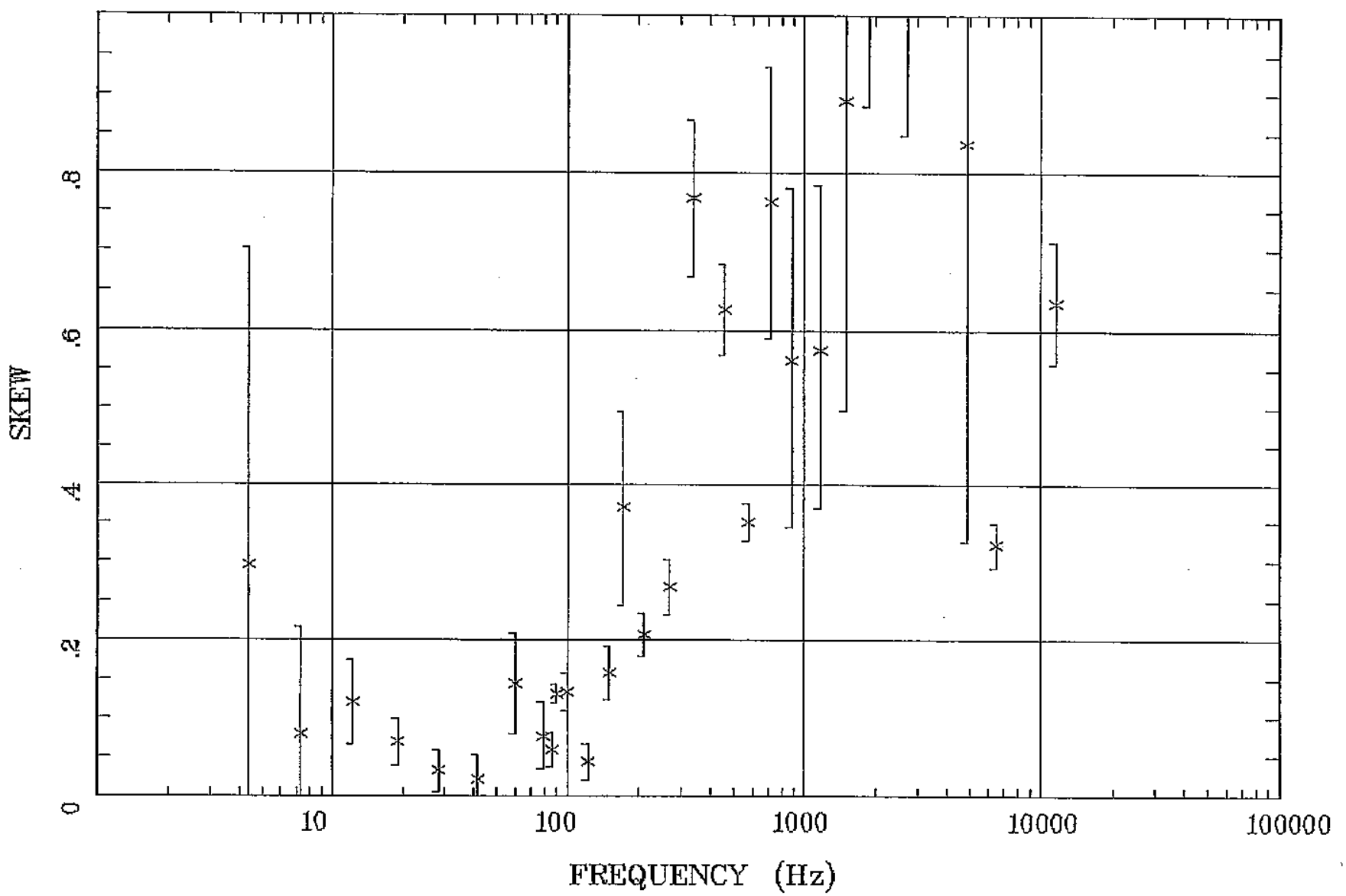

Client: Mineral Resources Program Remate: none

Acquired: 15:5 Apr 30, 2008

Survey Co:USGS
Rotation:

Filename: sp04aell.avg

Channels: Ch1 Ch2 Ch3 Ch4 Ch5 Ch3 Ch4

Plotted: 11:08 Mar 16, 2010

< EMI - ElectroMagnetic Instruments 


\section{Station 4}

E MULT Coh.

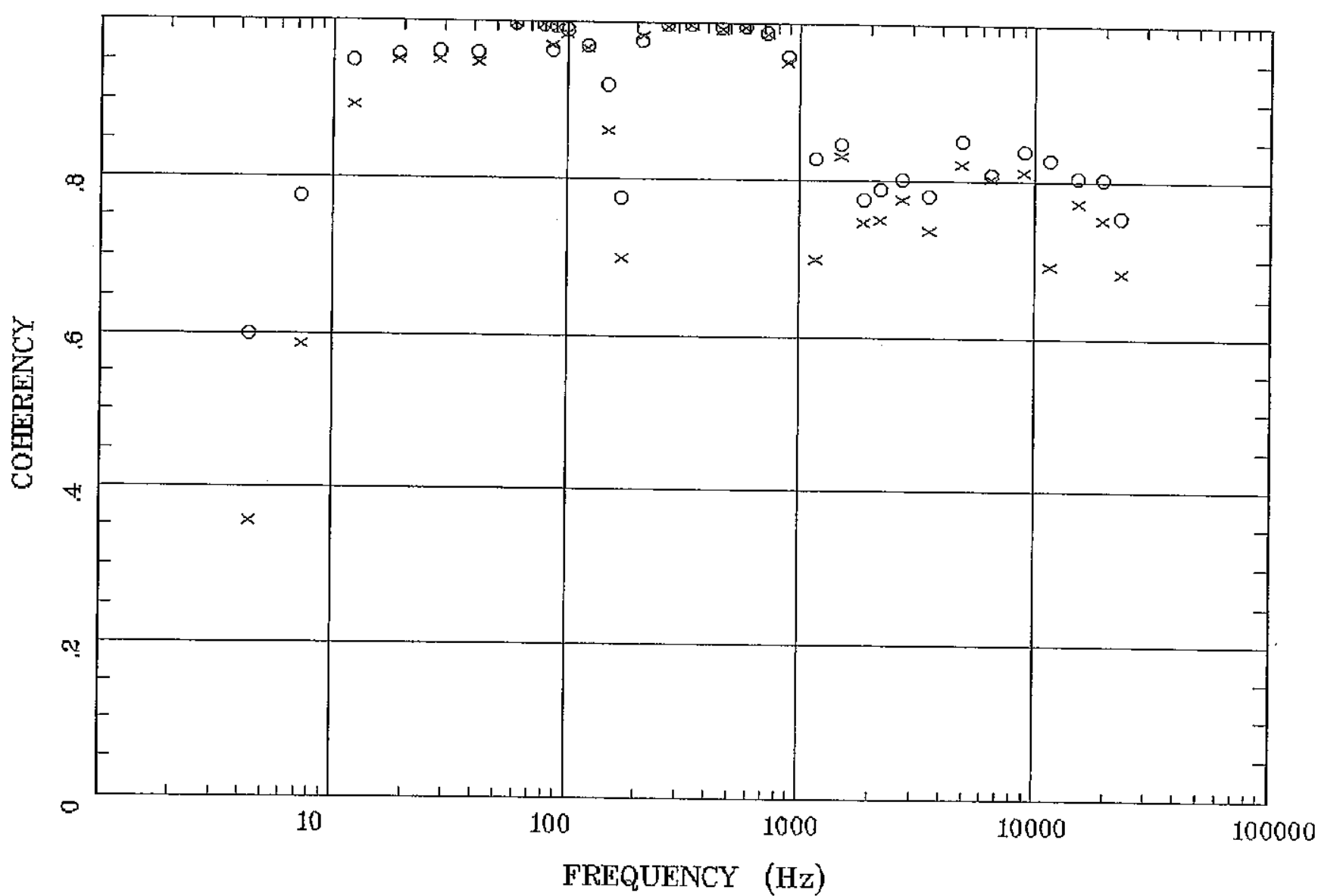

Client: Mineral Resources Program Remote: none

Acquired: 15.5 Apr 30,2008 Survey Co:USGS
Rotation:

Filename: sp04aall.avg

Channels: Ch1 ch2 Ch3 ch4 Ch5 ch3 ch4

Plotted: 11:08 Mar 16, 2010

< EMI - ElectroMagnetic Instruments > 
Station 4

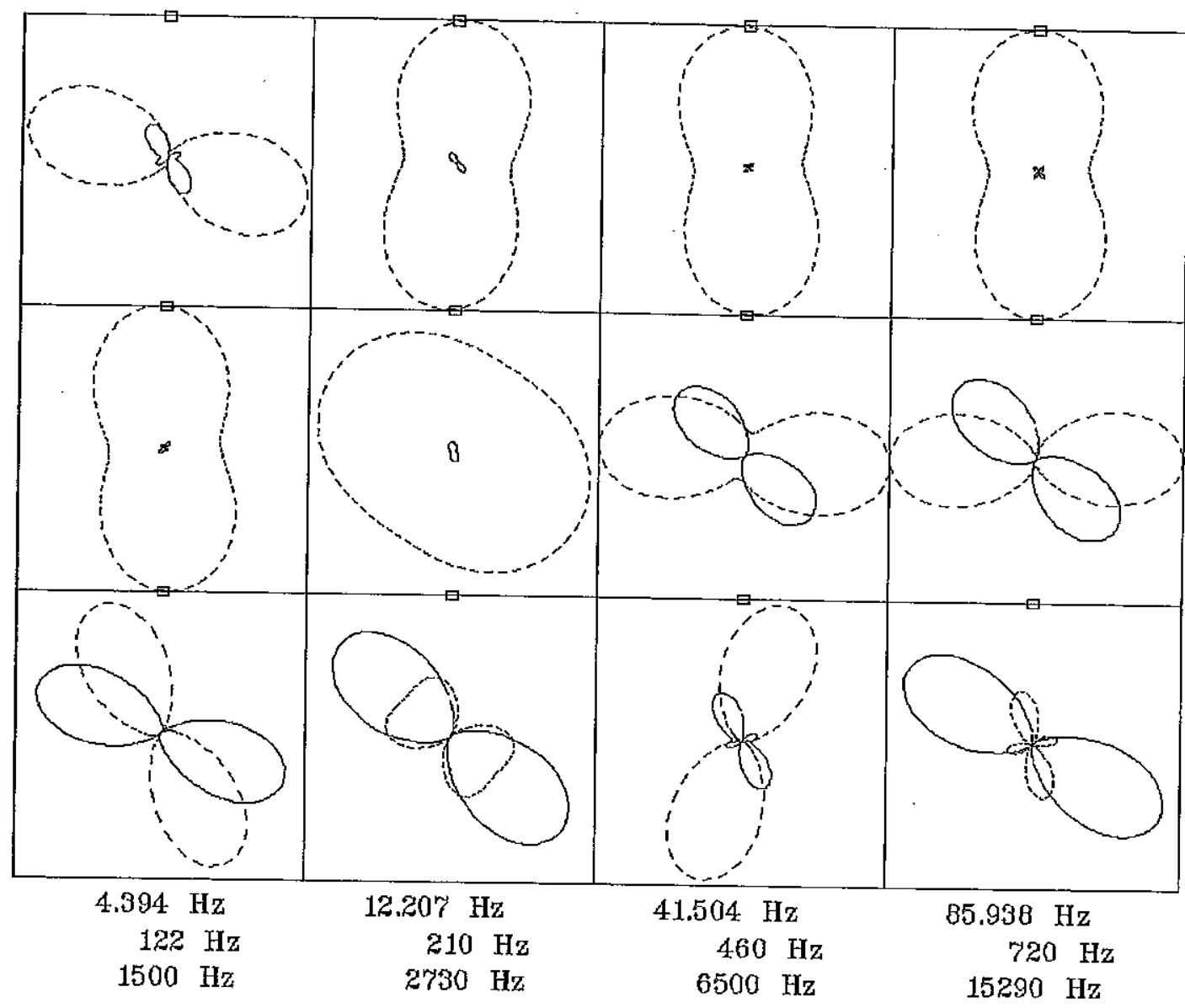

Client: Mineral Resources Program Remote: none Acquired: 15:5 Apr 30, 2008 Survey Co:USGS

Filename: sp04aall.avg

Channels: Ch1 Ch2 Ch3 Ch4 Ch5 Ch3 Ch4 Platted: 11:31 Mar 16, 2010

< EMI - ElectroMagnetic Instruments > 


\section{Station 4}

TIPPER MAGNITUDE

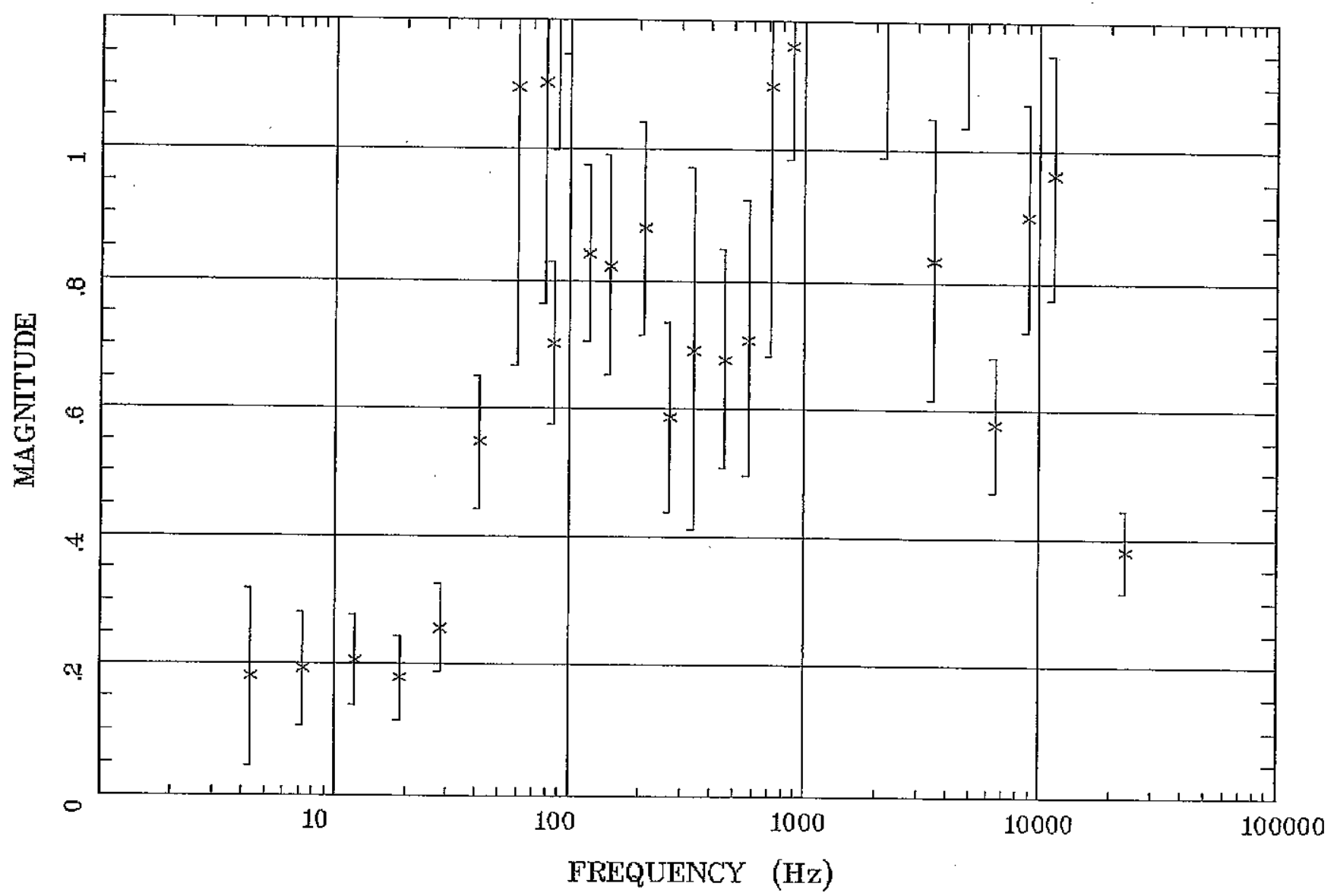

Client: Mineral Resources Program Remote: none

Acquired: $15: 5$ Apr 30, 2008 Survey Co:USGS
Rotation:

Filename: sp04aall.avy

Channels: Ch1 Ch2 Ch3 ch4 ch5 Ch3 Ch4 Plotted: 11:08 Mar 16, 2010

- EMI - ElectroMagnetic Instruments 
Station 4

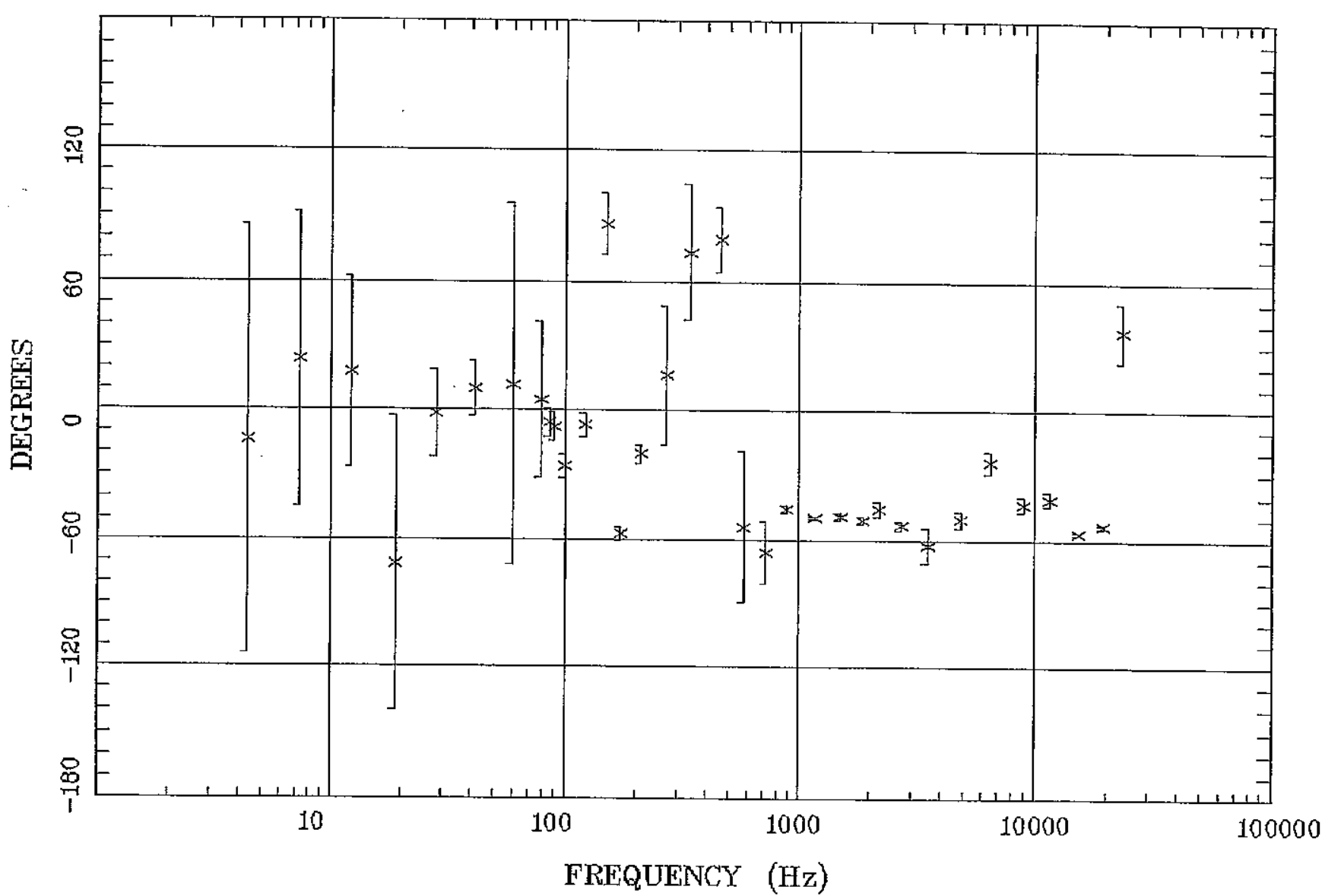

Client: Mineral Resources Program Remote: none

Acquired: 15:5 Apr 30, 2008 Survey Ca:USGS
Rotation:

Filename: sp04aall.avg

Channels: Ch1 Ch2 Ch3 Ch4 Ch5 Ch3 Ch4 Plotted: 11:08 Mar 16, 2010

< EMI - ElectroMagnetic Instruments > 
Station 4

HzHx.x Coh HzHy.o

Patagonia Mtns, Arizona

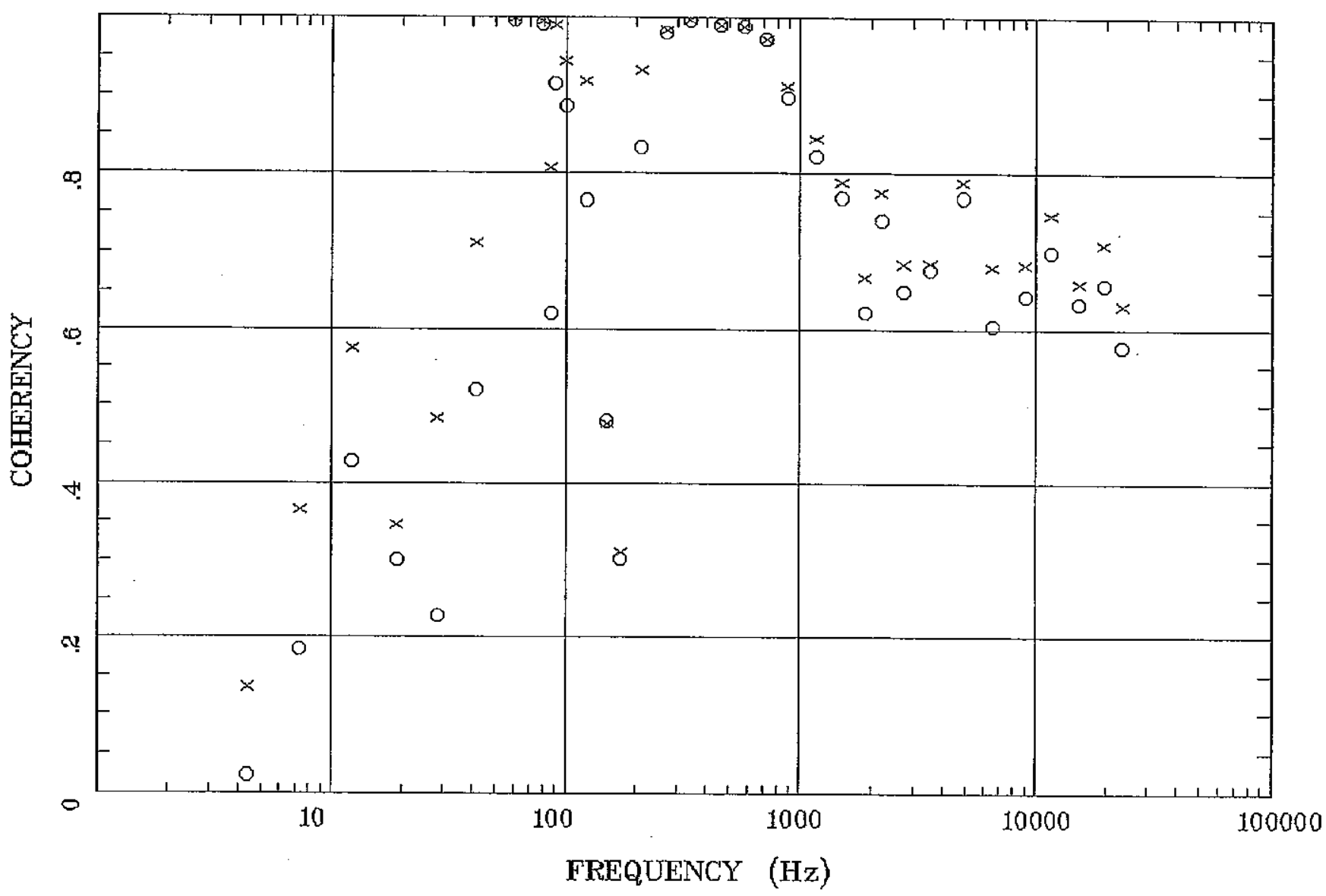

Client: Mineral Resources Program

\section{Rotation:}

Remote: none

Filename: sp04aall.avg

Acquired: $15: 5 \mathrm{Apr} \quad 30,2008$

Channels: Ch1 Ch2 Ch3 Ch4 Ch5 Ch3 Ch4

Plotted: 11:08 Mar 16, 2010

Survey Co:USGS

< EMI - ElectroMagnetic Instruments > 
Station 5

APPARENT RESISTIVITY

Patagonia Mtns, Arizona

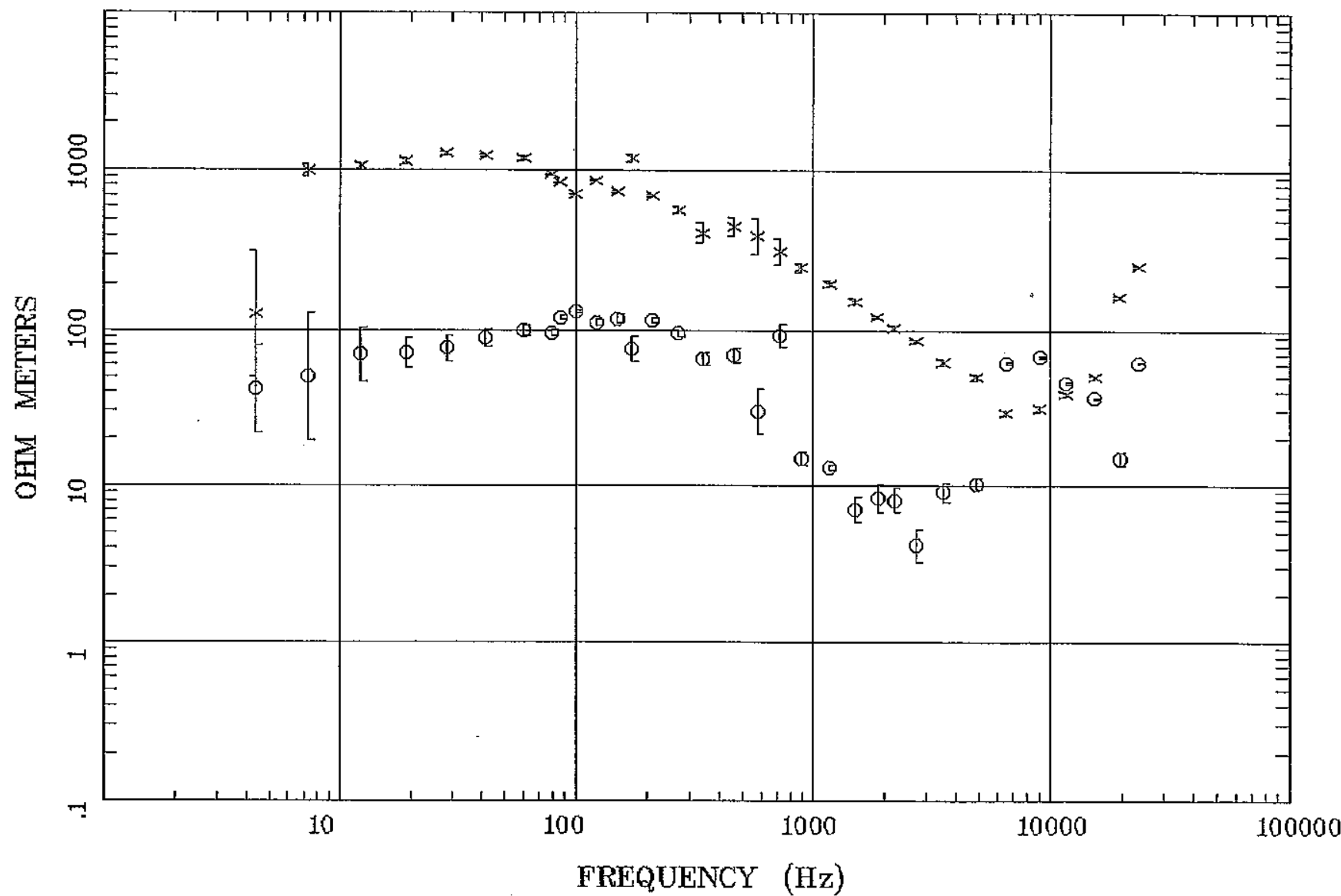

Client: Mineral Resources Program

Rotation:

Remote: none

Filename: sp05b.avg

Channels: Ch1 Ch2 Ch3 Ch4 Ch5 Ch3 Ch4

Acquired: 11:4 oct 30, 2009

Survey Co:USGS

Plotted: 11:08 Mar 16, 2010

< EMI - ElectroMagnetic Instruments > 


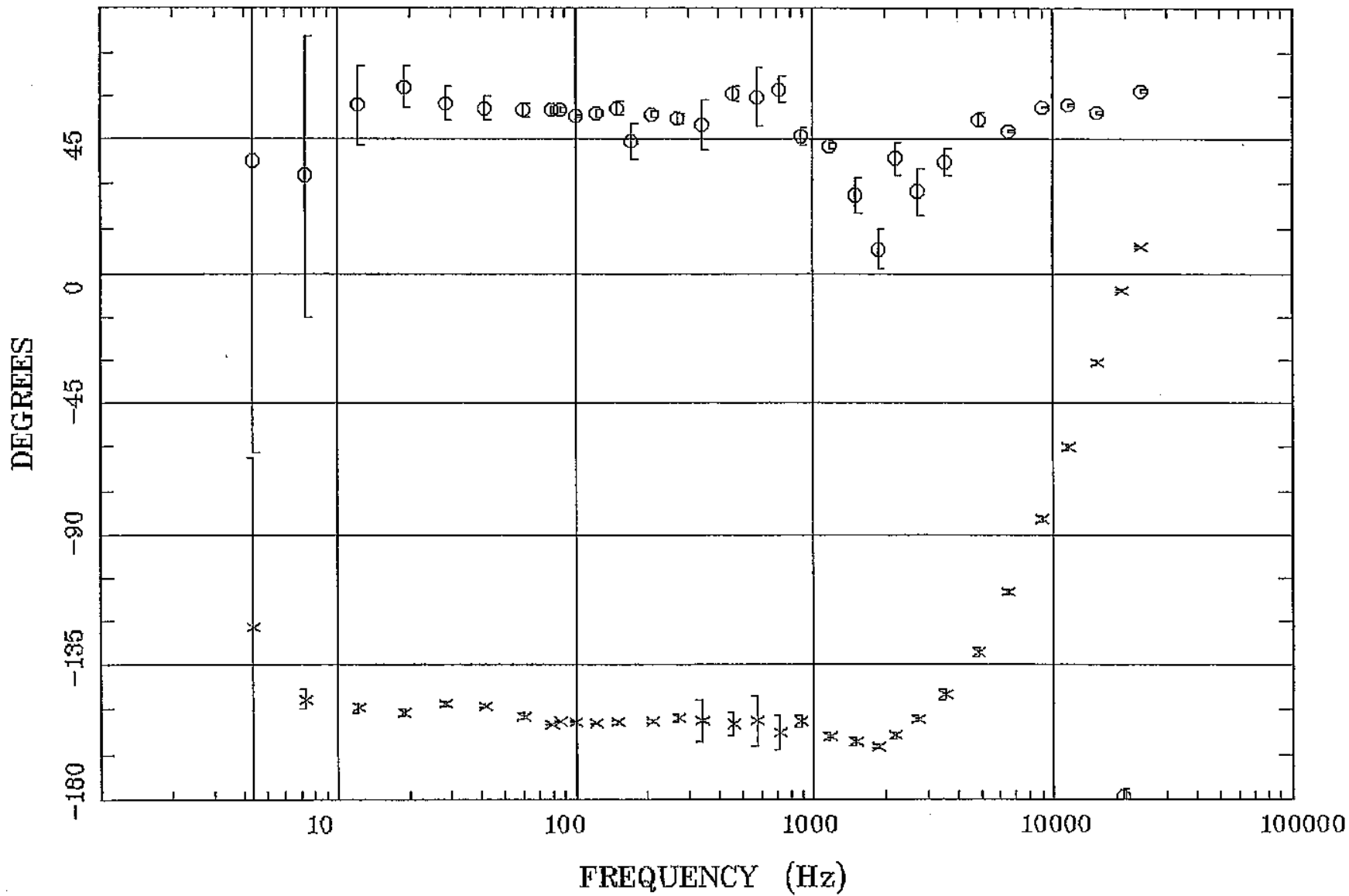

Client: Mineral Resources Program Remote: none

Acquired: $11: 4$ oct 30 , zo09 Survey Co:USGS
Rotation:

Filename: sp05b.avg

Channels: Ch1 Ch2 Ch3 Ch4 Ch5 Ch3 Ch4

Plotted: 11:08 Mar 16, 2010

< EMI - ElectroMagnetic Instruments > 
Station 5

IMPEDANCE SKEW

Patagonia Mtns, Arizona

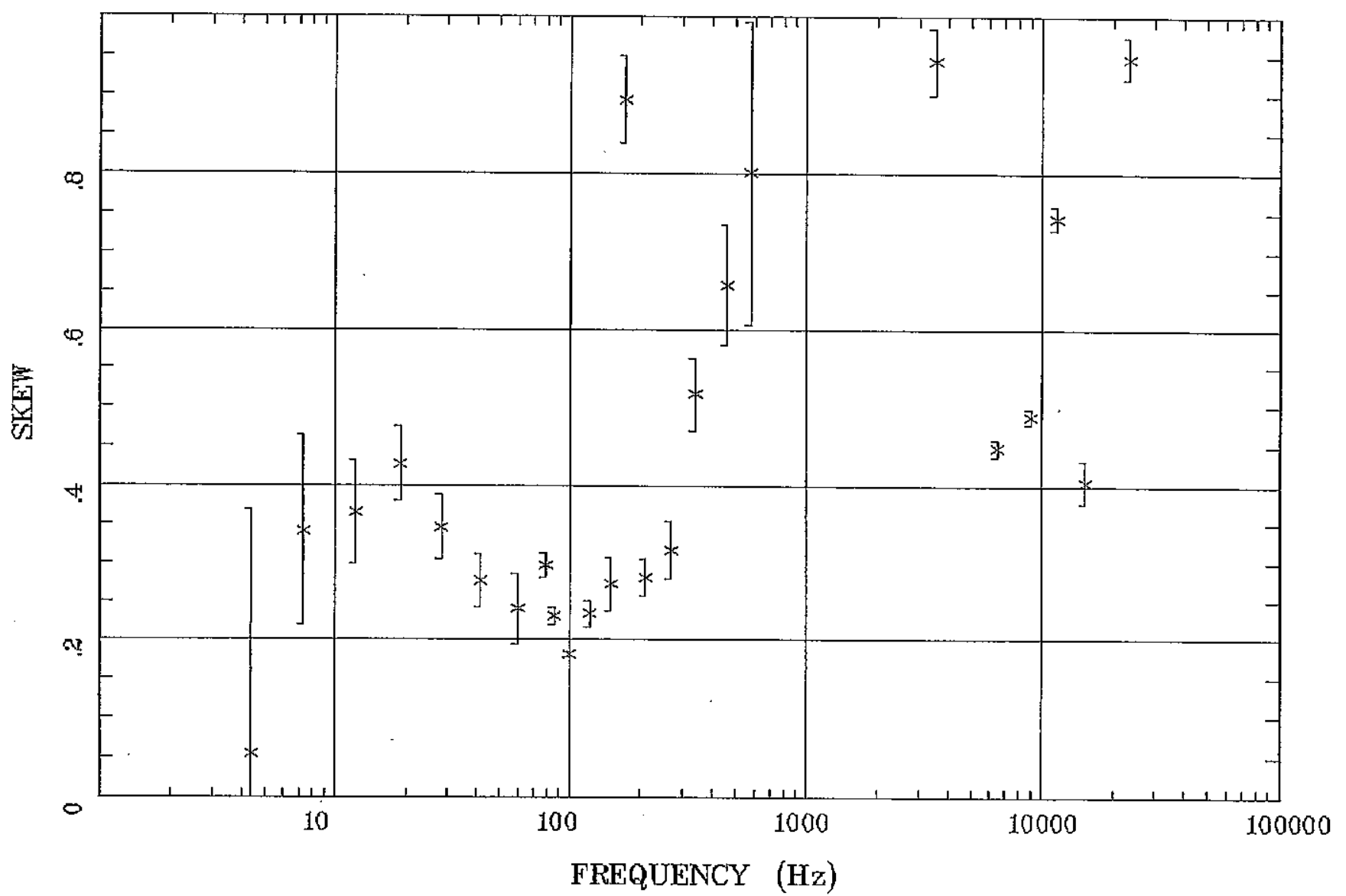

Client: Mineral Resources Program

Rotation:

Remote: none

Filename: sp05b.avg

Channels: Ch1 Ch2 Ch3 Ch4 Ch5 Ch3 Ch4

Acquired: 11:4 oct 30, 2009

Survey Co:USGS

Plotted: 11:08 Mar 16, 2010

< EMI - ElectroMagnetic Instruments 


\section{Station 5}

\section{E MULT Coh.}

Patagonia Mtns, Arizona

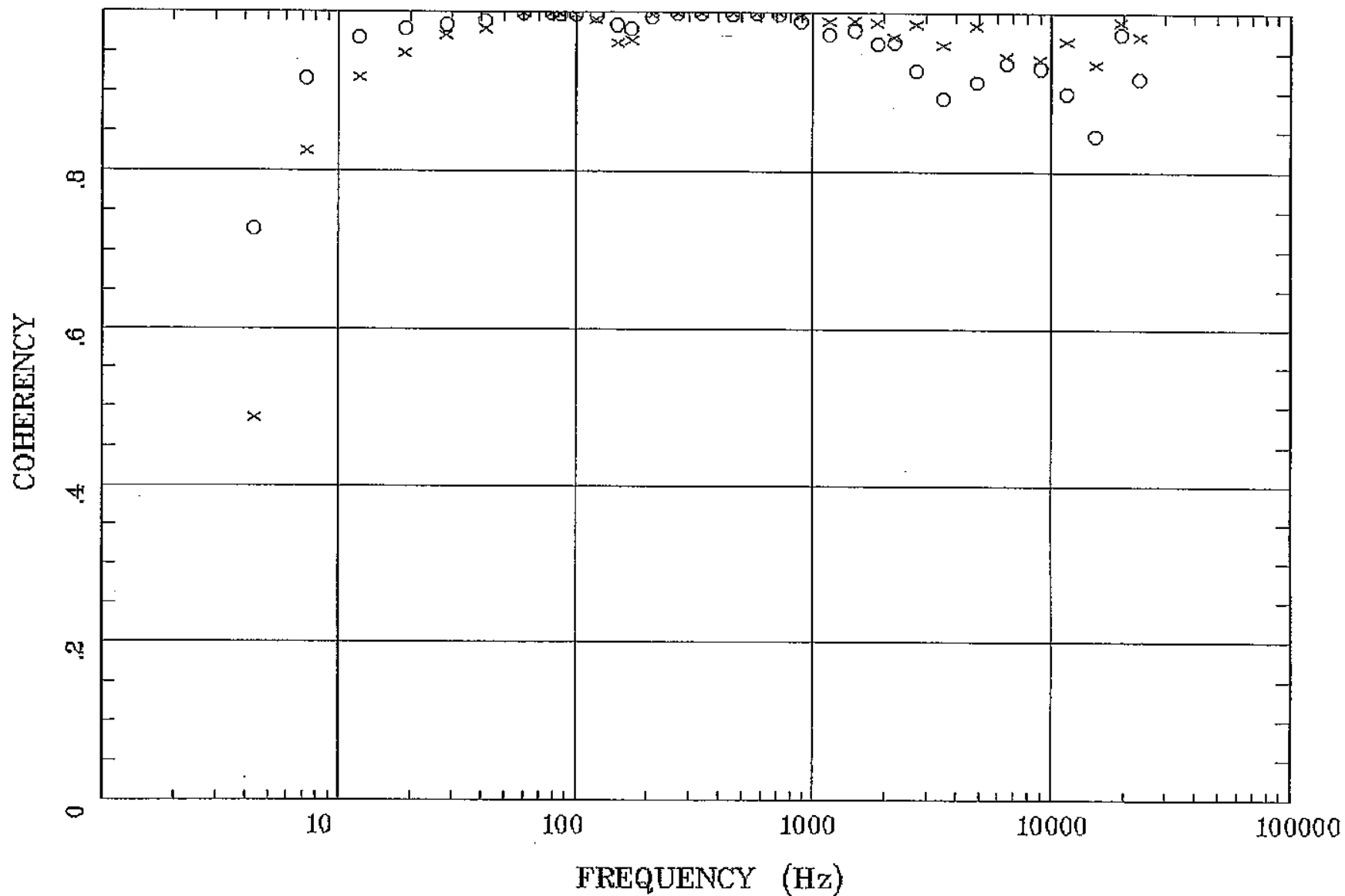

Client: Mineral Resources Program Remote: none

Acquired: 11:4 oct 30, 2009

Survey Co:USGS
Rotation:

Filename: sp05b.avg

Channels: Ch1 Ch2 Ch3 Ch4 Ch5 Ch3 Ch4

Plotted: 11:08 Mar 16, 2010

$<$ EMI - ElectroMagnetic Instrumentis 
Station 5

POLAR PLOTS

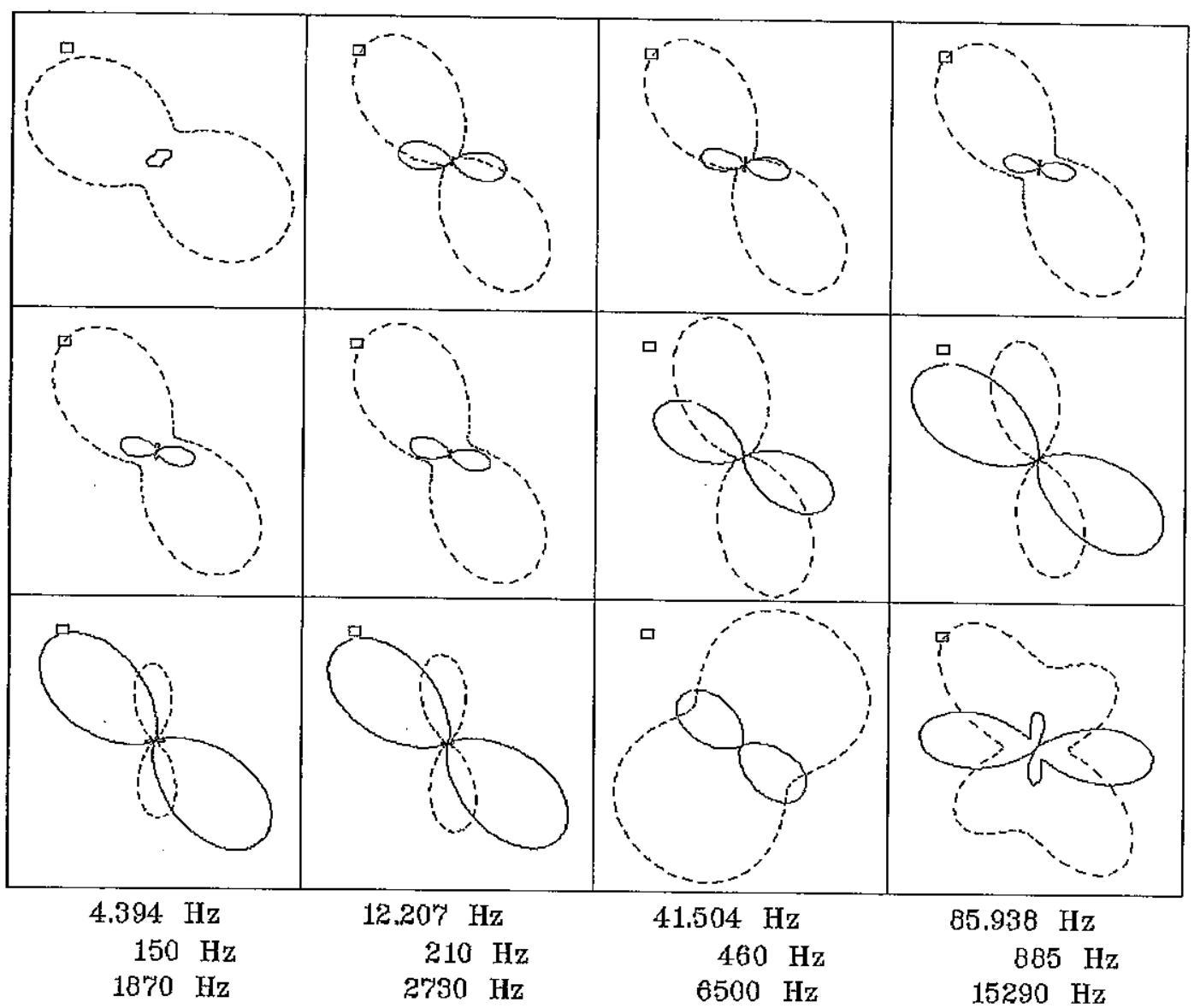

Client: Mineral Resources Program Remote: none

Acquired; 11:4 oct 30, 2009

Survey Co:USGS
Patagonia Mtns, Arizona

\section{Rotation:}

Filename: sp05b.avg

Channels: Ch1 Ch2 Ch3 Ch4 Ch5 Ch3 Ch4

Plotted: $11: 31$ Mar 16, 2010

< EMI - ElectroMagnetic Instruments > 


\section{Station 5}

TIPPER MAGNITUDE

Patagonia Mtns, Arizona

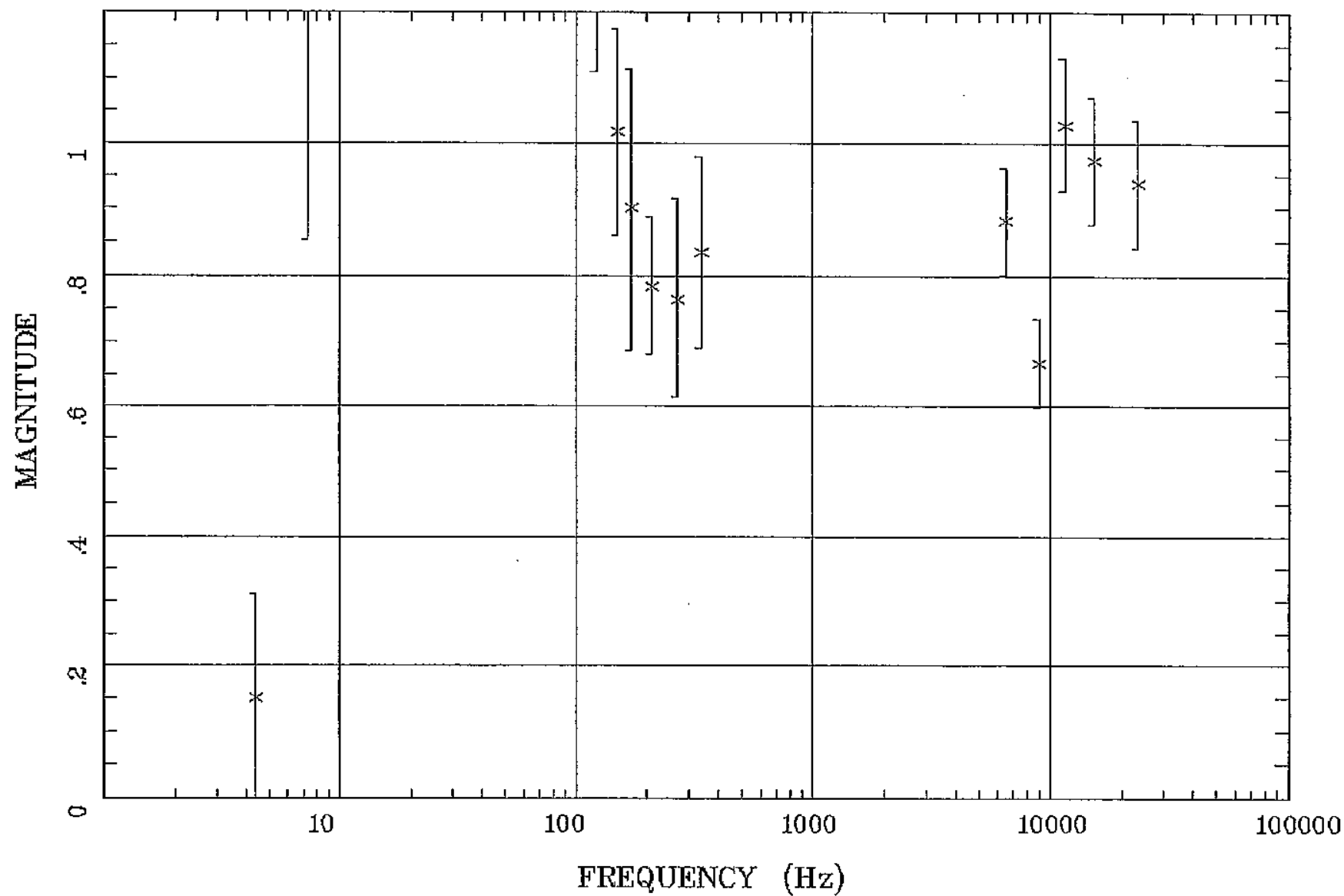

Client: Mineral Resources Program Remote: none

Acquired: $11: 4$ oct 30,2009

Survey Co:USGS
Rotation:

Filename: sp05b.avg

Channels: Ch1 Ch2 Ch3 Ch4 Ch5 Ch3 Ch4

Plotted: 11:08 Mar 16, 2010

< EMI - ElectroMagnetic Instruments > 


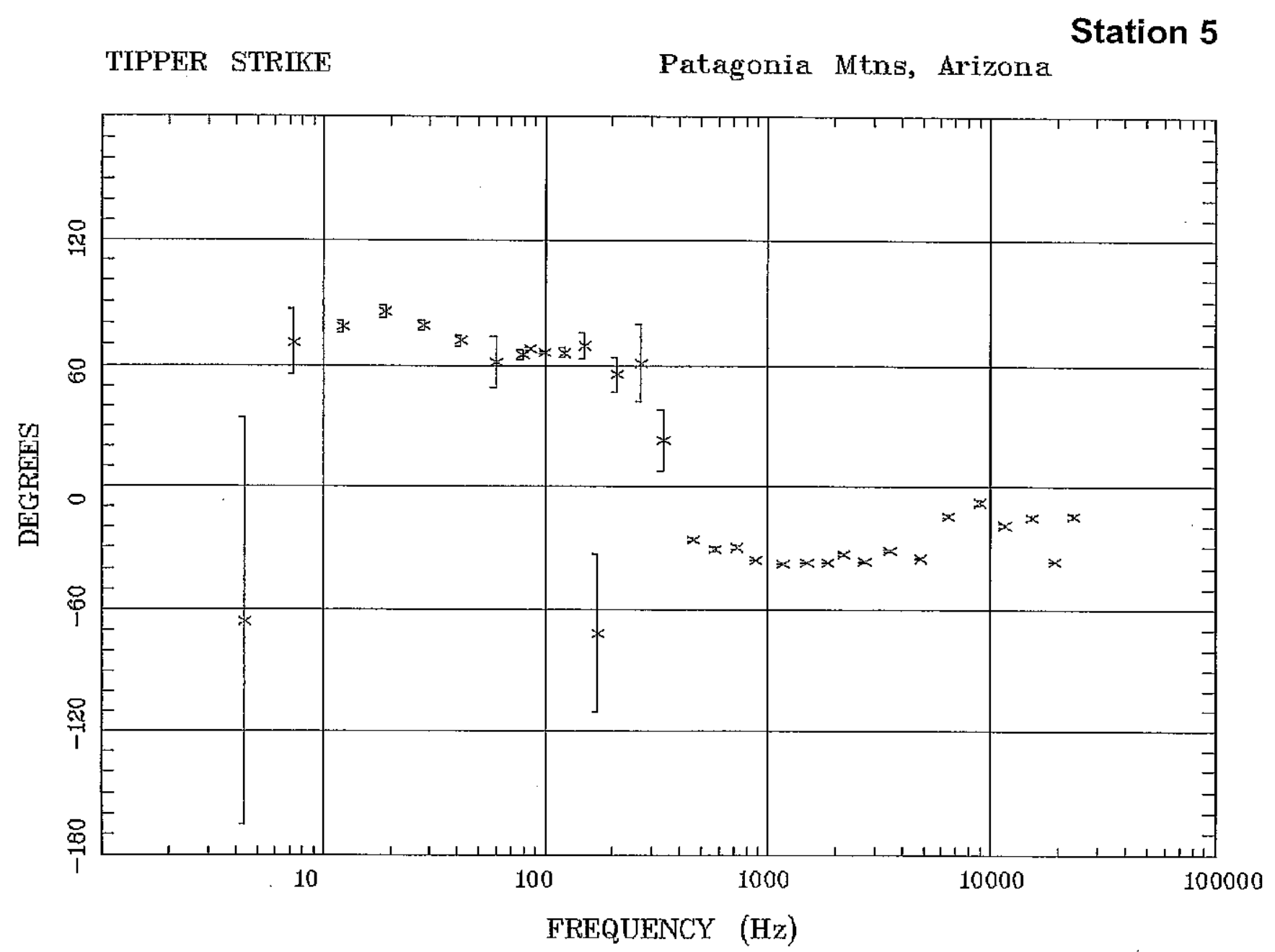

Client: Mineral Resources Program

Rotation:

Remote: none

Filename: sp05b.avg

Channels: Ch1 Ch2 Ch3 Ch4 Ch5 Ch3 Ch4

Acquired: 11:4 oct 30, 2009

Survey Co:USGS

Plotted: 11:08 Mar 16, 2010

< EMI - ElectroMagnetic Instruments > 
HzHx.x Coh HzHy.o

Station 5

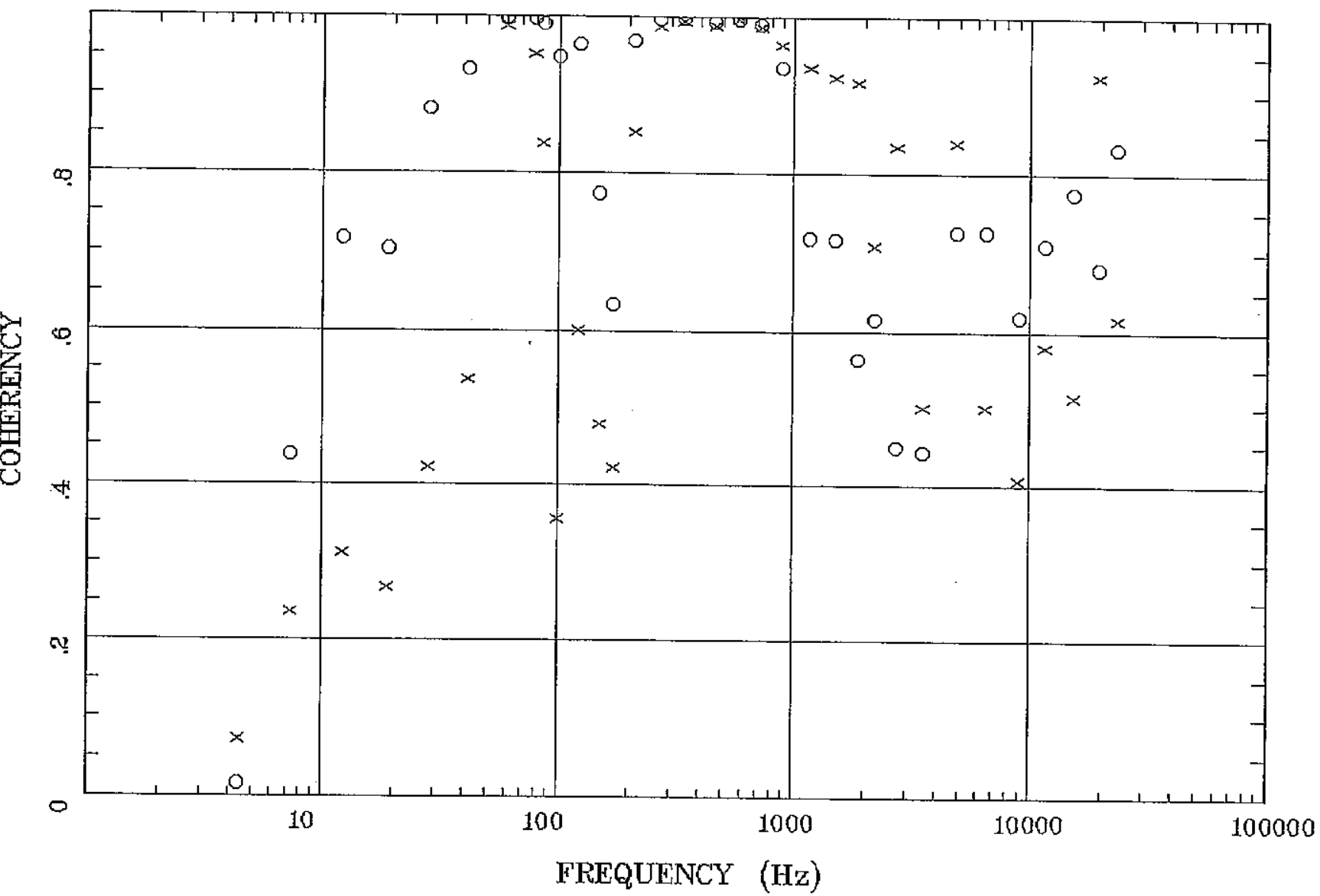

Client: Mineral Resources Program Remote: none

Acquired: 11:4 Oct 30, 2009 Survey Co:USGS

Rotation:

Filename: sp05b,ayg

Channels: Ch1 Ch2 ch3 Ch4 Ch5 ch3 Ch4

Plotted: 11:08 Mar 16, 2010

< EMI - ElectroMagnetic Instruments > 
Station 6

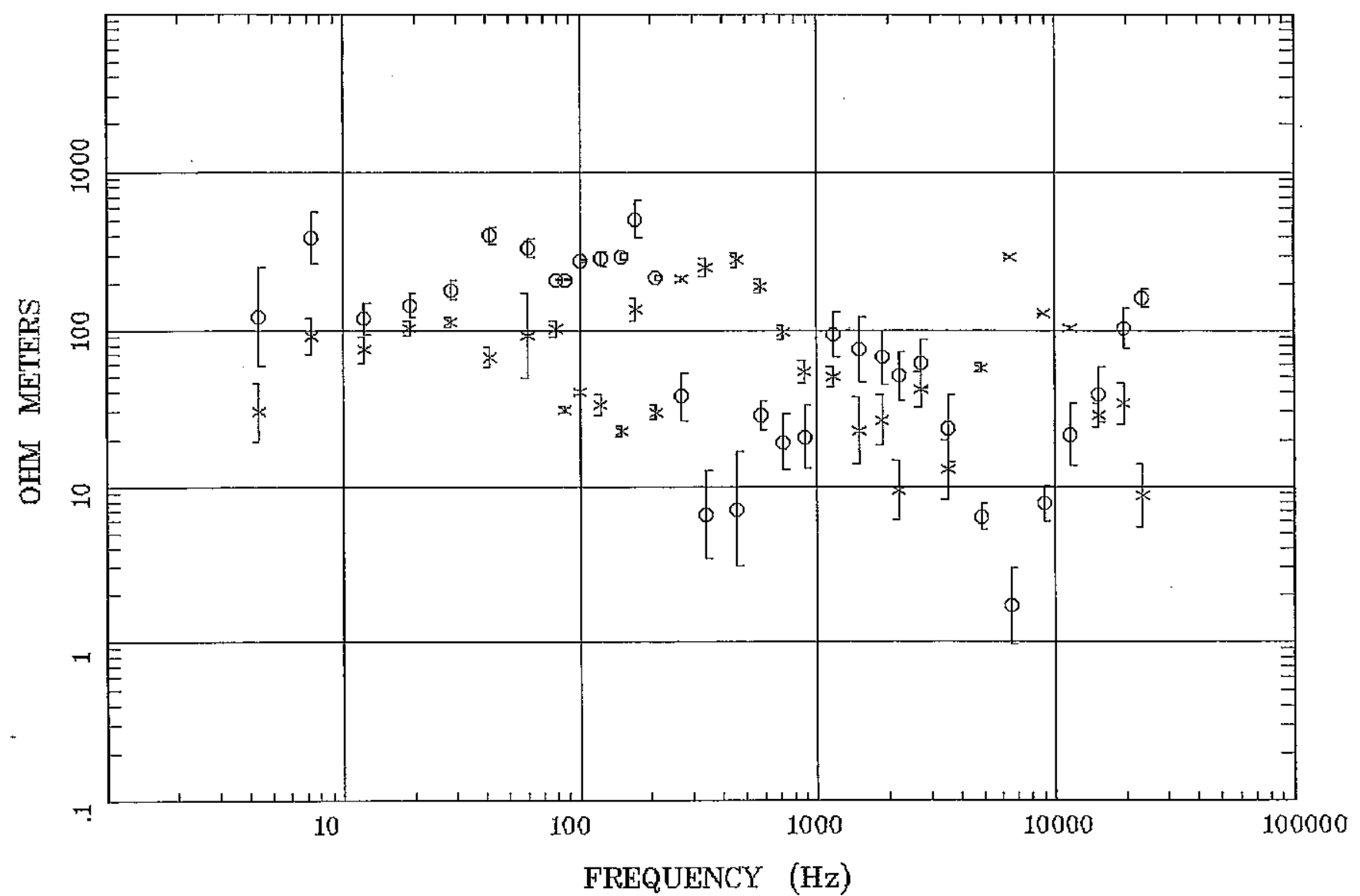

Client: Mineral Resources Program Remote: none

Acquired: 17:4 May 02, 2008 Survey Co:USGS
Rotation:

Filename: sp06aall.avg

Channels: Ch1 ch2 Ch3 ch4 ch5 ch3 ch4

Plotted: 11:09 Mar 16, 2010

< EMI - ElectroMagnetic Instruments > 
Station 6

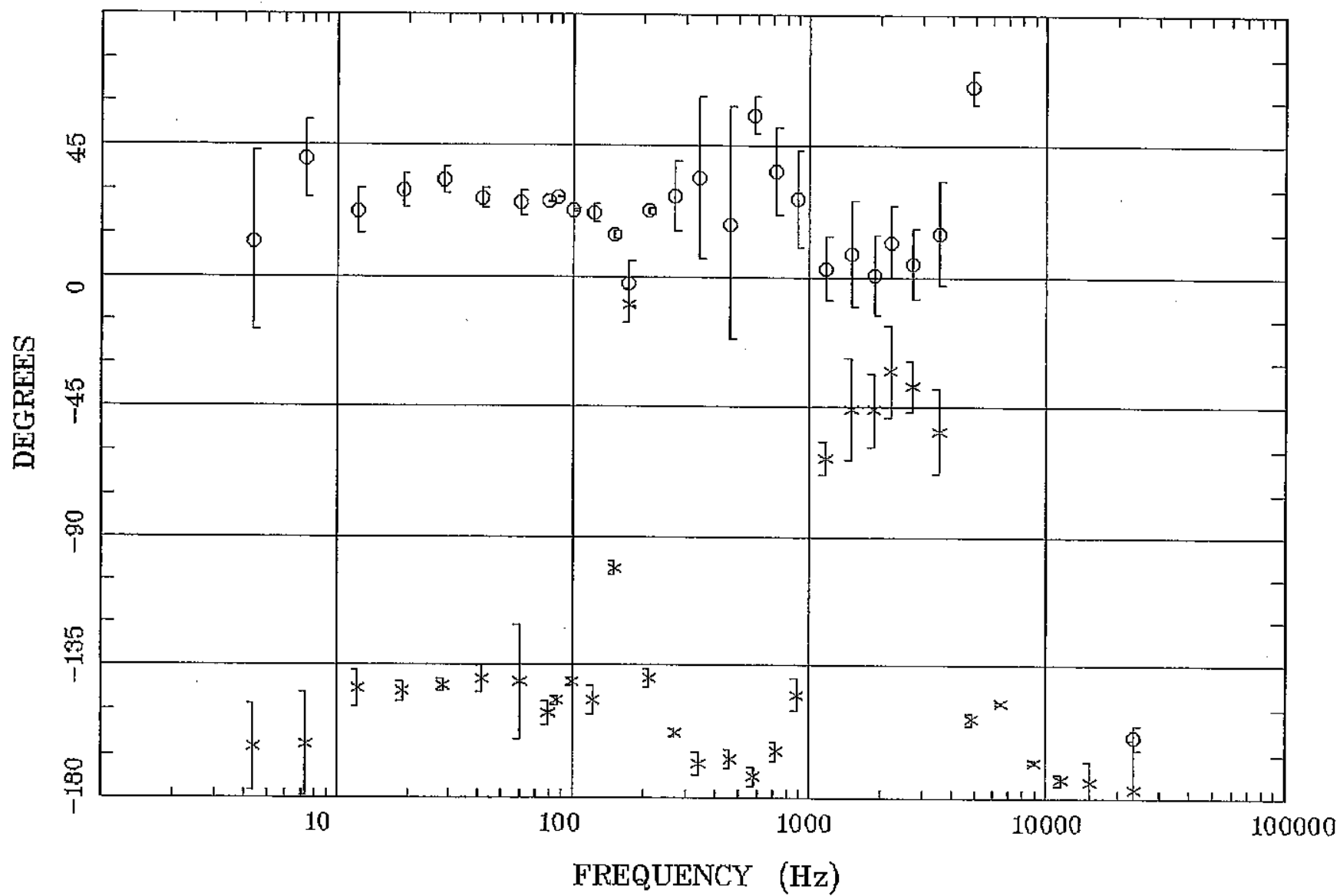

Client: Mineral Resources Program Remote: none

Acquired: 17:4 May 02, 2008 Survey Co:USGS
Rotation:

Filename: sp06aall.avg

Channels: Ch1 Ch2 Ch3 Ch4 Ch5 Ch3 Ch4

Plotted: 11:09 Mar 16, 2010

$<$ EMI - ElectroMagnetic Instruments > 


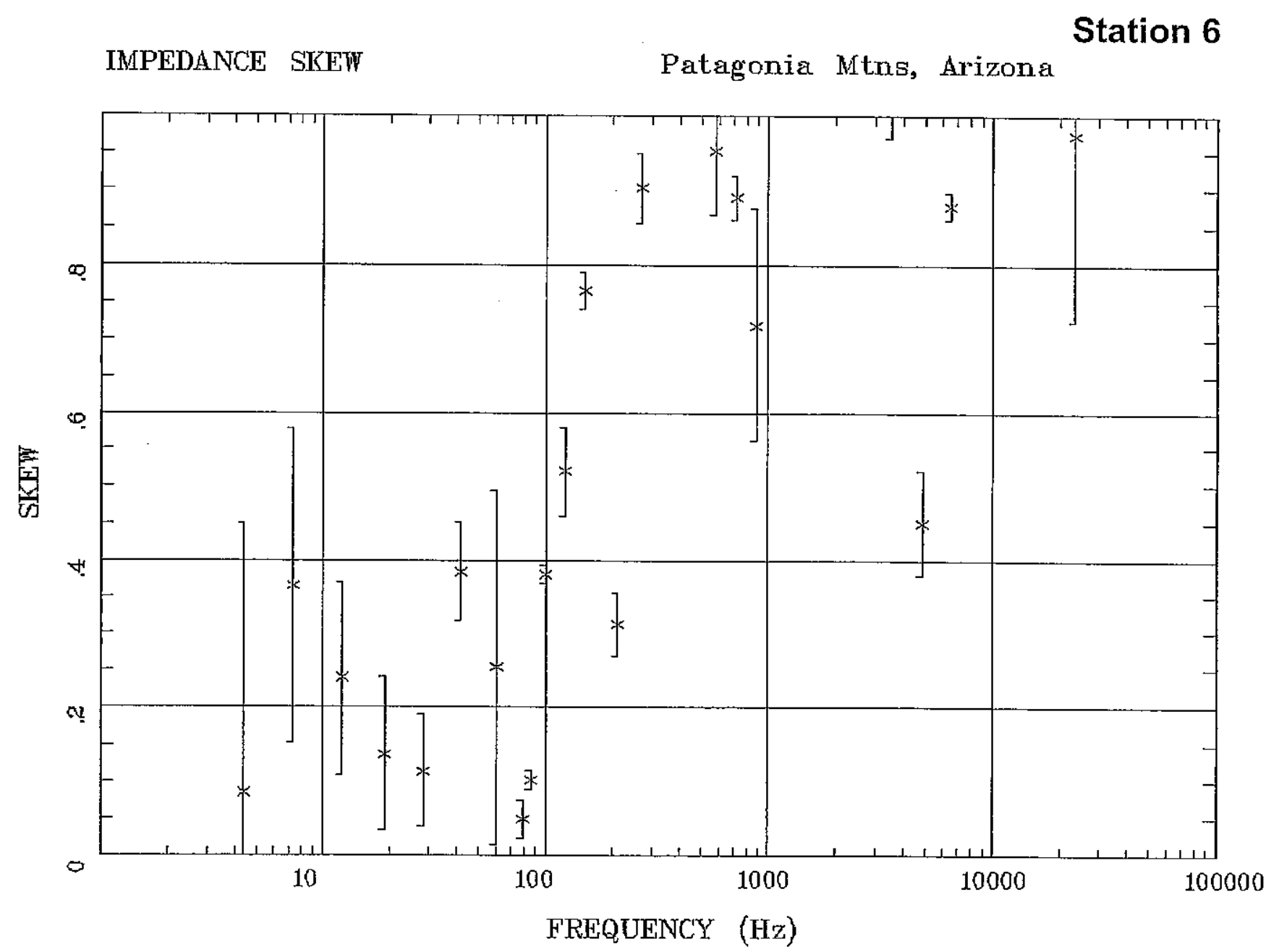

Client: Mineral Resources Program

\section{Rotation:}

Remote: none

Acquired: 17 :4 May 02, 2008

Survey Co:USGS

Filename: sp06aall.avg

Channels: Ch1 Ch2 Ch3 Ch4 Ch5 Ch3 Ch4

Plotted: 11:09 Mar 16, 2010

$<$ EMI - ElectroMagnetic Instruments 


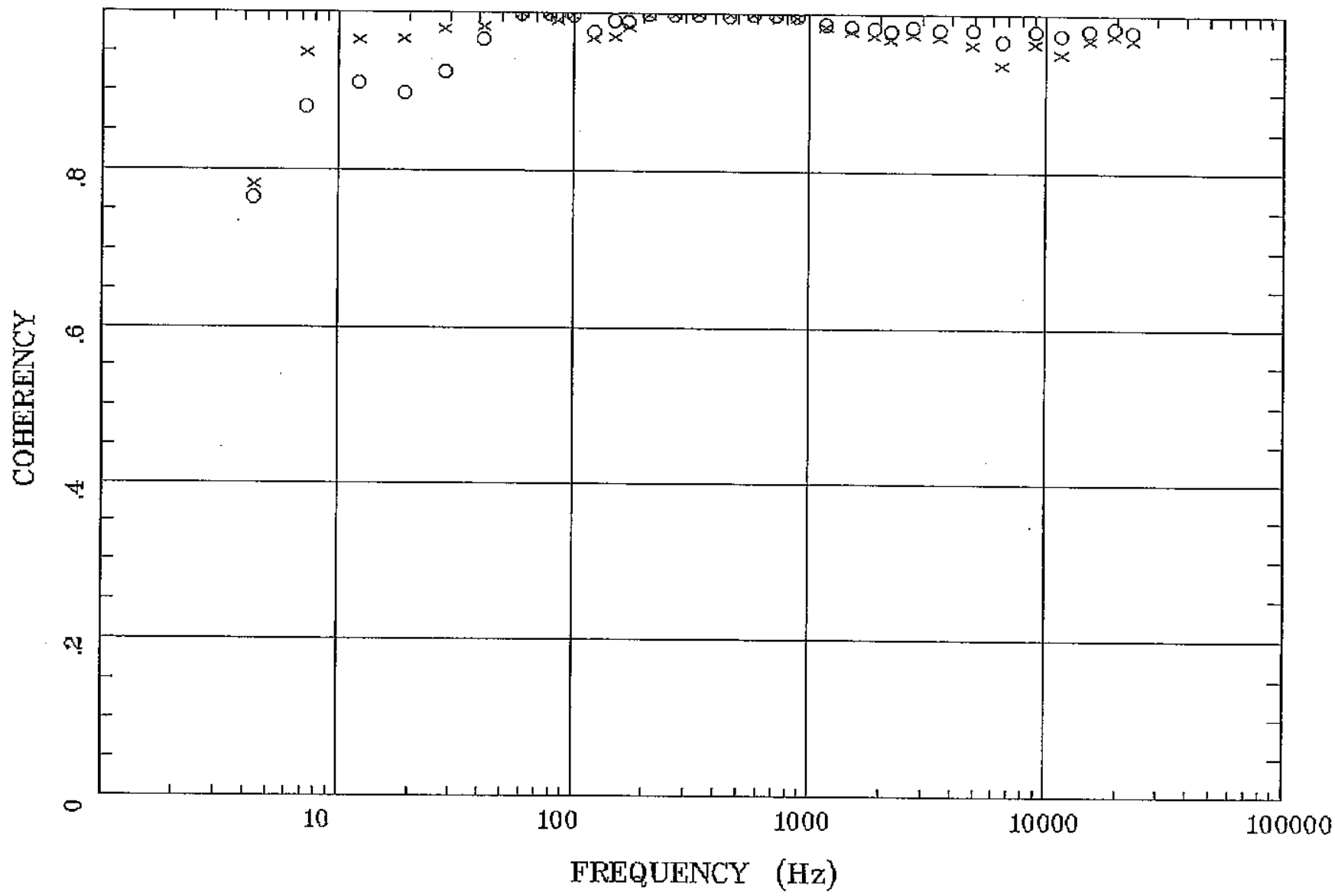

Client: Mineral Resources Program Remote: none

Acquired: $\quad 1^{r y}: 4$ May 02, 2008 Survey Co:USGS
Rotation:

Filename: sp06aall.avg

Channels: Ch1 Ch2 Ch3 Ch4 Ch5 Ch3 Ch4

Plotted: 11:09 Mar 16, 2010

< EMI - ElectroMagnetic Instruments > 


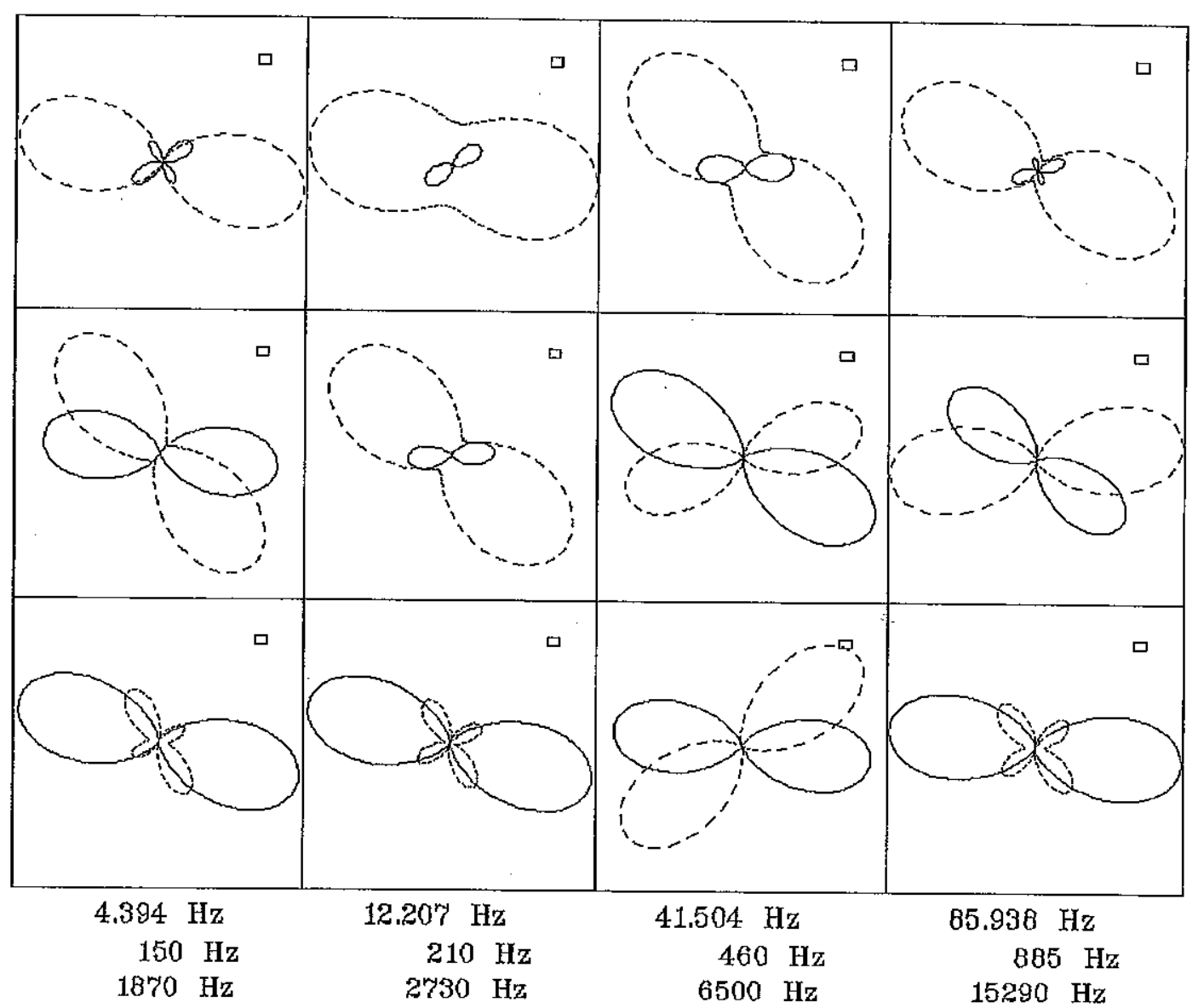

Client: Mineral Resources Program

Remote: none

Rotation:

Filename: sp06aall avg

Channels: Ch1 Ch2 Ch3 Ch4 Ch5 Ch3 Ch4

Plotted: 11:32 Mar 16, 2010

Survey Co:USGS

< EMI - ElectroMagnetic Instruments > 
Station 6

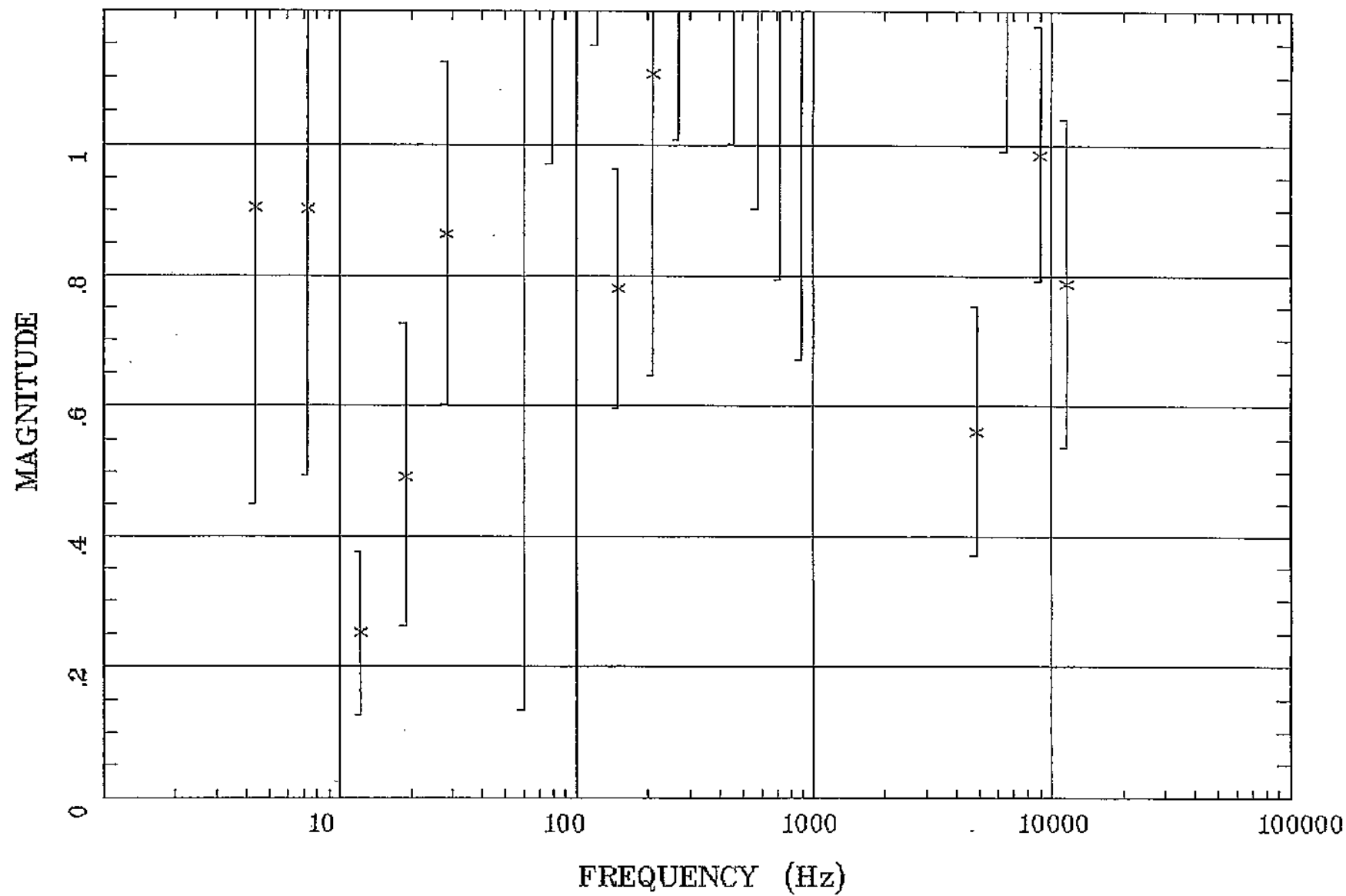

Client: Mineral Resources Program Remote: none

Acquired: 17:4 May 0z, z008 Survey Co:USGS
Rotation:

Filename: sp06aall.avg

Channels: Ch1 Ch2 Ch3 Ch4 Ch5 Ch3 Ch4

Plotted: 11:09 Mar 16, 2010

$<$ EMI - ElectroMagnetic Instruments > 
Station 6

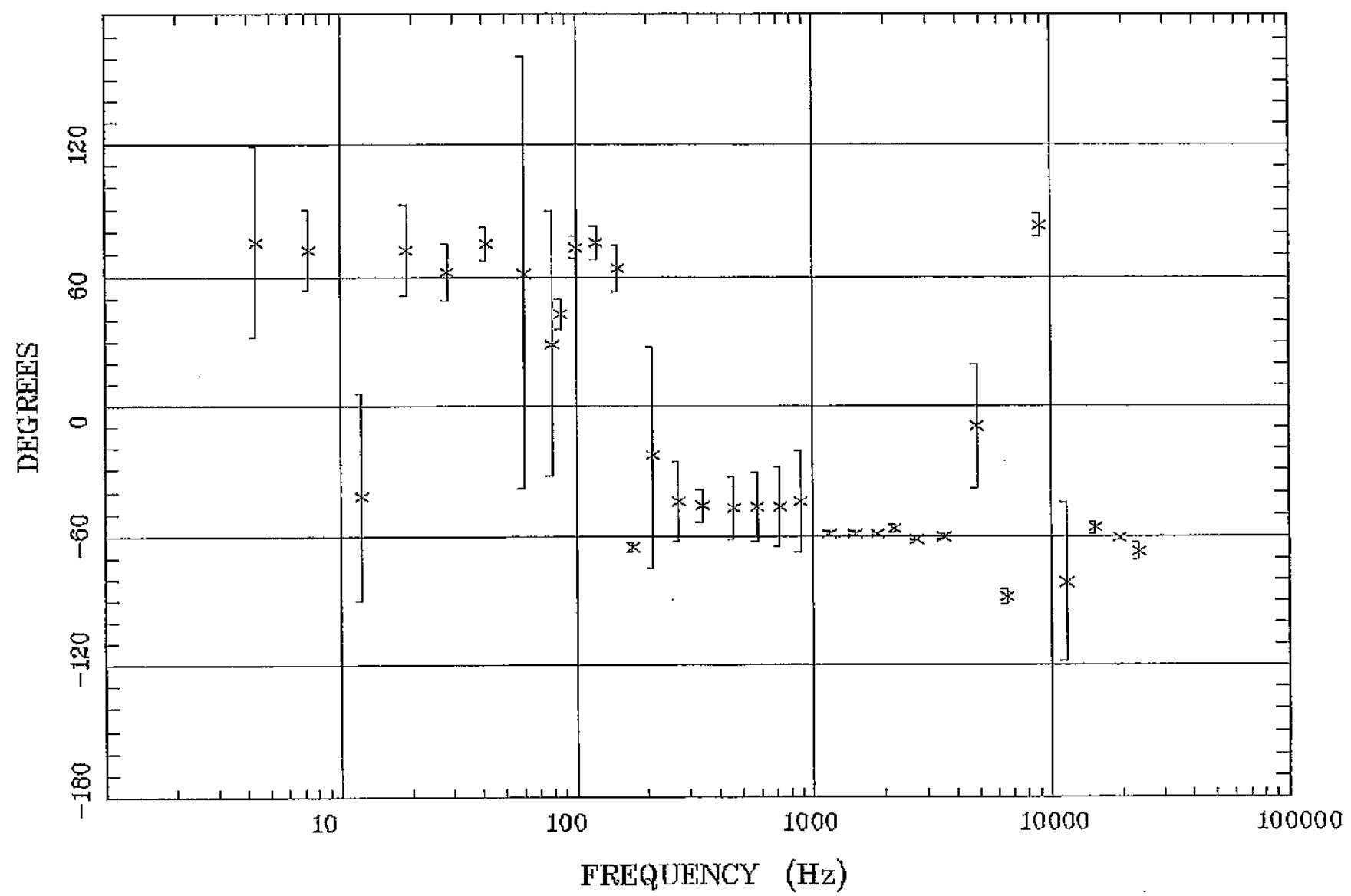

Rotation:

Filename: sp06aall.avg

Client: Mineral Resources Program Remote: none

Acquired: $17 \%: 4$ May 02, z008

Channels: Ch1 Ch2 Ch3 Ch4 Ch5 Ch3 Ch4

Plotted: 11:09 Mar 16, 2010

Survey Co:USGS

< EMI - ElectroMagnetic Instruments > 


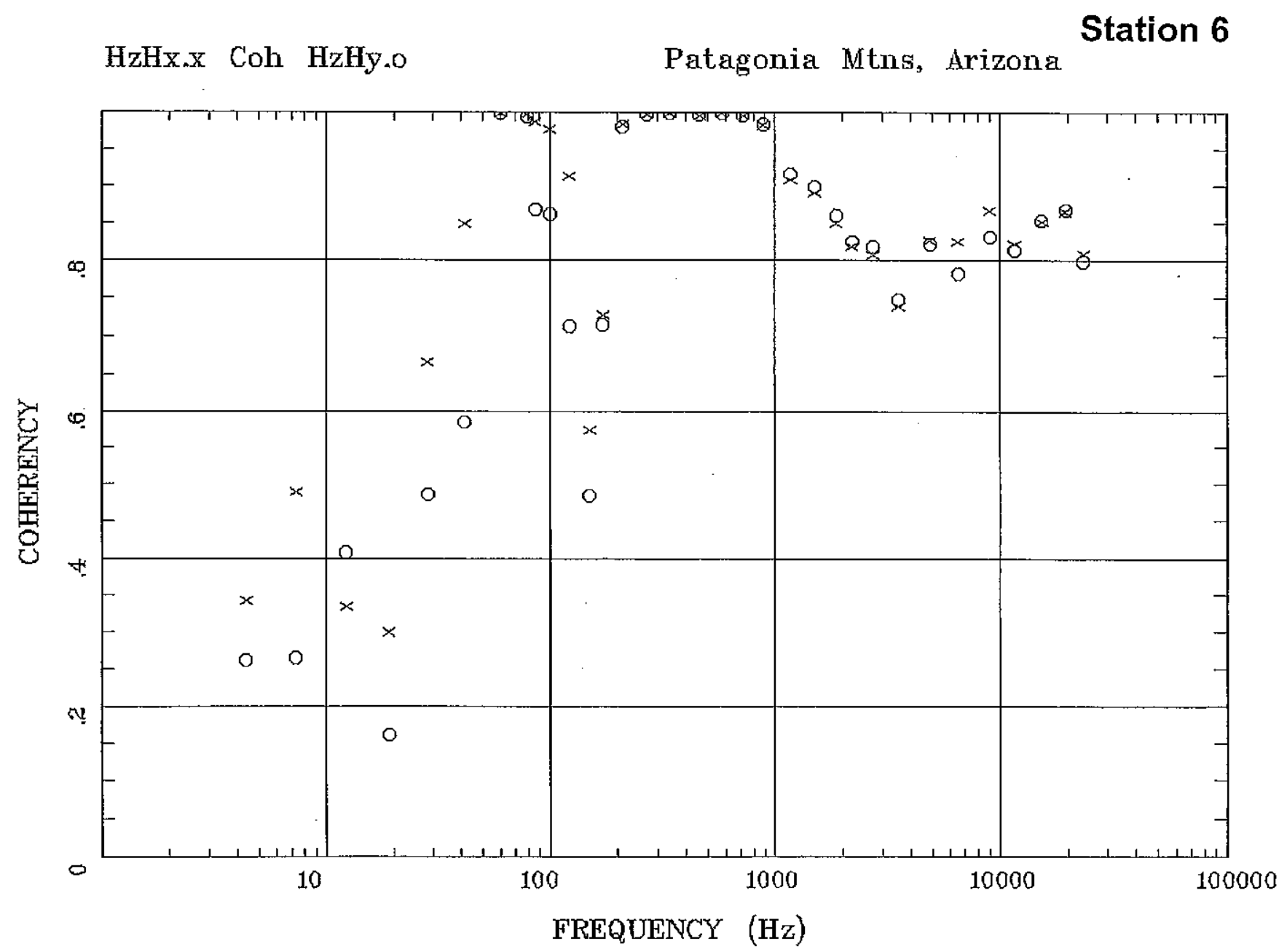

Client: Mineral Resources Program Remote: none

Acquired: 17:4 May 02, 2008 Survey Co:USGS

Rotation:

Filename: sp06aall.avg

Channels: Ch1 Ch2 Ch3 Ch4 Ch5 Ch3 Ch4

Plotted: 11:09 Mar 16, 2010

< EMI - ElectroMagnetic Instruments > 
Station 7

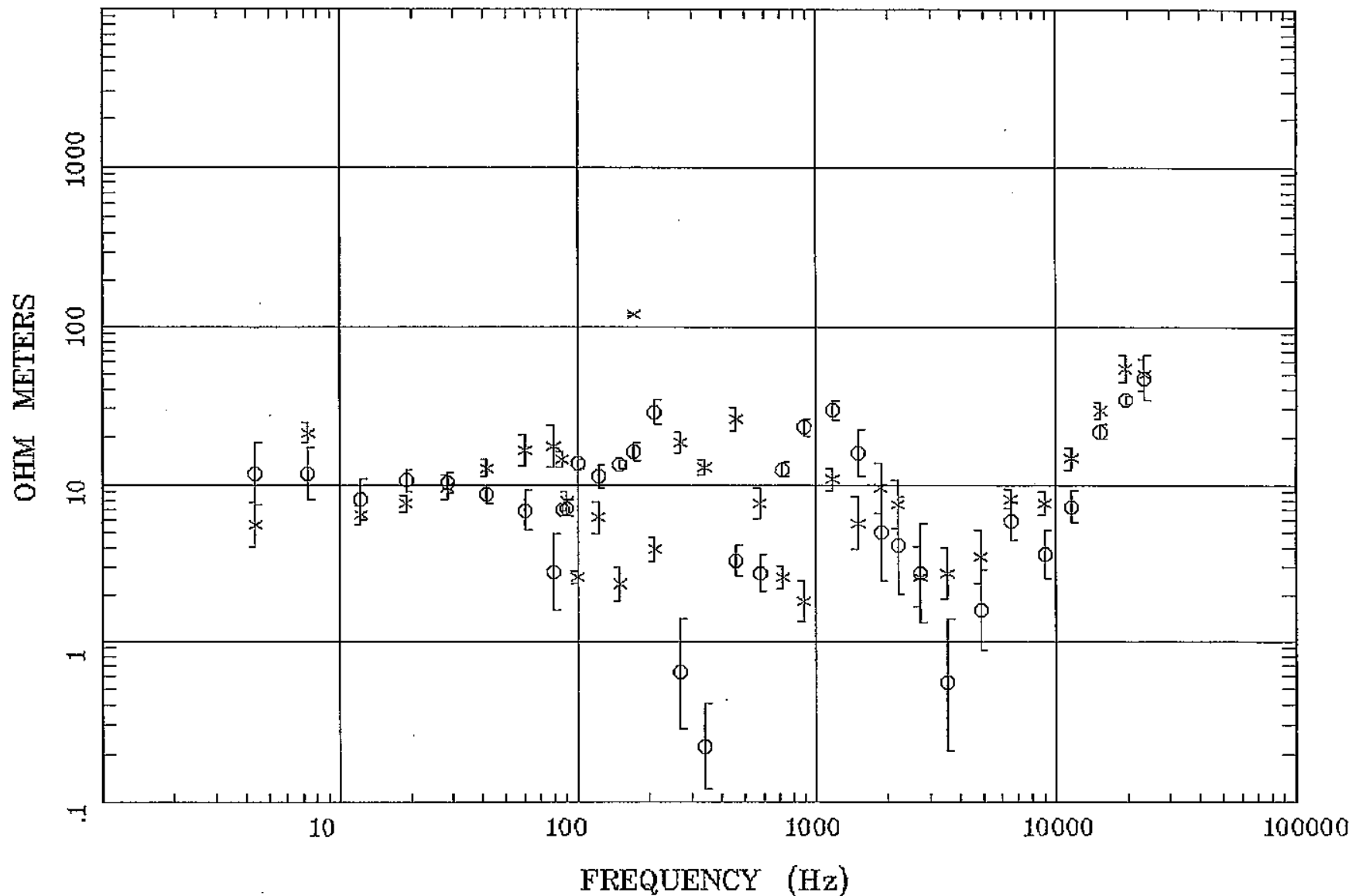

Client: Mineral Resources Program Remote: none

Acquired: 11:5 May 03, 2008 Survey Co:USGS
Rotation:

Filename: sportaall.avg

Channels: Ch1 Ch2 Ch3 Ch4 Ch5 Ch3 Ch4

Plotted: 11:09 Mar 16, 2010

< $\mathrm{EMI}$ - ElectroMagnetic Instruments > 


\section{Station 7}

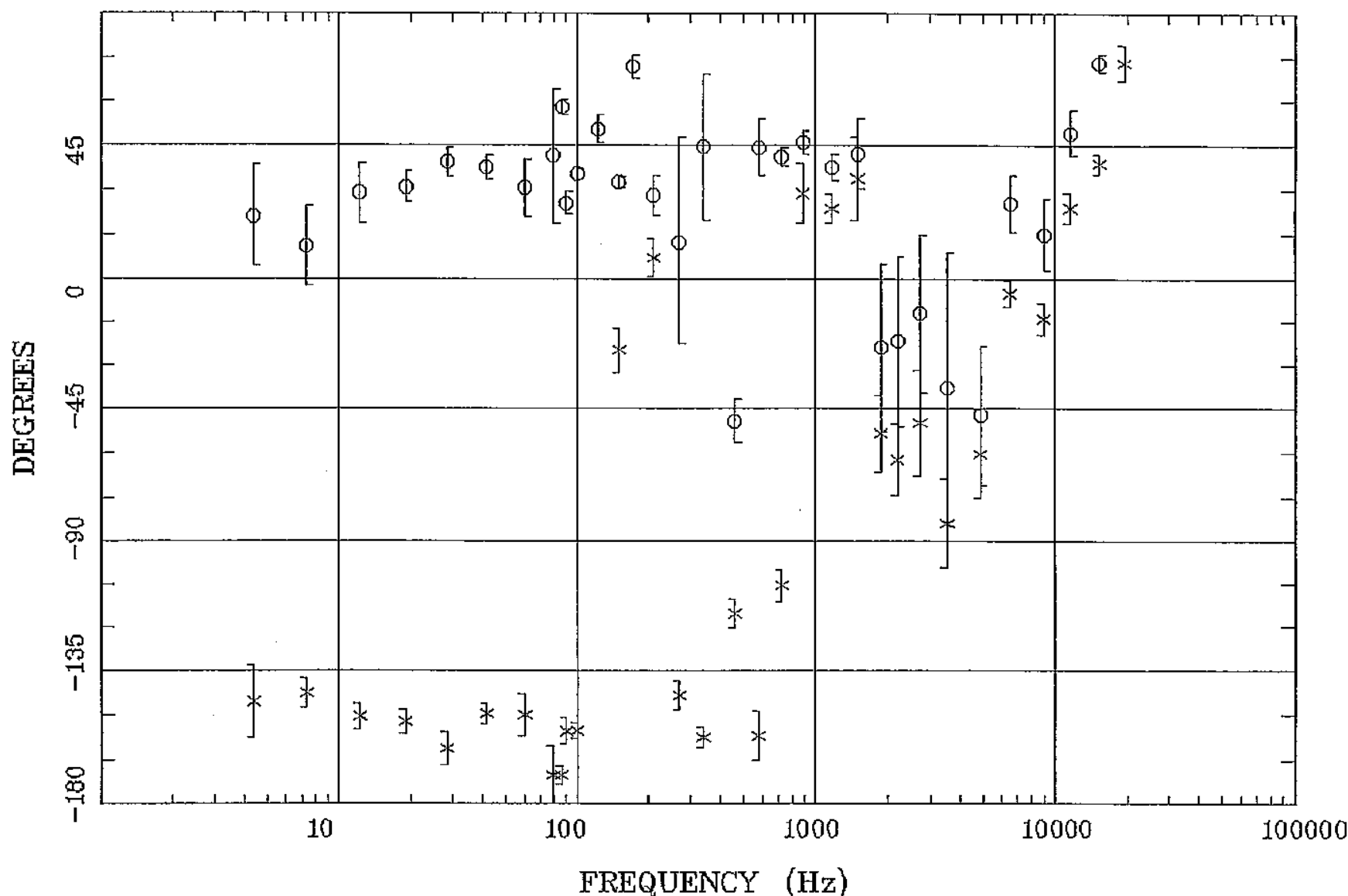

Client: Mineral Resources Programa Remote: none

Acquired: 11:5 May 03, 2008 Survey Co:USGS
Rotation:

Filename: sp07aall.avg

Channels: Ch1 Chz Ch3 Ch4 Ch5 Ch3 Ch4

Plotted: 11:09 Mar 16, 2010

< EMI - ElectroMagnetic Instruments > 
Station 7

IMPEDANCE SKEW

Patagonia Mtns, Arizona

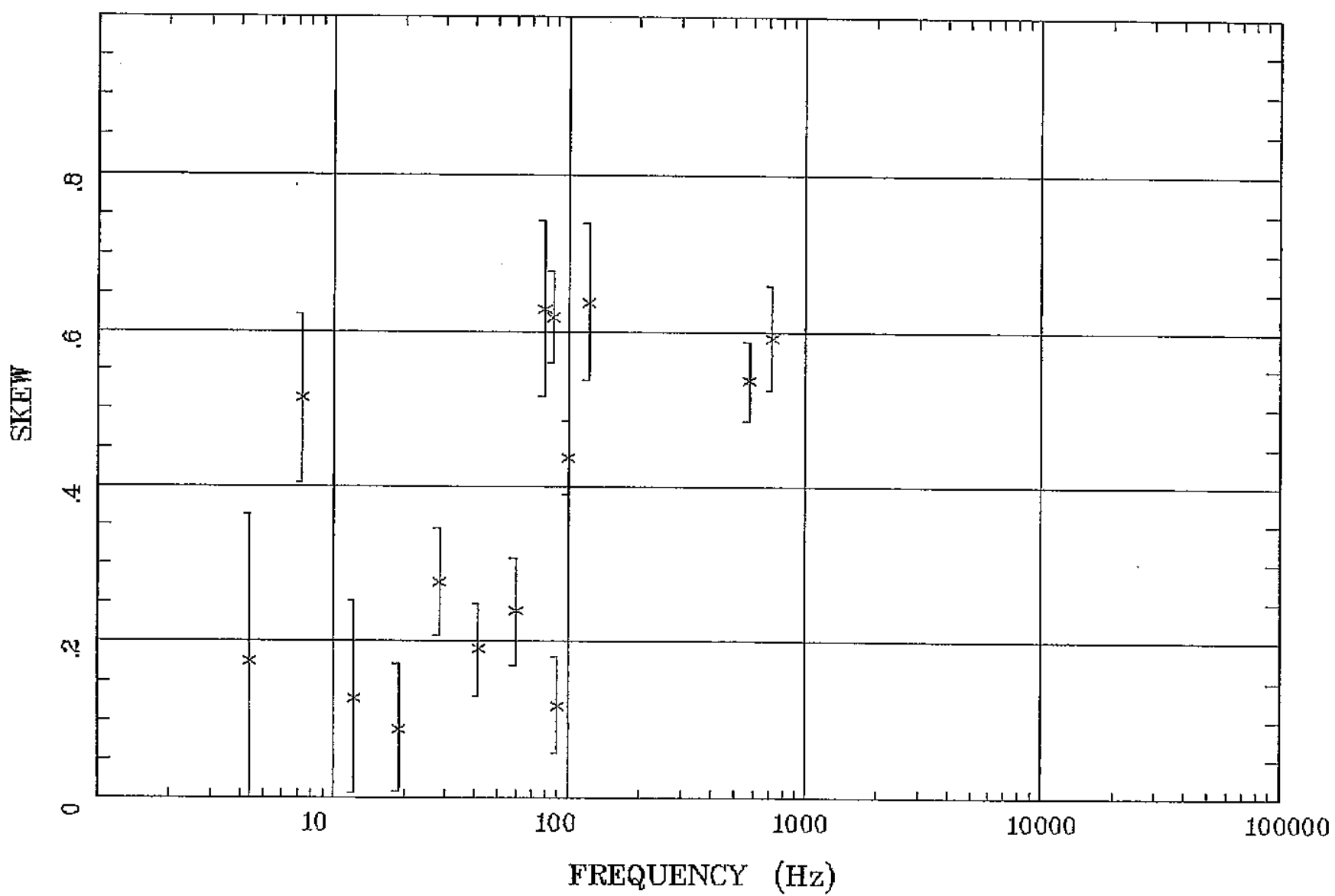

Client: Mineral Resources Program

Rotation:

Remote: none

Filename: sporaall.ayg

Acquired: 11:5 May 03, z008

Channels: Ch1 Ch2 Ch3 Ch4 Ch5 Ch3 Ch4

Plotted: 11:09 Mar 16, 2010

Survey Co:USGS

< EMI - ElectroMagnetic Instruments > 
Station 7

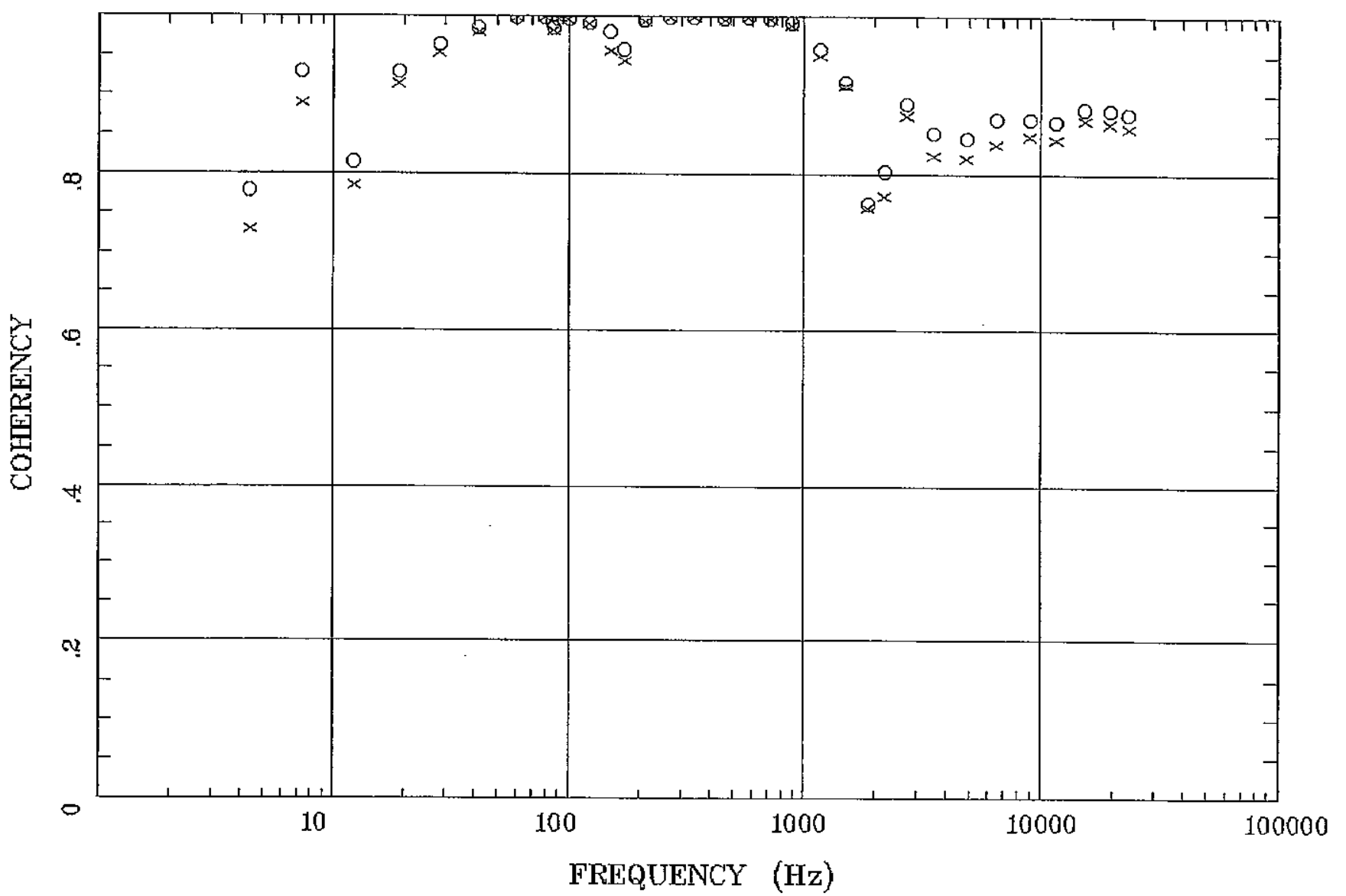

Client: Mineral Resources Program Remote: none

Acquired: 11:5 May 03, 2008

Survey Co:USGS
Rotation:

Filename: sp0\%aall.avg

Channels: Ch1 Ch2 Ch3 Ch4 Ch5 Ch3 Ch4

Plotted: 11:09 Mar 16, 2010

< EMI - ElectroMagnetic Instruments > 
Station 7

Patagonia Mtns, Arizona

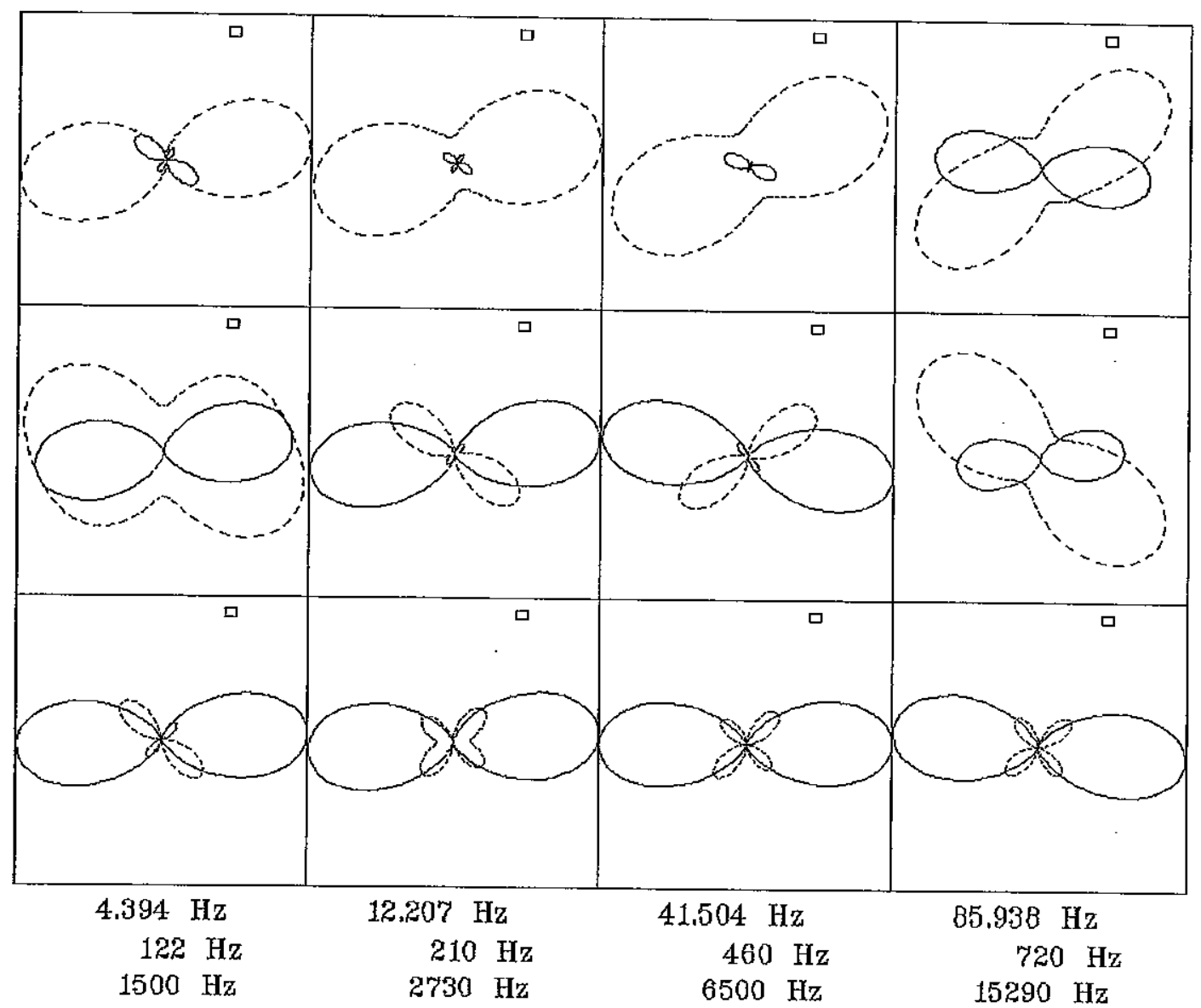

Client: Mineral Resources Program Remote: none

Acquired: 11:5 May 03, 2008

Survey Co:USGS

Filename: sporyall.avg

Channels: Ch1 Ch2 Ch3 Ch4 Ch5 Ch3 Ch4

Plotted: 11:32 Mar 16, 2010

< EMI - ElectroMagnetic Instruments > 
Station 7

TIPPER MAGNITUDE

Patagonia Mtns, Arizona

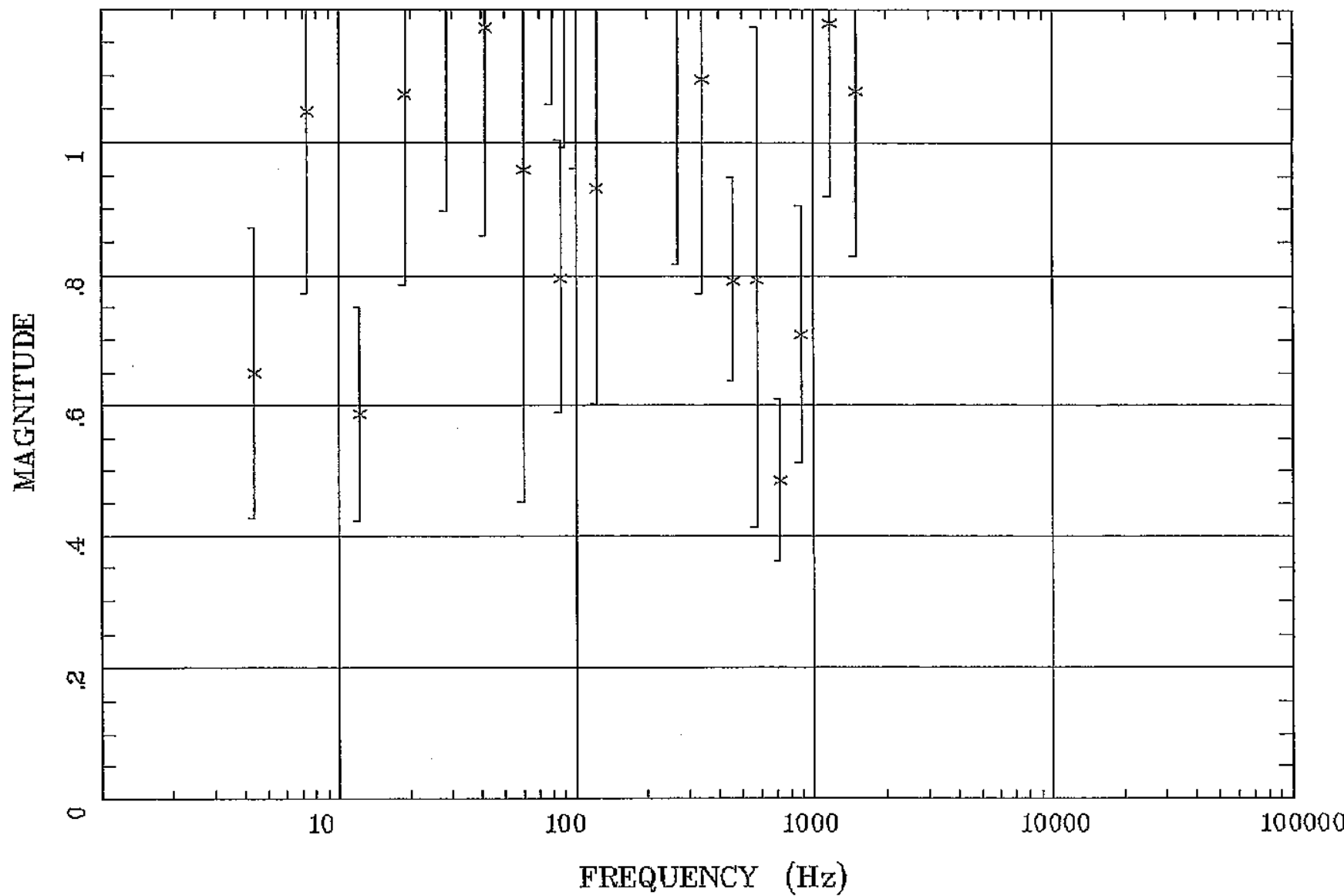

Client: Mineral Resources Program Remote: none

Acquired: 11:5 May 03, 2008

Survey Co:USGS
Rotation:

Filename: sportaall.avg

Channels: Ch1 Ch2 Ch3 Ch4 Ch5 Ch3 Ch4

Plotted: $11: 09 \mathrm{Mar}$ 16, 2010

$<$ EMI - ElectroMegnetic Instruments 
Station 7

TIPPER STRTKE

Patagonia Mtns, Arizona

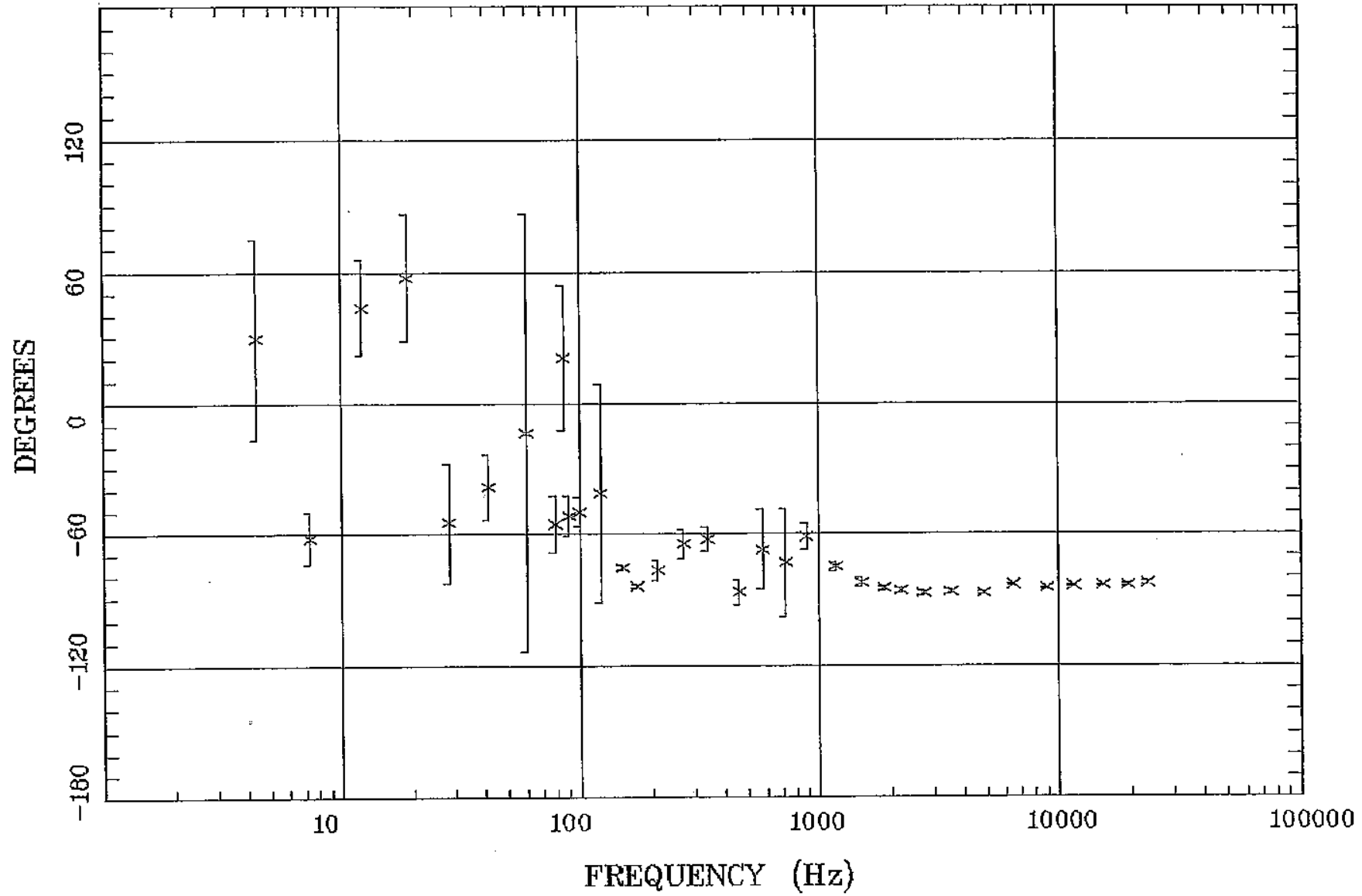

Rotation:

Filename: sp07aall.avg

Channels: Ch1 Ch2 Ch3 ch4 Ch5 Ch3 Ch4

Plotted: 11:09 Mar 16, 2010

Remote: none
Acquired: 11:5 May 03, z008

Survey Co:USGS

< EMI - ElectroMagnetic Instruments 


\section{Station 7}

HzHx.x Coh HzHy.o

Patagonia Mtns, Arizona

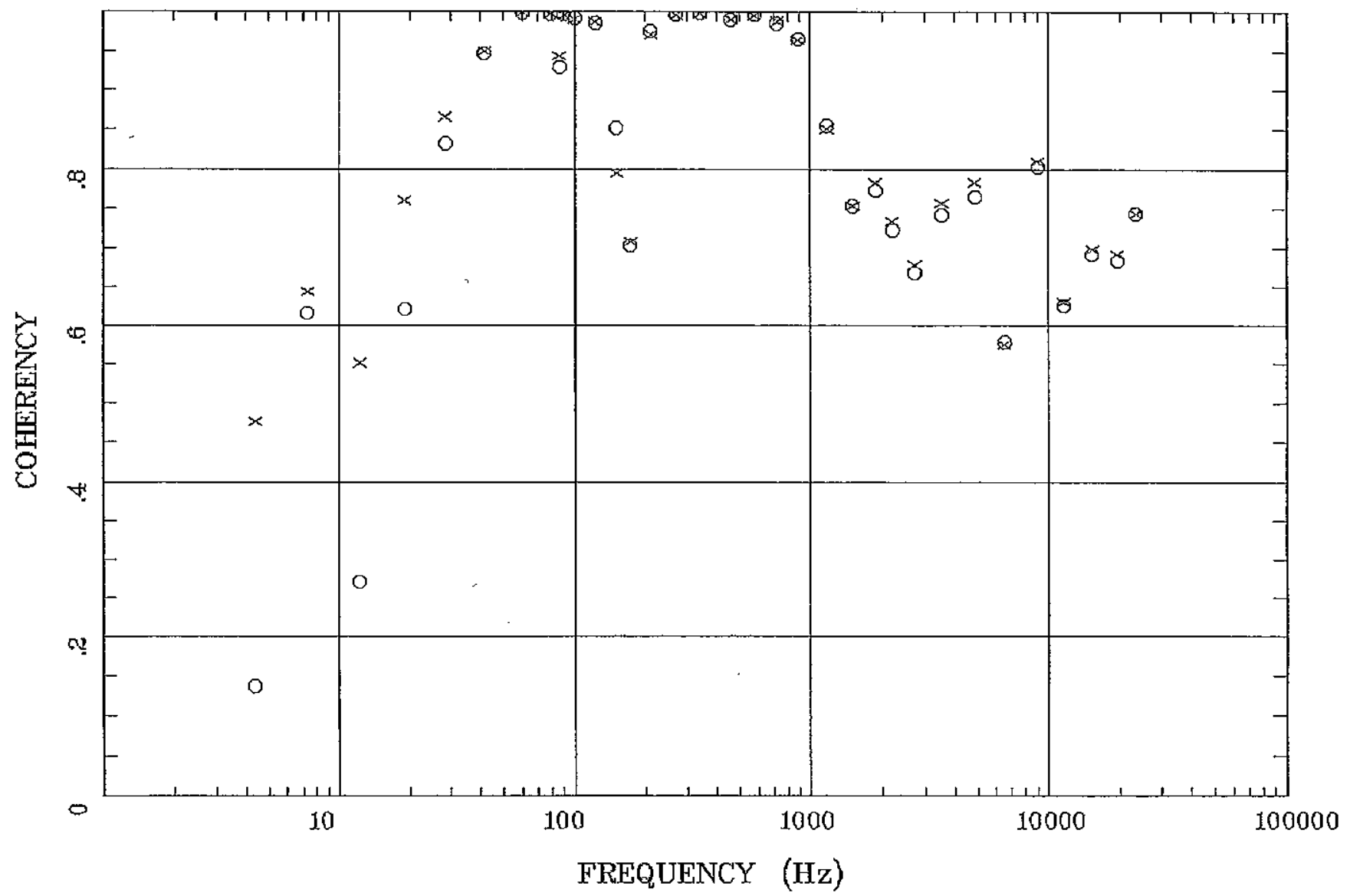

Rotation:

Client: Mineral Resources Program Remote: none

Acquired: 11:5 May 03, z008

Filename: sporyaall.avg

Channels: ch1 Ch2 Ch3 Ch4 Ch5 Ch3 ch4

Plotted: 11:09 Mer 16, 2010

Survey Co:USGS

< EMI - ElectroMagnetic Instruments 